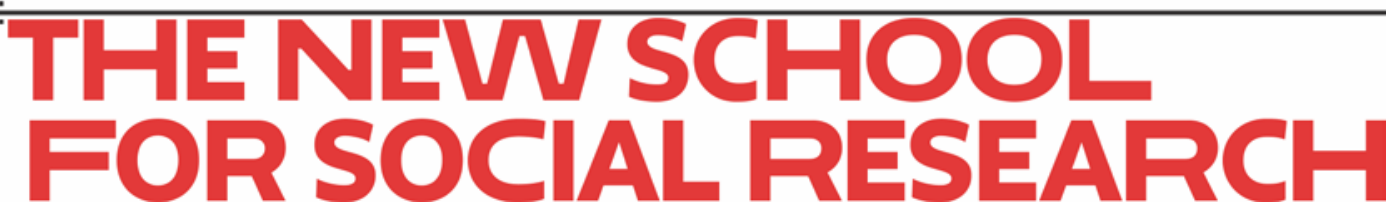

Pu Chen and Willi Semmler

\title{
Financial Stress, Regime Switching and Spillover Effects: Evidence from a Multi- Regime Global VAR Model
}

February 2017

Working Paper 08/2017

Department of Economics

The New School for Social Research 


\title{
Financial Stress, Regime Switching and Spill-over Effects: Evidence from a Multi-Regime Global VAR Model
}

\author{
$\mathrm{Pu}$ Chen*and Willi Semmler ${ }^{\dagger}$
}

October 17, 2016

\begin{abstract}
The globalization process leads to increasing synchronization of business cycle among different countries. As a consequence, many policy makers and Central Banks are afraid of vulnerabilities of their country arising from external risk drivers. In this paper we develop a multi-regime global VAR model to study the spill-over effects in financial markets, in goods markets and between financial markets and good markets across countries, which are assumed to be in a high financial stress regime or a low financial stress regime. It turns out that in both high and low stress regimes financial shocks to a country, big or small one, can have large and persistent impacts on financial markets of other countries, and only in the high stress regime financial shocks to a country can have some negative output effects on other countries. In high stress regime output shocks of a big country can have larger effects on financial stress than those of a small country, while in a low stress regime output shocks of a country, big or small, have little impact on financial conditions. Further, we study the effects of global and regional shocks, as well as the spillover effects of national monetary policies and internationally coordinated policies on the financial and real sectors.
\end{abstract}

${ }^{*}$ Melbourne Institute of Technology, Australia, email pchen@academic.mit.edu.au

${ }^{\dagger}$ Dept. of Economics, New School for Social Research, 79 Fifth Ave, New York, NY 10003, email:semmlerw@newschool.edu 


\section{Introduction}

Globalization has been one of the most striking processes of the world economy during the last few decades. Impacts and the consequences of this globalization process has been incisively demonstrated through the 2008-2009 global financial crisis. The U.S. subprime mortgage crisis triggered the financial crisis, deteriorated financial conditions world wide and led subsequently to the most severe economic recession since the Great Depression. This stimulated a renewed interest in economic research on the linkage between financial markets and economic activities and the spill-over of the financial crisis and economic recession across countries as well. Moreover, recently many policy makers and central bank officials are more and more worried about external risk drivers and spill-over effects of other countries policies to their own country.

A large body of literature has been generated on those issues. Backé, Gnan, and Hartmann (2010) give an overview on a selection of related research in this area. Another strand of research points to changes in the financial-real interaction during a crisis and during tranquil times. The key word "Regime Switching" denotes a link of the research on this topic. Mittnik and Semmler (2013) apply a dynamic decision model of Keynesian type and show the existence of different regimes, which provides a theoretical ground for the empirical analysis of a regime dependent fiscal multiplier. Diebold and Yilmaz (2015) introduce a connectedness measure into global modeling of real or financial contagion effects. ${ }^{1}$ Another strand of research concerns quantifying the spill-over effect across countries in a large system. Key words such as "Contagion and global VAR" links the research in this area ${ }^{2}$ The Global VAR (GVAR) has become a benchmark tool to study international spill-over effects. Binder and Gross (2013) combine the features of regime switching and global VAR and develop a Markov switching global vector autoregressive model to study regime-dependent spill-over effects.

Following such a line of research we want to address the following issues in the current paper: (1) To what extend do the international spill-overs impact the linkage between the financial market and the real activities? (2) Is the intensity of international spill-overs regime-dependent, meaning could a spill-over effects be stronger if a country is already in a bad state? (3) What is the difference between a big country's shock and small country's shock? (4) Given the nowadays strong economic and financial integration, how can we quantify the impact of a regional shock as well as the impact of a global shock? (5) What spill-over effects have national monetary policies or coordinate policies on other countries' financial and real sectors?

In order to address these issues we extends the work in Semmler and Chen (2014) in that we take into account of possible international spill-over influence in the financial-real interaction reflecting the increasingly globalized financial market as well as trade relations. Concretely, we will develop a multi-regime global vector autoregression model (MRGVAR) to carry out our study.

The remainder of our study is organized as follows. Sect 2 introduces the multi-

\footnotetext{
${ }^{1}$ This type of work started a stream of further literature connectedness and contagion in real and financial markets. Our approach is in this line of above literature, but allows to more explicitly explore the vulnerability and exposure of a country or region to the contagion of shocks.

${ }^{2}$ For GVAR methodology see https://sites.google.com/site/gvarmodelling/gvar and Pesaran, Schuermann, and Weiner (2004) for more details.
} 
regime global vector autoregression model (MRGVAR) to study spill-over effects. Sect. 3 discusses the data sources and provides some descriptive statics. Sect 4 presents estimation results and sect. 5 reports the state dependent impulse-responses in order to answer the above raised question. Sect. 6 studies then more explicitly what spill-over effects monetary policy, in particular a coordinated policy has on other countries' financial and real sectors? Sect. 7 concludes the paper. The appendix provides some technical explanations.

\section{A MRGVAR Model on International Spill-over Effects}

We consider a system consisting of $N$ countries. For a country indexed by $i$, the interaction between the financial conditions and the real activities is assumed to follow a two-regime VAR process, i.e. the interaction in a high financial stress regime is different than that in a low financial stress regime ${ }^{3}$. Formally a single country two-regime VAR is as follows.

$$
\begin{aligned}
y_{i, t} & =c_{i, S_{i, t}}+\sum_{l=1}^{p_{i, S_{i, t}}} A_{i, l, S_{i, t}} y_{t-l}+\sum_{l=1}^{q_{i, S_{i, t}}} A_{i, l, S_{i, t}}^{*} y_{i, t-l}^{*}+\epsilon_{i, S_{i, t}}, \quad \epsilon_{i, S_{i, t}} \sim\left(0, \Sigma_{S_{i, t}}\right), \\
S_{i, t} & = \begin{cases}1 & \text { for } f_{i, t-d}>\tau_{i} \\
2 & \text { for } f_{i, t-d} \leq \tau_{i}\end{cases}
\end{aligned}
$$

where $S_{i, t}=1,2$ is a state variable and the values of 1 and 2 indicate a high financial stress and a low financial stress regime respectively. $y_{i, t}$ is an $n$-vector containing domestic variables of country $i$ including variables describing financial conditions and variables measuring real activities as well. $y_{i, t}^{*}$ is an $n$-vector of foreign variables which are weighted average of the same set of variables of all countries excluding country $i: y_{i, t}^{*}=\sum_{j=1}^{N} w_{i, j} y_{j, t} . c_{i, S_{i}}, A_{i, l, S_{i}}$ and $A_{i, l, S_{i}}^{*}$ are regime specific coefficients for domestic variables and foreign variables respectively. They assume different values in different regimes. $w_{i, j}$ is the weight of country $j$ among the foreign variables of country $i$. By definition we have $\sum_{j=1}^{N} w_{i, j}=1$, with $w_{i, j}>0$ and $w_{i, i}=0$. Obviously, different countries will have different foreign variables and hence the weighting vectors are different across countries. The errors $\epsilon_{i, S_{i, t}}$ are technically assumed to be temporally uncorrelated and independent from the variables $y_{i, t}$ in the past. Its covariance matrix is state-dependent, i.e. for different states the error correlations are different.

\subsection{Construction of MRGVAR}

One of the most striking features of the GVAR methodology is that it enables us to obtain a large dimensional global VAR model from the estimated small dimensional single country VAR models, such that we can study inter-country, regional and global spill-over effects. This good feature is preserved in our country specific MRVAR

\footnotetext{
${ }^{3}$ See Mittnik and Semmler (2012) and Semmler and Chen (2014) for details of economic modeling of the existence of multiple-regimes. In this paper we will use as financial stress as regime defining variable. A different regime defining variable could be the output gap, see Gross and Semmler (2016), or output growth, see Mittnik and Semmler (2013).
} 
models. We can derive a multi-regime global VAR (MRGVAR) from the country specific MRVARs.

A combination of different regimes for each country can be represented by an $N$ vector with $S_{t}=\left(S_{1, t}, S_{2, t}, \ldots, S_{N, t}\right)$. $S_{t}=(1,2, \ldots, 2)^{\prime}$ means that at time $t$ country 1 is in the high stress regime, country 2 is in the low stress regime, etc. We call this vector state vector. It describes the state of countries in the system. For a given state vector, stacking all $N$ country specific MRVAR models (1) together and replacing the foreign variables in each country through the explicitly weighted averages of the domestic variables of other countries, we obtain a linear system in which the $n \times N$ domestic variables of all countries depend linearly on $n \times N$ lagged domestic variables. This is an $n \times N$ dimensional global VAR. In terms of components of state vector $S_{t}$ the country MRVAR can be written as follows.

$$
\begin{aligned}
& y_{i, t} \\
= & c_{i, S_{i, t}}+\sum_{l=1}^{p_{i, S_{i, t}}} A_{i, l, S_{i, t}} y_{t-l}+\sum_{l=1}^{q_{i, S_{i, t}}} A_{i, l, S_{i, t}}^{*} y_{i, t-l}^{*}+\epsilon_{i, S_{i, t}} \\
= & c_{i, S_{i, t}}+\sum_{l=1}^{p_{i, S_{i, t}}} A_{i, l, S_{i, t}} y_{t-l}+\sum_{l=1}^{q_{i, S_{i, t}}} A_{i, l, S_{i, t}}^{*}\left(w_{i, 1}, . w_{i, i-1}, 0, w_{i, 1+1} . ., w_{i, N}\right)\left(\begin{array}{c}
y_{1, t-l} \\
y_{2, t-l} \\
\vdots \\
y_{N, t-l}
\end{array}\right)+\epsilon_{i, S_{i, t}}
\end{aligned}
$$

Stacking the equation for $N$ countries together we have:

$$
\begin{aligned}
& \left(\begin{array}{c}
y_{1, t} \\
y_{2, t} \\
\vdots \\
y_{N, t}
\end{array}\right)=\left(\begin{array}{c}
c_{1, S_{1, t}} \\
c_{2, S_{2, t}} \\
\vdots \\
c_{N, S_{N, t}}
\end{array}\right)+\sum_{l=1}^{P}\left(\begin{array}{ccccc}
A_{1, l, S_{1, t}} & 0 & \ldots & 0 \\
0 & A_{2, l, S_{2, t}} & & \vdots \\
\vdots & & \ddots & 0 \\
0 & \ldots & 0 & A_{N, l, S_{N, t}}
\end{array}\right)\left(\begin{array}{c}
y_{1, t-l} \\
y_{2, t-l} \\
\vdots \\
y_{N, t-l}
\end{array}\right) \\
& +\sum_{l=1}^{P}\left(\begin{array}{ccccc}
A_{1, l, S_{1, t}}^{*} & 0 & \ldots & 0 \\
0 & A_{2, l, S_{2, t}}^{*} & \vdots \\
\vdots & & \ddots & 0 \\
0 & \ldots & 0 & A_{N, l, S_{N, t}}^{*}
\end{array}\right)\left(\begin{array}{cccc}
0 & w_{1,2} & \ldots & w_{1, N} \\
w_{2,1} & 0 & \ddots & w_{2, N} \\
\vdots & \ddots & \ddots & \vdots \\
w_{N, 1} & \ldots & w_{N, N-1} & 0
\end{array}\right)\left(\begin{array}{c}
y_{1, t-l} \\
y_{2, t-l} \\
\vdots \\
y_{N, t-l}
\end{array}\right) \\
& +\left(\begin{array}{c}
\epsilon_{1, S_{1, t}} \\
\epsilon_{2, S_{2, t}} \\
\vdots \\
\epsilon_{N, S_{N, t}}
\end{array}\right),
\end{aligned}
$$

where $P$ is the maximum lags among all countries and regimes. It is to note that in the notation above we have extended the lags of all countries in both regimes to the maximum lag $P$ by filling the extended coefficient matrix with zeros, i.e. $A_{i, l, S_{i, t}}=A_{i, l, S_{i, t}}$ for $l \leq p_{i, S_{i, t}}$ and $A_{i, l, S_{i, t}}=0$ for $l>p_{i, S_{i, t}}$. The same holds for the coefficient of the foreign variables, i.e. $A_{i, l, S_{i, t}}^{*}=A_{i, l, S_{i, t}}^{*}$ for $l \leq q_{i, S_{i, t}}$ and $A_{i, l, S_{i, t}}^{*}=0$ for $l>q_{i, S_{i, t}}$. Using the notation:

$$
y_{t}=\left(y_{1, t}^{\prime}, y_{2, t}^{\prime}, \ldots, y_{N, t}^{\prime}\right)^{\prime}
$$




$$
\begin{aligned}
& \epsilon_{S_{t}}=\left(\epsilon_{1, S_{1, t}}^{\prime}, \epsilon_{2, S_{2, t}}^{\prime}, \ldots, \epsilon_{N, S_{N, t}}^{\prime}\right)^{\prime} \\
& c_{S_{t}}=\left(c_{1, S_{1, t}}^{\prime}, c_{2, S_{2, t}}^{\prime}, \ldots, c_{N, S_{N, t}}^{\prime}\right)^{\prime} \\
& G_{l, S_{t}}=\left(\begin{array}{cccc}
A_{1, l, S_{1, t}} & 0 & \cdots & 0 \\
0 & A_{2, l, S_{2, t}} & & \vdots \\
\vdots & & \ddots & 0 \\
0 & \ldots & 0 & A_{N, l, S_{N, t}}
\end{array}\right) \\
& +\left(\begin{array}{cccc}
A_{1, l, S_{1, t}}^{*} & 0 & \cdots & 0 \\
0 & A_{2, l, S_{2, t}}^{*} & & \vdots \\
\vdots & & \ddots & 0 \\
0 & \ldots & 0 & A_{N, l, S_{N, t}}^{*}
\end{array}\right)\left(\begin{array}{cccc}
0 & w_{1,2} & \ldots & w_{1, N} \\
w_{2,1} & 0 & \ddots & w_{2, N} \\
\vdots & \ddots & \ddots & \vdots \\
w_{N, 1} & \ldots & w_{N, N-1} & 0
\end{array}\right)
\end{aligned}
$$

we can write the multi regime global VAR in a more compact form:

$$
y_{t}=c_{S_{t}}+\sum_{l=1}^{P} G_{l, S_{t}} y_{t-l}+\epsilon_{S_{t}}, \quad \epsilon_{S_{t}} \sim N\left(0, \Sigma_{S_{t}}\right),
$$

This is an $n \times N$ dimensional multi regime global VAR (MRGVAR). The country specific MRVAR specification and the weighting matrices have imposed a large number of restrictions for the MRGVAR coefficients. For a system of $N$ countries we can have $2^{N}$ different configurations of states at each time $t$. A direct estimation of the coefficients in the MRGVAR is impossible due to the curse of dimension. However, applying the analytic tools developed in the GVAR methodology, we can calculate the coefficients of the MRGVAR models and conduct the intended analysis. Concretely we can estimate coefficients of the country MRVAR (2.1) for each single country and construct MRGVAR (2.3) as described above. Then we can, for example, conduct an impulse response study for selected configurations of states, which are relevant for our economic analysis.

\subsection{Modeling Issues}

\subsubsection{Specification of Country MRVARs}

In the single country MRVAR (2.1), if the threshold value $\tau_{i}$ and the regime specific lags $p_{i, S_{i}}$ and $q_{i, S_{i}}$ are known, within each regime, model (2.1) is an ordinary vector autoregression with lagged dependent variables as regressors and independent residuals, we can apply the least squares (LS) method to obtain a consistent estimate of the parameters. Hence determination of the threshold value and the regime specific lag lengths is crucial for the parameter estimation. Here we apply a model selection approach to determine the threshold value and the regime specific lag lengths. The AIC criterion for model (2.1) can be calculated as follows.

$$
A I C\left(\tau_{i}, p_{i, 1}, p_{i, 2}, q_{i, 1}, q_{i, 2}\right)=\sum_{S_{i}=1}^{2}\left[T \log |\hat{\Sigma}|+2 n\left(n\left(q_{i, S_{i}}+p_{i, S_{i}}\right)+\frac{n+3}{2}\right)\right],
$$


where $\tau_{i}$ is the threshold value and $T$ is the number of periods. $n$ is the number of variables in $y_{i, t} . \Sigma$ is the estimated covariance matrix of the residuals ${ }^{4}$. For a series of chosen values of $\tau_{i}$ and all combinations of lags up to a maximum length of 10 we calculate the corresponding AIC values. The specification with the minimal AIC value is taken as the specification for our model (2.1). It is to note that we also compute the AIC value of one regime VAR which corresponds to setting $\tau_{i}$ at the maximum value of the switching variable $f_{i, t-d}$. In this way we indirectly test the hypothesis of one regime VAR against two regime VAR.

\subsubsection{GVAR with mixed Regimes}

In the MRGVAR (2.3) it is not necessary that every country has to be represented by a MRVAR. If for some countries in the system the one regime VARs(ORVARs) are more suitable statistical models, we can easily accommodate these ORVARs into the MRGVAR model (2.3). In fact an ORVAR can be seen as a MRVAR with identical coefficient in the two regimes with an arbitrary threshold value. So in the construction of the MRGVAR, country specific ORVARs are artificially taken as MRVARs with identical parameters.

\subsection{Estimation}

The estimation of the model parameters are carried out in the single country two regime VAR models (2.1). Under the model assumption of independent and temporally uncorrelated errors, the least squares method will provide consistent estimate of $A_{i, l, S_{i, t}}$ and $A_{i, l, S_{i, t}}^{*}$. For each country we obtain estimated country-specific residuals $\hat{\epsilon}_{i, S_{t}}$ for $i=1,2, \ldots N$. These residuals can be collected to estimate the state dependent covariance matrix. Given a state vector $S=\left(S_{1}, S_{2}, \ldots, S_{N}\right)$, throughout

the whole sample we have $\eta_{1}$ residuals of $\hat{\epsilon}_{1, S_{1, t}=S_{1}}, \eta_{2}$ residuals of $\hat{\epsilon}_{2, S_{2, t}=S_{2}}, \ldots$ and $\eta_{N}$ residuals of $\hat{\epsilon}_{N, S_{N, t}=S_{N}}$. Let $\eta_{S}$ be the intersection of the $N$ sets of residuals of the given state $S$. We collect the $N$ sets of residuals to form a $\eta_{S} \times n N$ residual matrix $\hat{\epsilon}_{S_{t}}$ with $t \in \eta_{S}$. Then we can have an estimate of the state-specific variance-covariance matrix $\Sigma_{S}$.

$$
\hat{\Sigma}_{S}=\frac{1}{\left[\eta_{S}\right]} \sum_{t \in \eta_{S}} \hat{\epsilon}_{S_{t}} \hat{\epsilon}_{S_{t}}^{\prime},
$$

where $\left[\eta_{S}\right]$ is the number of time periods collected in the intersection set $\eta_{S}$. After obtaining estimate for each country-specific two-regime VAR, we can stack the $N$ country-specific equations together to construct the MRGVAR according to Equation $(2.2)$.

\section{$3 \quad$ Data and Descriptive Statistics}

\subsection{Data Source}

In our empirical model we include two types of variables that measure the financial conditions and the real activities respectively. We use the IMF financial stress index

\footnotetext{
${ }^{4}$ See Mittnik and Semmler (2013) for a similar application of AIC.
} 
as a measure of financial conditions in our model ${ }^{5}$. The IMF FSI has the following components:

$$
\begin{aligned}
F S I= & \text { bankbeta }+ \text { TEDspread }+ \text { invertedtermspread }+ \\
& \text { corporatebondspread }+ \text { stockmarketreturn }+ \\
& \text { stockmarketvolatility }+ \text { exchangeratevolatility }
\end{aligned}
$$

The FSI is available for a large number of EU countries. ${ }^{6}$ The IMF's (2014) FSI ${ }^{7}$ refers to three major sources and measures of instability, namely: 1) a bank related index-a 12-month rolling beta of bank stock index and a Ted or interbank spread, 2) a security related index-a corporate bond yield spread, an inverted term spread, and a monthly stock returns (measured as declines), six-month rolling monthly squared stock returns and finally, 3) an exchange rate index-a six-month rolling monthly squared change in real exchange rates. All three sets of variables are detrended and scaled with their standard deviations in order to normalize the measures. A higher value if FSI implies a worsened financial condition, while a lower FSI value reflect a good financial conditions.

As a measure for the real activities we take the index of monthly industrial production for all countries, or what is more proper in the context of our model, the growth rate of the monthly index of industrial production. Data are taken from the OECD Statistics ${ }^{8}$.

\subsection{Financial Stress and Real Activities}

In Fig. 1 to Fig. 3 we plot a country's FSI and the 5-month-moving-average of the growth rate of the index of industrial production(GIP) of the same country together. Generally we observe a kind of counter-cyclical behavior of FSI in most countries ${ }^{9}$.

\footnotetext{
${ }^{5}$ See Semmler and Chen (2014) and Mittnik and Semmler (2012) for more detailed discussion on the choice of financial stress measures.

${ }^{6}$ The Federal Reserve Bank of Kansas City and the Fed St. Louis have also developed a general financial stress index, called KCFSI and STLFSI respectively. The KCFSI and the STLFSI, take into account the various factors generating financial stress. The $\mathrm{KC}$ index is a monthly index, the STL index a weekly index, to capture more short run movements, see also Hatzius et al. (2010). Those factors can be taken as substitutes for the leverage ratios as measuring financial stress. See also the Bank of Canada index for Canada, i.e. Illing and Lui (2006). Both the KCFSI and STLFSI include a number of variables and financial stress is related to an: 1) increase the uncertainty of the fundamental value of the assets, often resulting in higher volatility of the asset prices, 2) increase uncertainty about the behavior of the other investors, 3) increase in the asymmetry of information, 4) increase to the flight to quality, 5) decrease in the willingness to hold risky assets, and 6) decrease in the willingness to hold illiquid assets. The principle component analysis is then used to obtain the FSI. Linear OLS coefficients are normalized through their standard deviations and their relative weights computed to explain an FSI index. A similar procedure is used by Adrian and Shin (2010) to compute a macro economic risk premium. We want to note that most of the variables used are highly correlated with credit spreads, see Mittnik and Semmler (2016). The latter have usually the highest weight in the index, for details see also Hakkio and Keeton (2009, Tables 2-3.).

${ }^{7}$ This is published for advanced as well for developing countries, see IMF (2008) and IMF FSI (2011)

${ }^{8}$ http://stats.oecd.org/

${ }^{9}$ We want to note that the financial stress index can also be linked to some broader index of economic activity, see Hakkio and Keeton (2009).
} 
Against the smoothed growth rate of the industrial production index the financial stress index is low in good times, but high in bad times. Clearly, financial markets and financial institutions are doing better in economic booms than in recessions.

This counter-cyclical behavior is well pronounced during economic crisis, in particular, during the global financial crisis and less clearly pronounced during good time. Furthermore, the counter-cyclical behavior of FSI is more clear in large economies such as USA, Japan, Germany, the United Kingdom and France and less clear in small economies such as Norway, Netherlands and Belgium. As is common to all countries the global financial crisis 2008-2009 is reflected in a large increase in the FSI and a large decrease in GIP. 

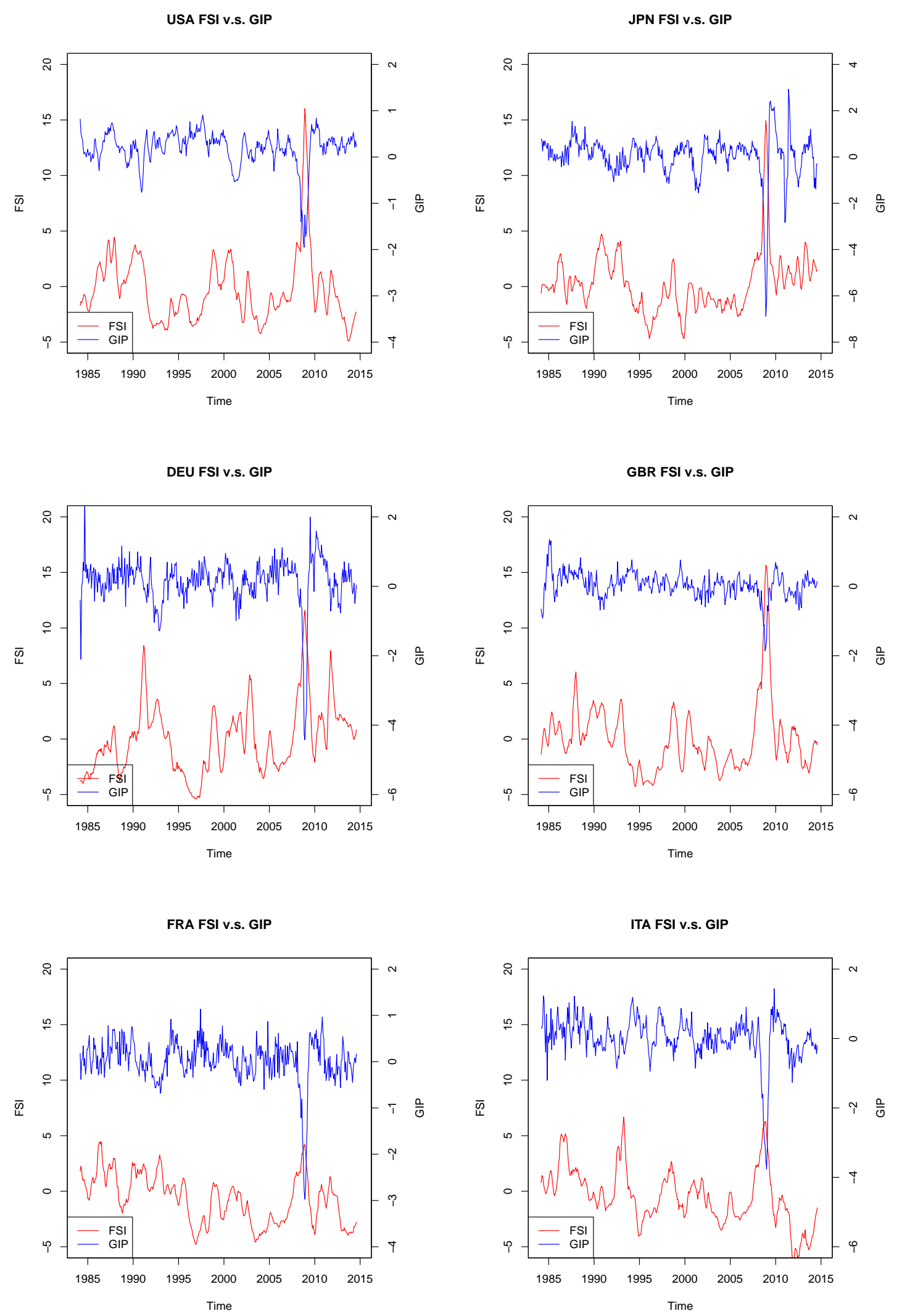

Figure 1: Financial stress index (FSI, 5 month moving average, lower graph) plotted against growth rates of industrial production (5 month moving average, upper graph) for selected countries 

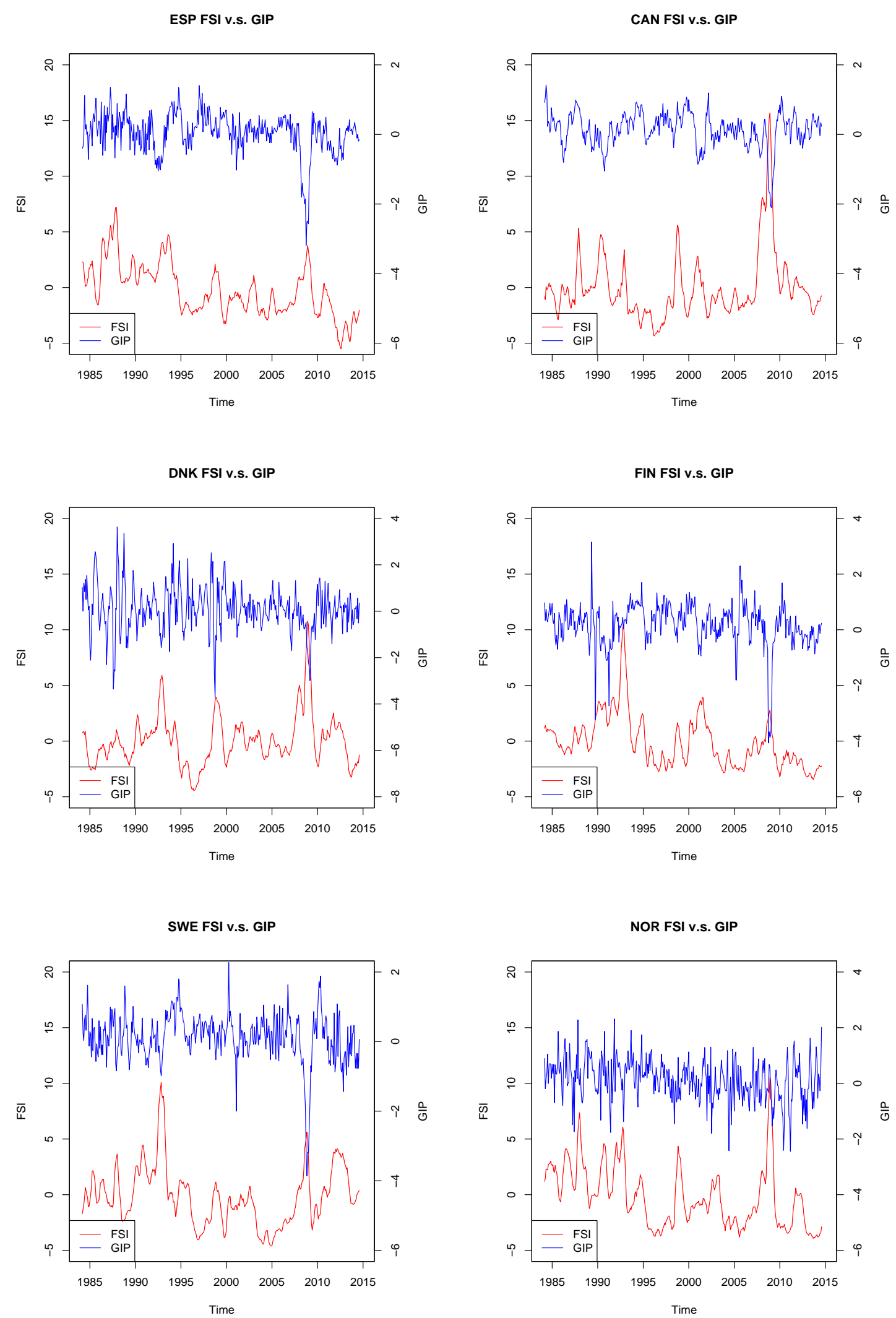

Figure 2: Financial stress index (FSI, 5 month moving average, lower graph) plotted against growth rates of industrial production ( 5 month moving average, upper graph) for selected countries 

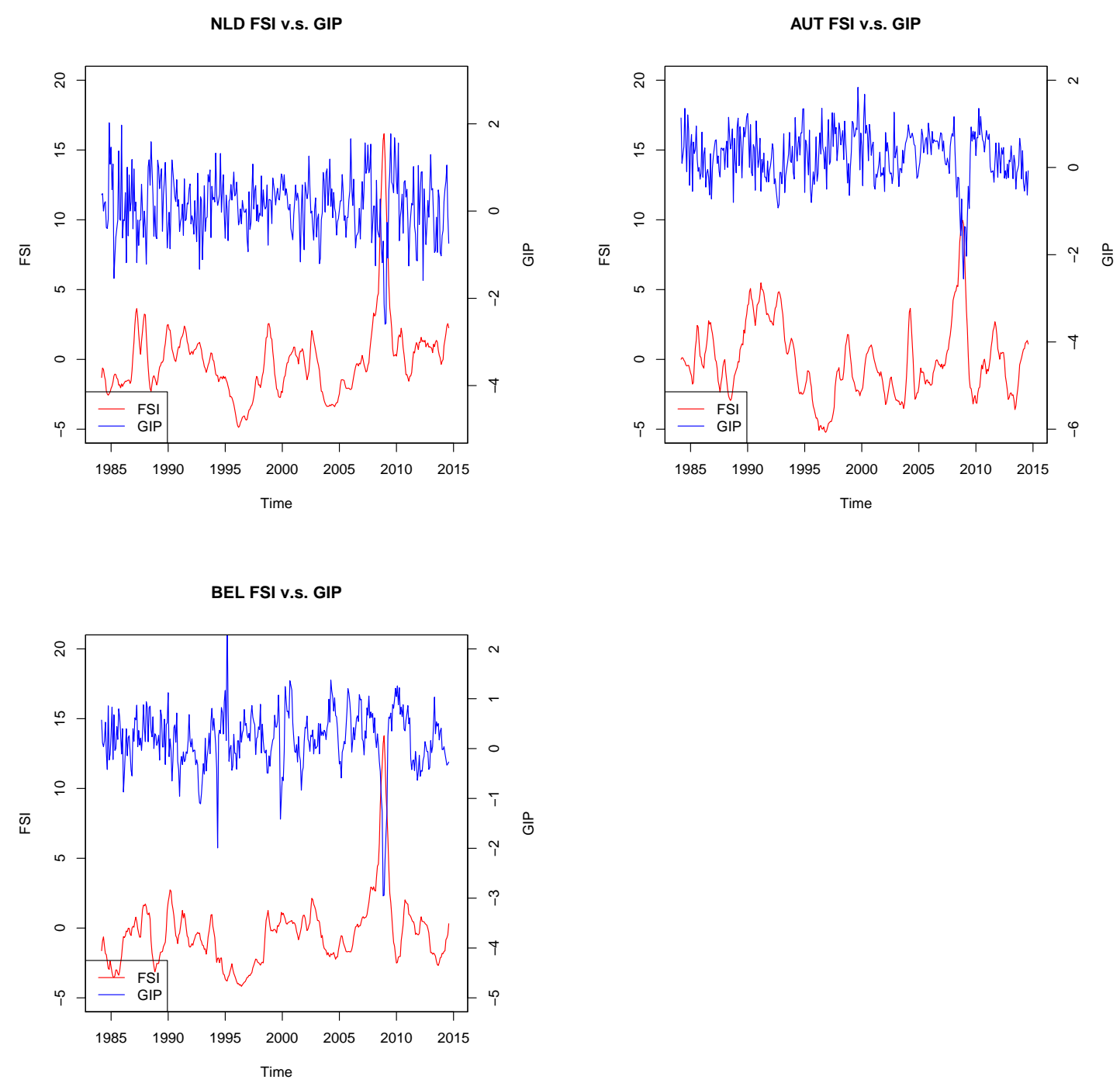

Figure 3: Financial stress index (FSI, 5 month moving average, lower graph) plotted against growth rates of industrial production ( 5 month moving average, upper graph) for selected countries

We observe for all 15 countries the FSI series and the GIP series are moving in opposite directions. Higher financial stress is correlated with lower real activities and higher real activities are correlated with lower financial stress. We also observe that FSI series show significant co-movements across most countries, in particular during the 2008-2009 GFC periods, while the co-movements of GIP series are less significant. These graphical features are reflected in the descriptive statistics of the series in the following Table 3 
Table 1: Correlation Coefficients

\begin{tabular}{|c|c|c|c|c|}
\hline & USA_FSI & USA_GIP & USA_FFSI & USA_FGIP \\
\hline USA_FSI & 1.0000 & -0.3271 & 0.7584 & -0.3108 \\
\hline USA_GIP & -0.3271 & 1.0000 & -0.3488 & 0.3032 \\
\hline USA_FFSI & 0.7584 & -0.3488 & 1.0000 & -0.4133 \\
\hline \multirow[t]{2}{*}{ USA_FGIP } & -0.3108 & 0.3032 & -0.4133 & 1.0000 \\
\hline & JPN_FSI & JPN_GIP & JPN_FFSI & JPN_FGIP \\
\hline JPN_FSI & 1.0000 & -0.2943 & 0.7006 & -0.4057 \\
\hline JPN_GIP & -0.2943 & 1.0000 & -0.2404 & 0.2624 \\
\hline JPN_FFSI & 0.7006 & -0.2404 & 1.0000 & -0.4172 \\
\hline \multirow[t]{2}{*}{ JPN_FGIP } & -0.4057 & 0.2624 & -0.4172 & 1.0000 \\
\hline & DEU_FSI & DEU_GIP & DEU_FFSI & DEU_FGIP \\
\hline DEU_FSI & 1.0000 & -0.1900 & 0.6387 & -0.3998 \\
\hline DEU_GIP & -0.1900 & 1.0000 & -0.2016 & 0.2920 \\
\hline DEU_FFSI & 0.6387 & -0.2016 & 1.0000 & -0.4371 \\
\hline \multirow[t]{2}{*}{ DEU_FGIP } & -0.3998 & 0.2920 & -0.4371 & 1.0000 \\
\hline & FRA_FSI & FRA_GIP & FRA_FFSI & FRA_FGIP \\
\hline FRA_FSI & 1.0000 & -0.1369 & 0.6495 & -0.2522 \\
\hline FRA_GIP & -0.1369 & 1.0000 & -0.2241 & 0.4468 \\
\hline FRA_FFSI & 0.6495 & -0.2241 & 1.0000 & -0.4605 \\
\hline \multirow[t]{2}{*}{ FRA_FGIP } & -0.2522 & 0.4468 & -0.4605 & 1.0000 \\
\hline & GBR_FSI & GBR_GIP & GBR_FFSI & GBR_FGIP \\
\hline GBR_FSI & 1.0000 & -0.1741 & 0.8883 & -0.4424 \\
\hline GBR_GIP & -0.1741 & 1.0000 & -0.1618 & 0.3280 \\
\hline GBR_FFSI & 0.8883 & -0.1618 & 1.0000 & -0.4537 \\
\hline \multirow[t]{2}{*}{ GBR_FGIP } & -0.4424 & 0.3280 & -0.4537 & 1.0000 \\
\hline & CAN_FSI & CAN_GIP & CAN_FFSI & CAN_FGIP \\
\hline CAN_FSI & 1.0000 & -0.2203 & 0.8322 & -0.4083 \\
\hline CAN_GIP & -0.2203 & 1.0000 & -0.2414 & 0.3805 \\
\hline CAN_FFSI & 0.8322 & -0.2414 & 1.0000 & -0.4500 \\
\hline \multirow[t]{2}{*}{ CAN_FGIP } & -0.4083 & 0.3805 & -0.4500 & 1.0000 \\
\hline & SWE_FSI & SWE_GIP & SWE_FFSI & SWE_FGIP \\
\hline SWE_FSI & 1.0000 & -0.1231 & 0.4714 & -0.2398 \\
\hline SWE_GIP & -0.1231 & 1.0000 & -0.1899 & 0.3102 \\
\hline SWE_FFSI & 0.4714 & -0.1899 & 1.0000 & -0.4536 \\
\hline \multirow[t]{2}{*}{ SWE_FGIP } & -0.2398 & 0.3102 & -0.4536 & 1.0000 \\
\hline & BEL_FSI & BEL_GIP & BEL_FFSI & BEL_FGIP \\
\hline BEL_FSI & 1.0000 & -0.1285 & 0.7986 & -0.4689 \\
\hline BEL_GIP & -0.1285 & 1.0000 & -0.1429 & 0.2153 \\
\hline BEL_FFSI & 0.7986 & -0.1429 & 1.0000 & -0.4528 \\
\hline BEL_FGIP & -0.4689 & 0.2153 & -0.4528 & 1.0000 \\
\hline
\end{tabular}


Table 2: Table 1 (continuous)

\begin{tabular}{|c|c|c|c|c|}
\hline & ITA_FSI & ITA_GIP & ITA_FFSI & ITA_FGIP \\
\hline ITA_FSI & 1.0000 & -0.0833 & 0.5014 & -0.2399 \\
\hline ITA_GIP & -0.0833 & 1.0000 & -0.2210 & 0.4496 \\
\hline ITA_FFSI & 0.5014 & -0.2210 & 1.0000 & -0.4570 \\
\hline \multirow{2}{*}{ ITA_FGIP } & -0.2399 & 0.4496 & -0.4570 & 1.0000 \\
\hline & ESP_FSI & ESP_GIP & ESP_FFSI & ESP_FGIP \\
\hline ESP_FSI & 1.0000 & -0.0162 & 0.4854 & -0.0939 \\
\hline ESP_GIP & -0.0162 & 1.0000 & -0.1872 & 0.2781 \\
\hline ESP_FFSI & 0.4854 & -0.1872 & 1.0000 & -0.4567 \\
\hline \multirow[t]{2}{*}{ ESP_FGIP } & -0.0939 & 0.2781 & -0.4567 & 1.0000 \\
\hline & DNK_FSI & DNK_GIP & DNK_FFSI & DNK_FGIP \\
\hline DNK_FSI & 1.0000 & -0.0898 & 0.7113 & -0.3943 \\
\hline DNK_GIP & -0.0898 & 1.0000 & -0.1068 & 0.1381 \\
\hline DNK_FFSI & 0.7113 & -0.1068 & 1.0000 & -0.4538 \\
\hline \multirow{2}{*}{ DNK_FGIP } & -0.3943 & 0.1381 & -0.4538 & 1.0000 \\
\hline & FIN_FSI & FIN_GIP & FIN_FFSI & FIN_FGIP \\
\hline FIN_FSI & 1.0000 & -0.0394 & 0.3506 & -0.1840 \\
\hline FIN_GIP & -0.0394 & 1.0000 & -0.1501 & 0.2156 \\
\hline FIN_FFSI & 0.3506 & -0.1501 & 1.0000 & -0.4545 \\
\hline \multirow[t]{2}{*}{ FIN_FGIP } & -0.1840 & 0.2156 & -0.4545 & 1.0000 \\
\hline & AUT_FSI & AUT_GIP & AUT_FFSI & AUT_FGIP \\
\hline AUT_FSI & 1.0000 & -0.0941 & 0.6611 & -0.3840 \\
\hline AUT_GIP & -0.0941 & 1.0000 & -0.1189 & 0.1828 \\
\hline AUT_FFSI & 0.6611 & -0.1189 & 1.0000 & -0.4538 \\
\hline \multirow[t]{2}{*}{ AUT_FGIP } & -0.3840 & 0.1828 & -0.4538 & 1.0000 \\
\hline & NLD_FSI & NLD_GIP & NLD_FFSI & NLD_FGIP \\
\hline NLD_FSI & 1.0000 & -0.0901 & 0.8411 & -0.4700 \\
\hline NLD_GIP & -0.0901 & 1.0000 & -0.0760 & 0.1813 \\
\hline NLD_FFSI & 0.8411 & -0.0760 & 1.0000 & -0.4567 \\
\hline \multirow[t]{2}{*}{ NLD_FGIP } & -0.4700 & 0.1813 & -0.4567 & 1.0000 \\
\hline & NOR_FSI & NOR_GIP & NOR_FFSI & NOR_FGIP \\
\hline NOR_FSI & 1.0000 & 0.0555 & 0.6538 & -0.3259 \\
\hline NOR_GIP & 0.0555 & 1.0000 & 0.0008 & 0.0350 \\
\hline NOR_FFSI & 0.6538 & 0.0008 & 1.0000 & -0.4576 \\
\hline NOR_FGIP & -0.3259 & 0.0350 & -0.4576 & 1.0000 \\
\hline
\end{tabular}

The descriptive statistics above show two main features: (1) the domestic FSIs and the domestic GIPs are negatively correlated except for Norway, which reflects the opposite movement of the two pairs of time series in the graphs of Figure 1 to Figure 3. (2) the domestic FSIs and foreign FSIs are highly positively correlated. 
The correlation coefficients of 11 out of the 15 countries are above 0.6 . These two features are reflected also in the negative correlation between domestic GIPs and foreign FSIs, and the negative correlation between domestic FSIs and foreign GIPs.

\subsection{Propagation and Synchronization}

As a consequence of globalization, the GFC is reflected in the comovement of FSI and GIP across all countries but in opposite directions. The high correlations between the domestic variables and the foreign variables indicate the tendency of synchronization of business cycles across countries. Here we calculate the average correlation coefficients over 24 months of FSI and GIP across 15 countries, respectively, in order to gauge how the globalization proceeds.

$$
\begin{aligned}
\rho_{F S I, t} & =\frac{\sum_{i=1}^{N} \sum_{j=1, j \neq i}^{N} \sum_{\tau=1}^{L}\left(F S I_{i, t-\tau}-\overline{F S I}_{i, t}\right)\left(F S I_{j, t-\tau}-\overline{F S I}_{j, t}\right)}{N(N-1) L} \\
\rho_{G I P, t} & =\frac{\sum_{i=1}^{N} \sum_{j=1, j \neq i}^{N} \sum_{\tau=1}^{L}\left(G I P_{i, t-\tau}-\overline{G I P}_{i, t}\right)\left(G I P_{j, t-\tau}-\overline{G I P}_{j, t}\right)}{N(N-1) L}
\end{aligned}
$$

\section{Average Correlation}

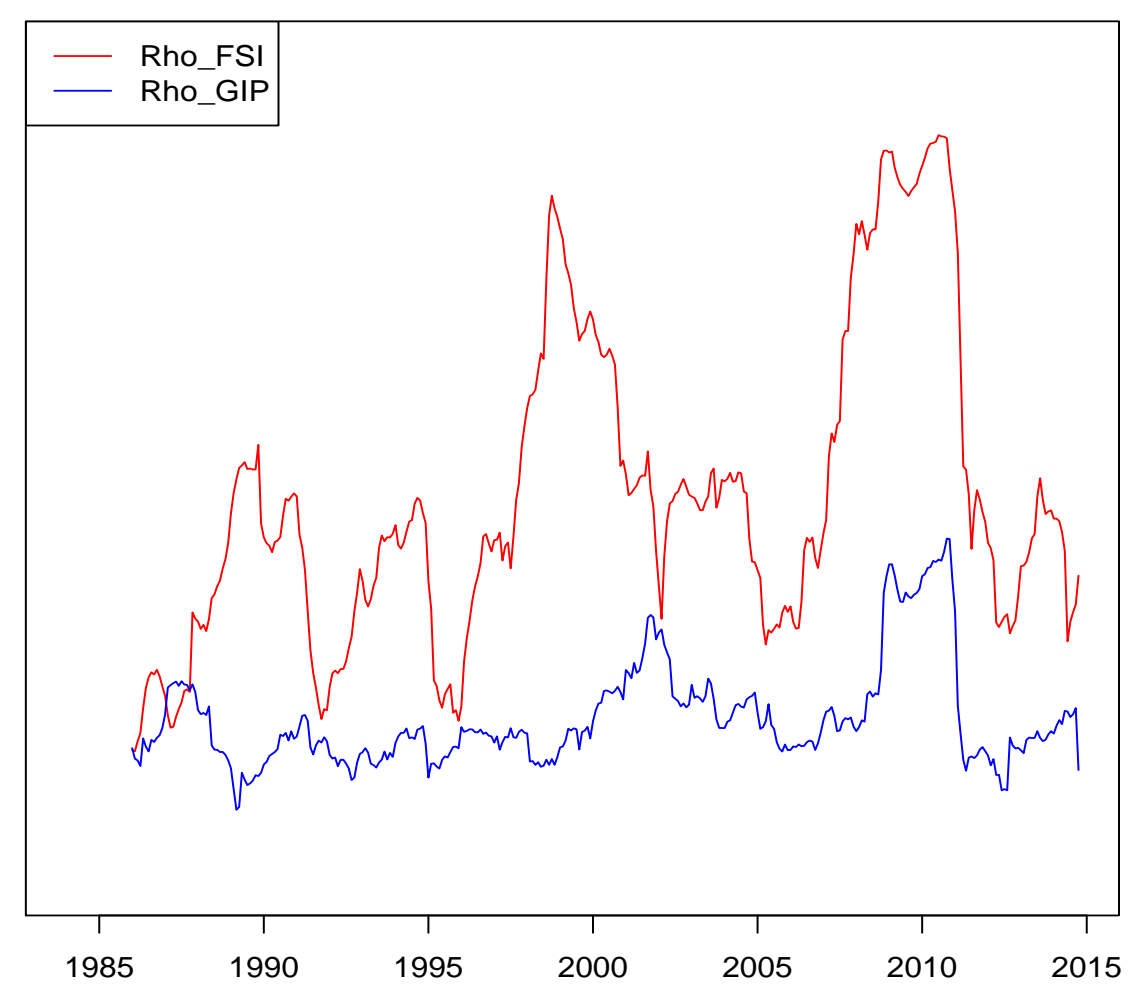

Figure 4: Average Correlation Coefficients of FSI and IPG among Countries over Time

Obviously, the average correlation coefficients of FSI and that of GIP increase both over time, indicating that progressing of globalization process leads to in- 
creasingly synchronization of business cycle world wide. That the value of average correlation coefficient of FSI is much higher than that of GIP implies that countries are closer related through financial channels than trade channels. Figure 5 shows episodes of high financial stress across all countries. Here we use FSI $>2$ as a criterion to gauge the high financial stress regime.

Combining Figure 5 and Figure 4, we observe that during high financial stress periods the average correlations among FSIs as well as that of GIPs are higher, indicating the business cycle are more synchronized during high stress periods, and the business cycle is less synchronized during the low stress periods. This suggests that the interaction between the financial market and real activities are different during high and low stress periods, which supports the modeling idea underlying MRGVAR. This is an interesting result, since it refines in some way the results ${ }^{10}$ for cases where one uses solely connectedness measures to study contagion of shocks, without referring to regimes.

High Financial Stress

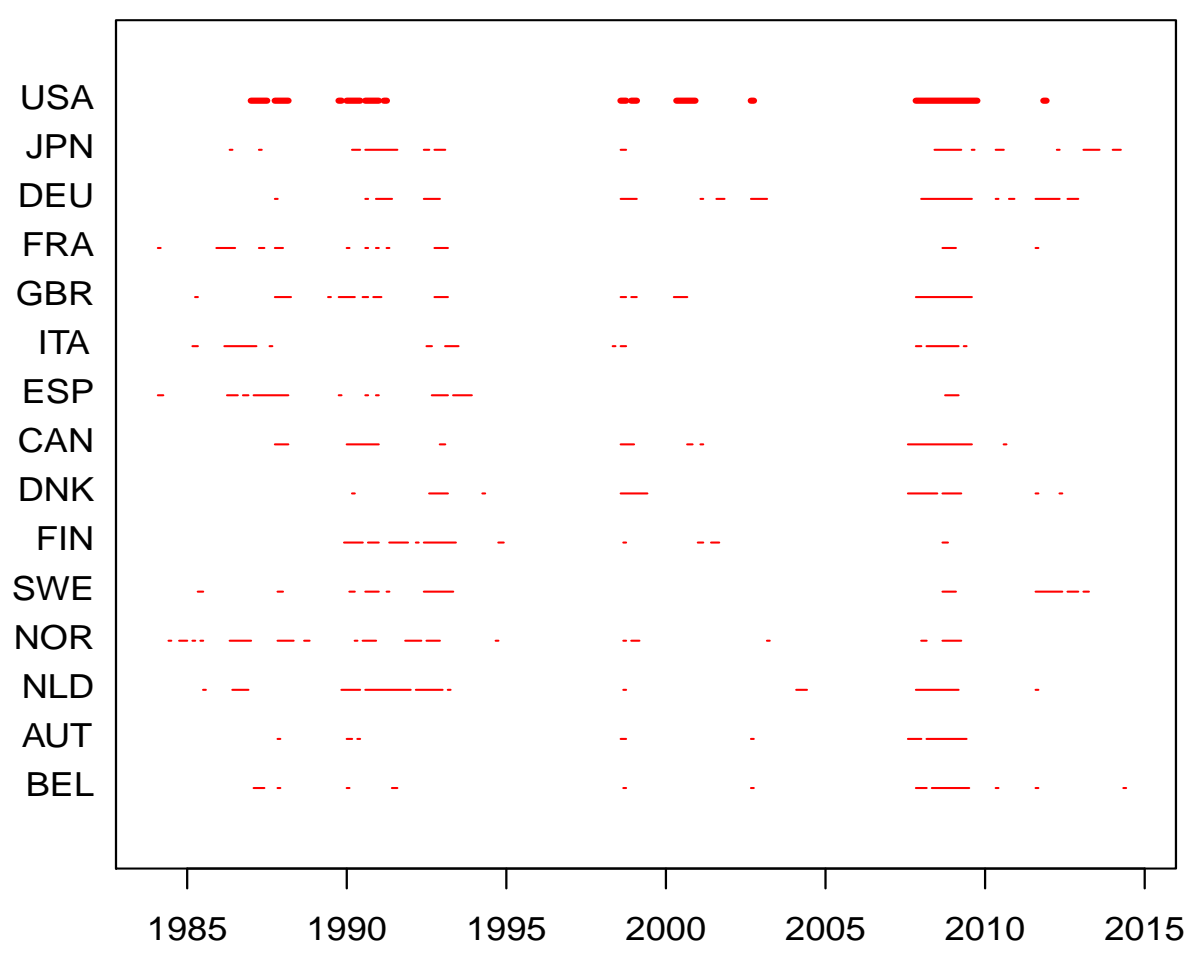

Figure 5: Stressed Regimes across Countries

\footnotetext{
${ }^{10}$ See Diebold and Yiemaz (2013).
} 


\section{Estimation Results}

In our empirical model we consider two variables for each country: the IMF financial stress index(FSI) and the growth rate of monthly industrial output(IP).

$$
y_{i, t}=\left(F S I_{i, t}, G I P_{i, t}\right)^{\prime}=\left(F S I_{i, t}, 100 \Delta \log \left(I P_{i, t}\right)\right)^{\prime}
$$

Accordingly $y_{i, t}^{*}$ contains the weighted averages of foreign financial stress indexes and growth rates of foreign industrial output:

$$
y_{i, t}^{*}=\left(\sum_{j=1, j \neq i}^{N} w_{i, j} F S I_{j, t}, \sum_{j=1, j \neq i}^{N} w_{i, j} G I P_{j, t}\right)^{\prime} .
$$

The specification process is as follows: For country $i$ we choose first a set of discrete threshold values in the high range of FSI, typically in the interval $\tau_{i} \in(1.5,3.5)$ with an increment of 0.1 , and 10 as the maximum value for lag length. Then we calculate the model selection criterion (2.4) for all possible combination of $\left(p_{i, S_{i}}, q_{i, S_{i}}\right)$ and $\tau_{i}$ and choose that specification with the lowest AIC value as our model specification for country $i$. The result is summarized in Table 3 .

Table 3: Specifications of Country MRVAR models

\begin{tabular}{c|r|ccccr}
\hline & ORVAR & \multicolumn{5}{|c}{ MRVAR } \\
Country & AIC & $p_{i, 1}$ & $p_{i, 2}$ & $q_{i}$ & $\tau_{i}$ & AIC \\
\hline USA & -87.6368 & 1 & 3 & 1 & 2.50 & -152.4382 \\
JPN & 861.7891 & 1 & 3 & 1 & 1.40 & 813.0264 \\
DEU & 781.2331 & 1 & 2 & 1 & 2.50 & 741.4963 \\
FRA & 314.1914 & 1 & 3 & 1 & 2.10 & 312.2542 \\
GBR & 326.1758 & 1 & 2 & 1 & 2.50 & 280.5573 \\
ITA & 502.8720 & 1 & 3 & 1 & 2.90 & 475.3559 \\
ESP & 551.2986 & 1 & 2 & 1 & 1.70 & 550.9194 \\
CAN & 351.5207 & 1 & 4 & 3 & 2.85 & 325.2638 \\
DNK & 1136.1410 & 1 & 3 & 1 & 2.90 & 1101.1670 \\
FIN & 862.0191 & 1 & 3 & 1 & 2.60 & 825.5763 \\
SWE & 780.7644 & 1 & 2 & 1 & 2.10 & 770.8952 \\
NOR & 1089.0630 & 1 & 4 & 2 & 1.55 & 1076.8780 \\
AUT & 738.3621 & 2 & 2 & 2 & 2.20 & 756.7732 \\
BEL & 692.1981 & 3 & 4 & 1 & 2.30 & 668.4824 \\
NLD & 995.3075 & 1 & 4 & 1 & 3.10 & 979.9926 \\
\hline
\end{tabular}

Notes: Table 3 reports the results of specifications MRVAR for all countries in the system using AIC criterion. The second column gives the AIC values of ORVAR. The right panel are the results of MRVAR. The columns under headings of $p_{i, 1}, p_{i, 2}$ and $q_{i}$ are the lag order of domestic variables in the high stress regime, the low stress regime and the lag order of the foreign variables respectively. The column under the heading $\tau_{i}$ are threshold values of regime switching. A key for the abbreviation of the country names is given in the appendix.

According to the results in Table 3 our estimated MRGVAR consists of 15 countries. 14 countries follow a two regime VAR process and only AUT follows a one regime VAR process. 


\section{$5 \quad$ Impulse Response Analysis}

Impulse response function is a standard tool used in empirical analysis of VAR systems. It tells us how a particular shock propagates through the dynamics of the system. Following the tradition of GVAR literature we will use the generalized impulse response functions ${ }^{11}$, which depend on the overall state $\Omega_{t}$, that is all the information available at time $t$, type of shocks $v_{t}$, and the response horizon $h$. The GIR are defined by

$$
\operatorname{GIR}_{h}\left(v_{t}, \Omega_{t-1}\right)=E\left(y_{t+h} \mid v_{t}, \Omega_{t-1}\right)-E\left[y_{t+h} \mid \Omega_{t-1}\right] \text { for } h=0,1, \ldots,
$$

where the overall state, $\Omega_{t-1}$, reflects the relevant information set at time $t-1$. For a MS-VAR process, $\Omega_{t-1}$ comprises the information about the past realizations of $y_{t}$ and the states; for an MRVAR process with known threshold values, it needs to contain only information about past realizations of $y_{t-1}, y_{t-2}, \ldots y_{t-\max } p_{i}$. While simulation method can be used to trace out the GIR for a given $\Omega_{t-1}$ and $v_{t}$, this is, however, not helpful to understand the differences in the characteristics of different state configurations because the states would evolve through different configurations depending on the magnitude of $v_{t}$ and the particular realizations $\Omega_{t-1}$.

The regime-specific impulse response function as given by Ehrmann, Ellison, and Valla (2003), however, is helpful to investigate the dynamic characteristics of particular state configurations. In this paper we will conduct the analysis with the regime-specific impulse response functions. When we calculate a regime-specific impulse response function for a given state configuration $S$ we assume that the MRGVAR remains in the state for the duration of response. Concretely, for a chosen state vector $S$, we calculate the GIR of equation system (2.3) and treat the system (2.3) as if it were a conventional VAR. This assumption of no regime migration is particularly reasonable when we are interested in short-term analysis and want to understand the state-specific dynamics.

\section{$5.1 \quad$ Impact of Country Shocks}

\subsubsection{Impact of domestic shocks}

We first look at the effect of domestic shocks on domestic variables. The following 4 sets of figures are the responses of domestic variables to the domestic shocks under the high stress and low stress regimes in the examples USA, JPN, DEU and GBR respectively.

\footnotetext{
${ }^{11}$ See Koop, Pesaran, and Potter (1996) for more details
} 

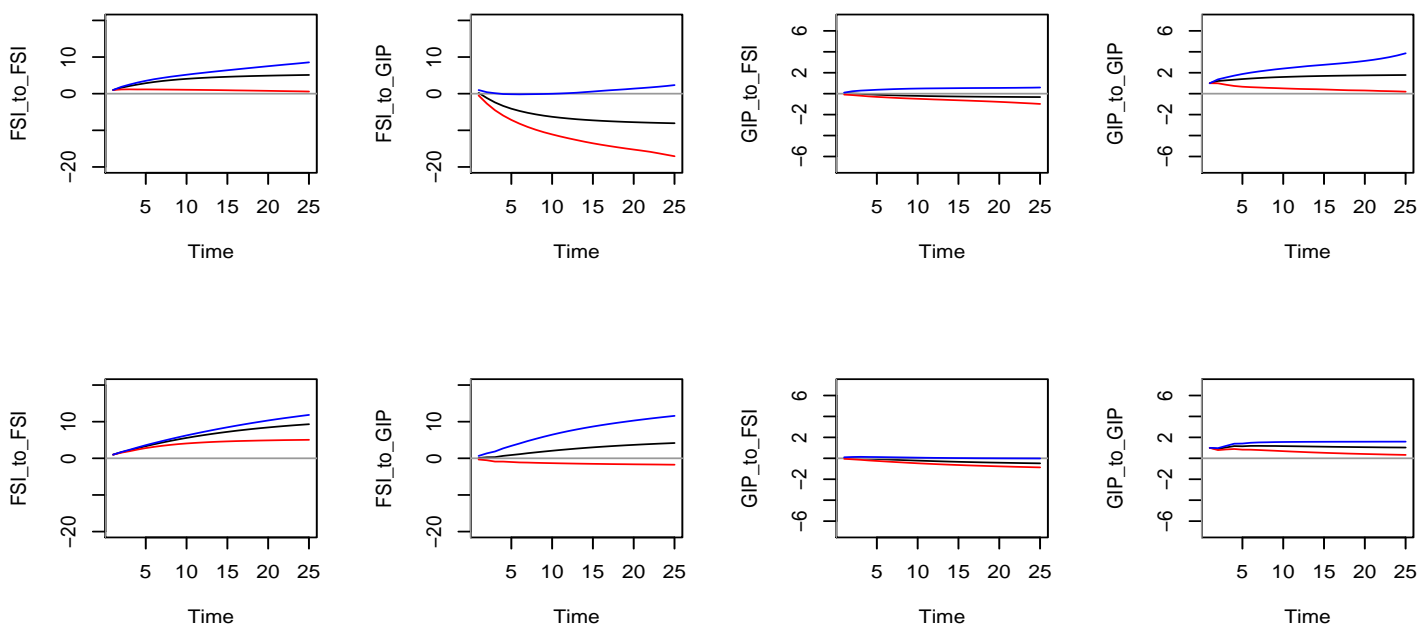

Figure 6: USA responses to domestic one standard deviation shocks in the high stress regime (upper 4 graphs) and in the low stress regime (lower 4 graphs)

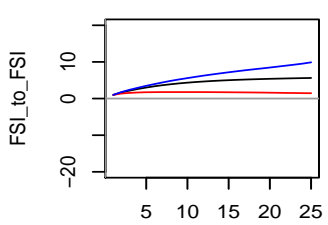

Time

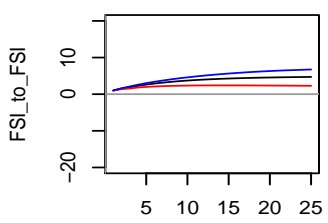

Time
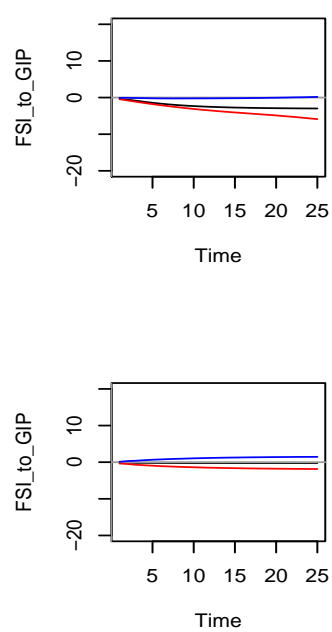
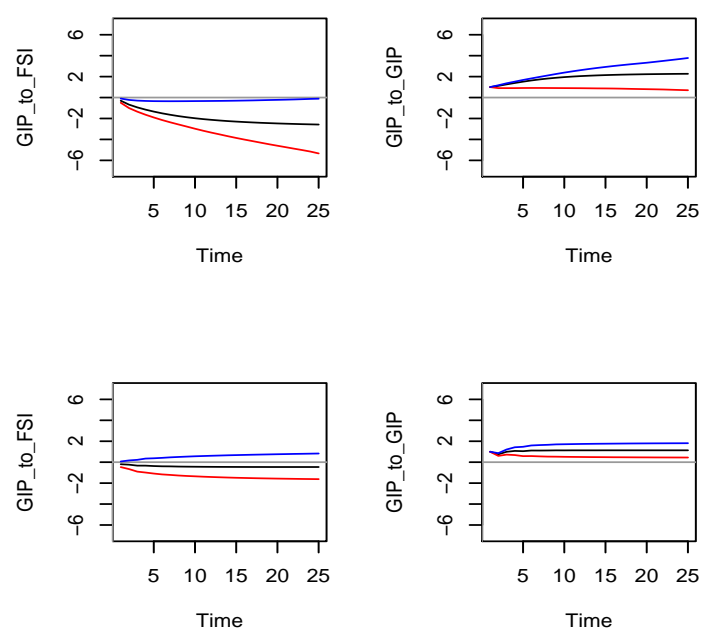

Figure 7: JPN responses to domestic one standard deviation shocks in the high stress regime (upper 4 graphs) and in the low stress regime (lower 4 graphs) 

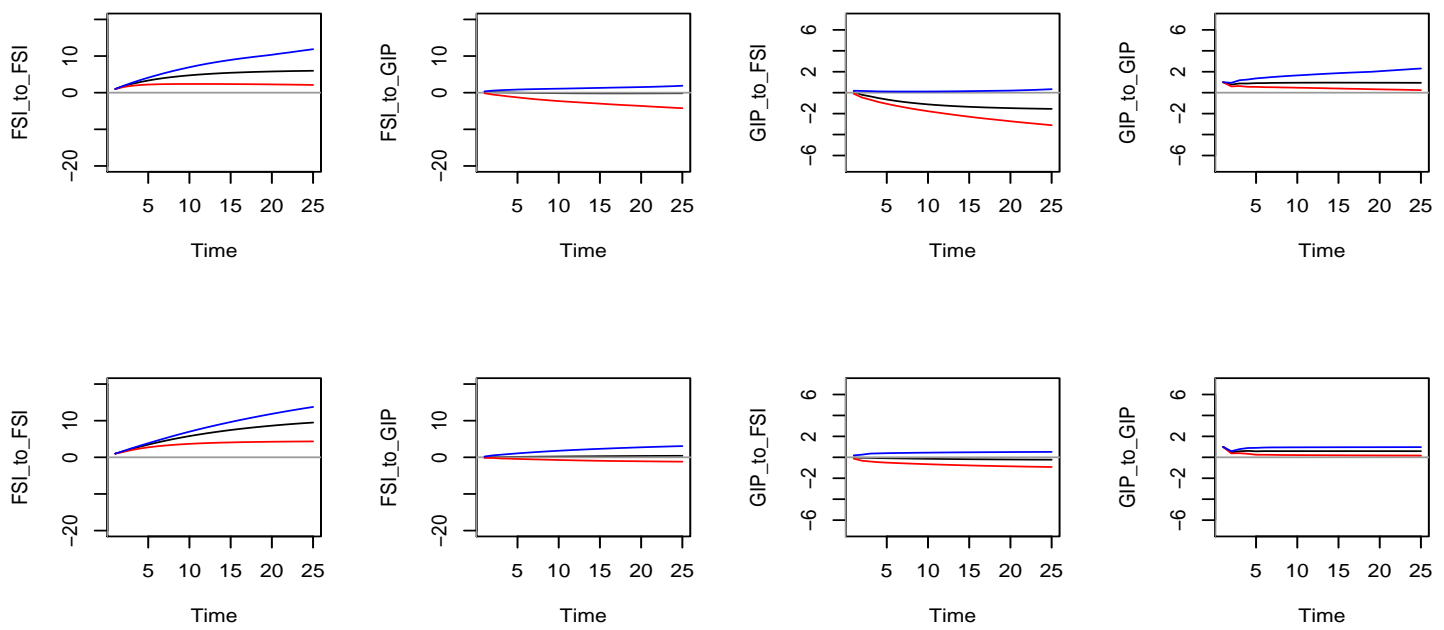

Figure 8: DEU responses to domestic one standard deviation shocks in the high stress regime (upper 4 graphs) and in the low stress regime (lower 4 graphs)

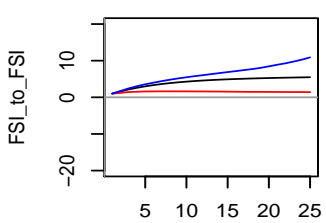

Time

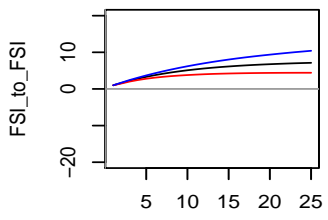

Time
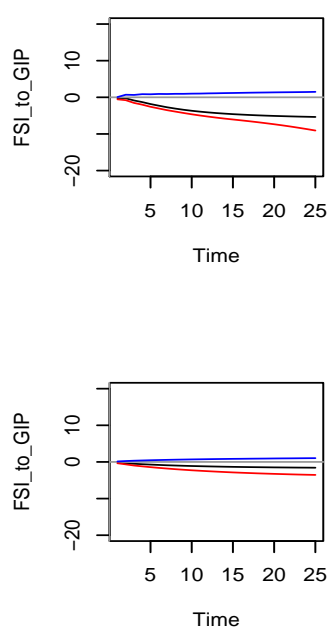
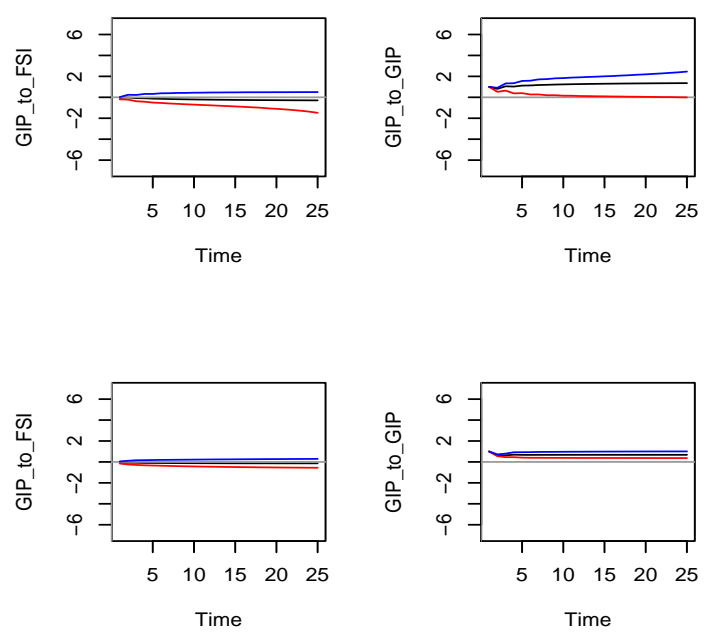

Figure 9: GBR responses to domestic one standard deviation shocks in the high stress regime (upper 4 graphs) and in the low stress regime (lower 4 graphs)

In the high stress regime domestic financial shocks will significantly increase the financial stress and at same time the shocks will decrease the growth of industrial output in all four countries. The effects on the domestic financial stress are more significant than on the industrial output. Positive domestic output shocks will reduce the financial stress, however the effects are statistically significant only in JPN and DEU. At same time, the positive output shocks will significantly increase the growth of industrial output in all four countries.

In the low stress regime the effects are smaller than in the high stress regime. The domestic financial shocks will still significantly increase the financial stress and domestic output shock will also still have significant effects in growth on industrial output. But financial shocks do not have significant effects on output and the output 
shocks have no significant effects on financial stress either. These domestic results largely confirm the findings in MRVAR country models in Mittnik and Semmler (2013) and Semmler and Chen (2014). It is to note that in the low stress regime the domestic positive output shocks in USA have a tendency to increase the financial stress though they are statistically insignificant.

\subsubsection{Impact of large and small countries}

In the MRGVAR we can investigate the international spill-overs from one country to the others. Here we are particularly interested in the impact of a large country, say USA, and the impact of a small country, say BEL, on the other countries in the system. Again we look at the state-specific GIR of high stress regime and low stress regime respectively.
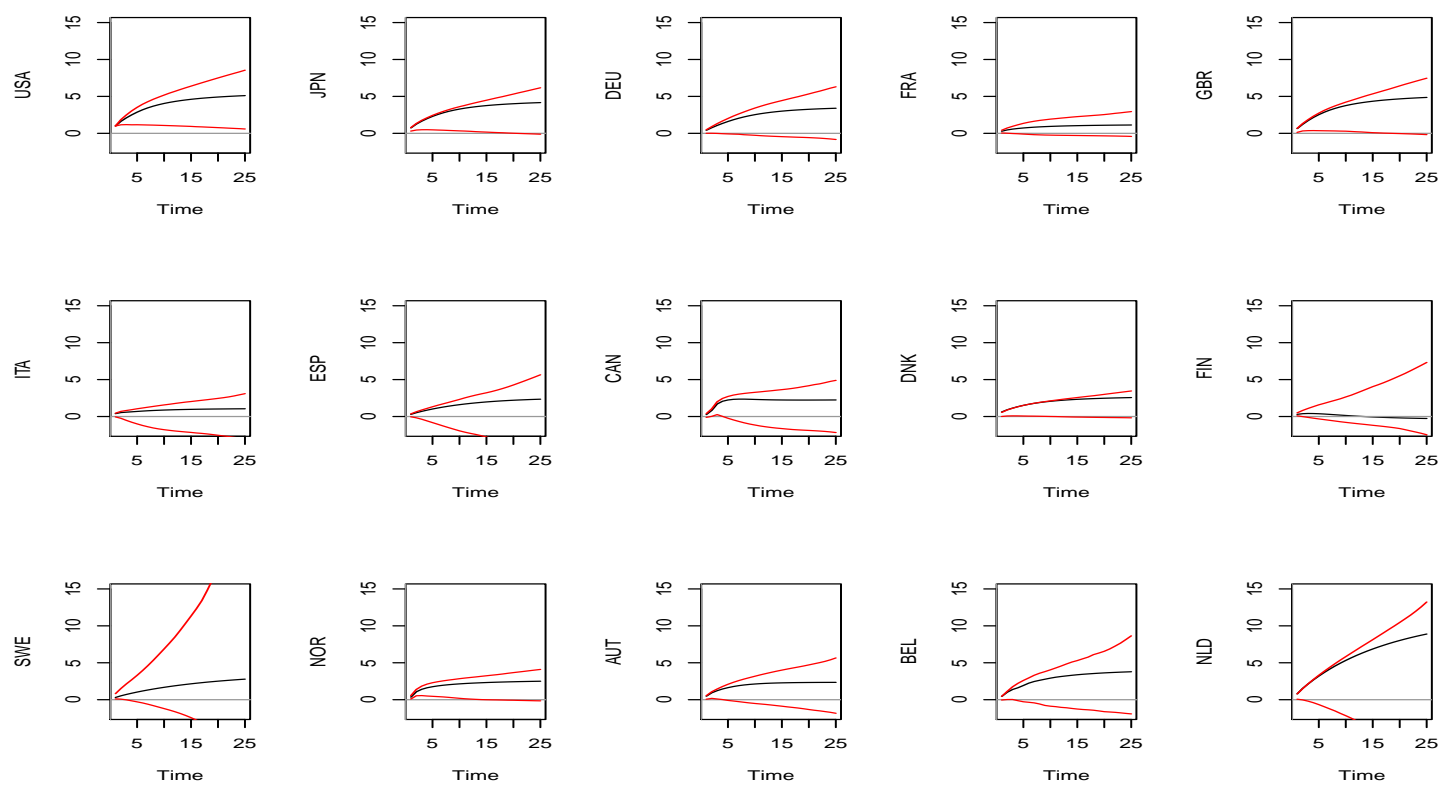

Figure 10: Responses of financial stress to a USA financial shock in the high stress regime 

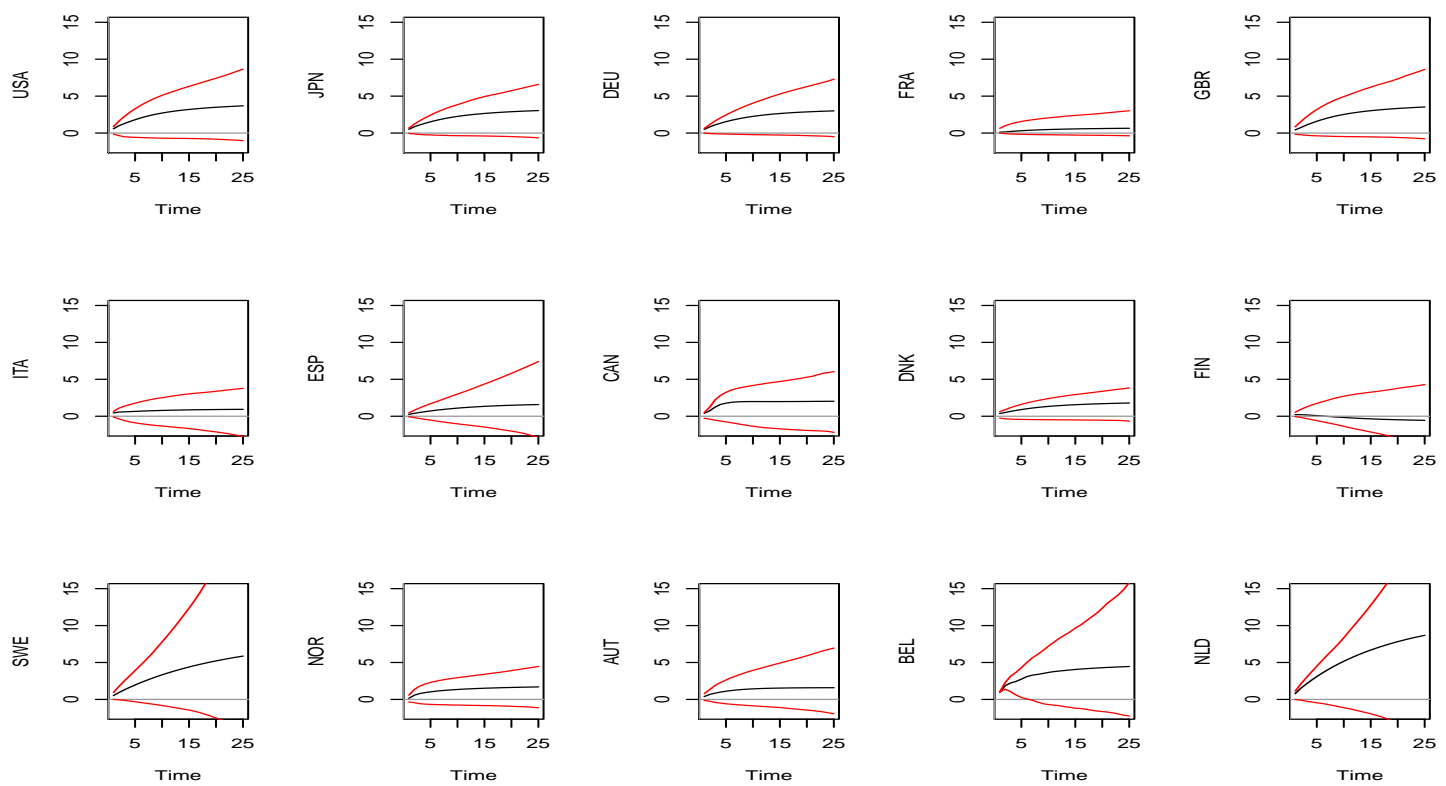

Figure 11: Responses of financial stress to a BEL financial shock in the high stress regime

Figure 10 and Figure 11 are the cumulative financial stress responses to a one unit financial shock from USA and BEL in high stress state respectively. Qualitatively the responses are similar, foreign financial shocks will increase the domestic financial stress. Quantitatively, the responses to the financial shocks from USA are larger than those to shocks from BEL. The effects of the USA financial shocks are, at least in the short run (up to 5 quarters), statistically significant in US, JPN, GBR, DEU, FRA, and NOR, while the effects of the BEL financial shocks are less statistically significant. The responses of industrial output growth to the one unit financial shocks from USA and BEL are shown in Figure 12 and Figure 13. 

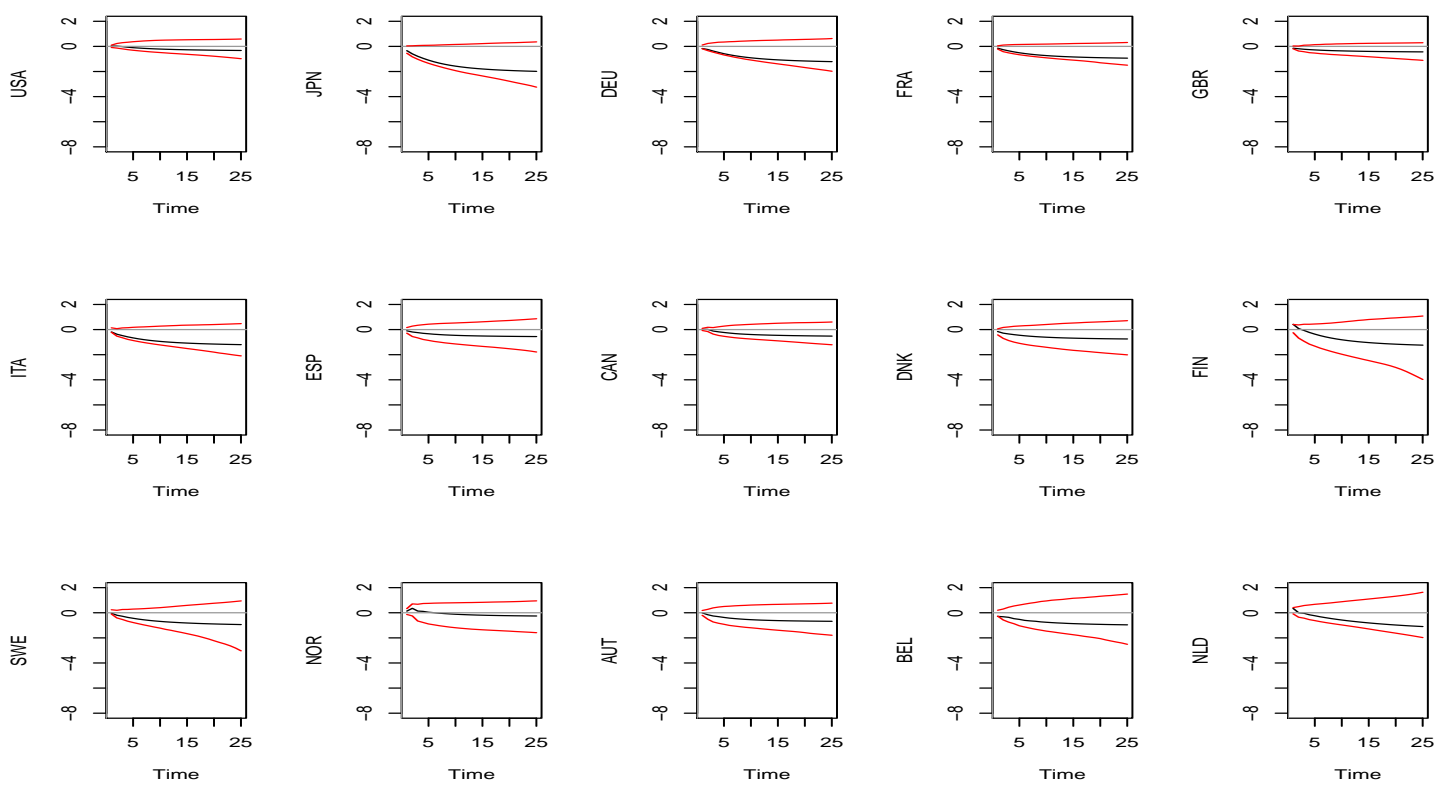

Figure 12: Responses of GIP to a USA financial shock in the high stress regime
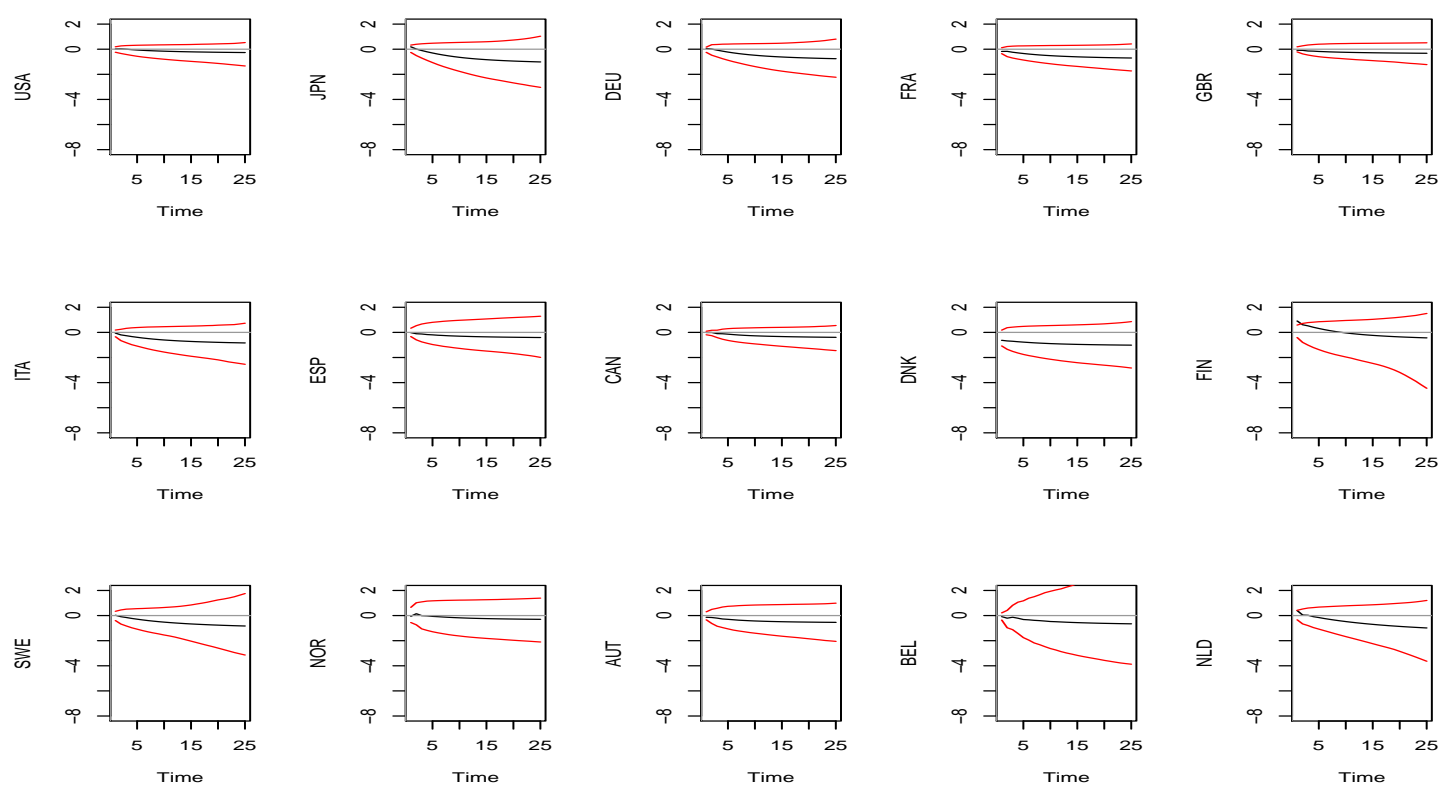

Figure 13: Responses of GIP to a BEL financial shock in the high stress regime

Generally the financial shocks have a negative effect on the growth of industrial output across all countries. The confidence intervals of the cumulative response functions lie largely in the negative ranges. The effects of the USA financial shocks are larger than the effects of the BEL financial shocks. The cumulative responses to a one unit GIP shocks, i.e. one percent growth per quarter, from USA and BEL are shown in Figure 14 and Figure 15. 

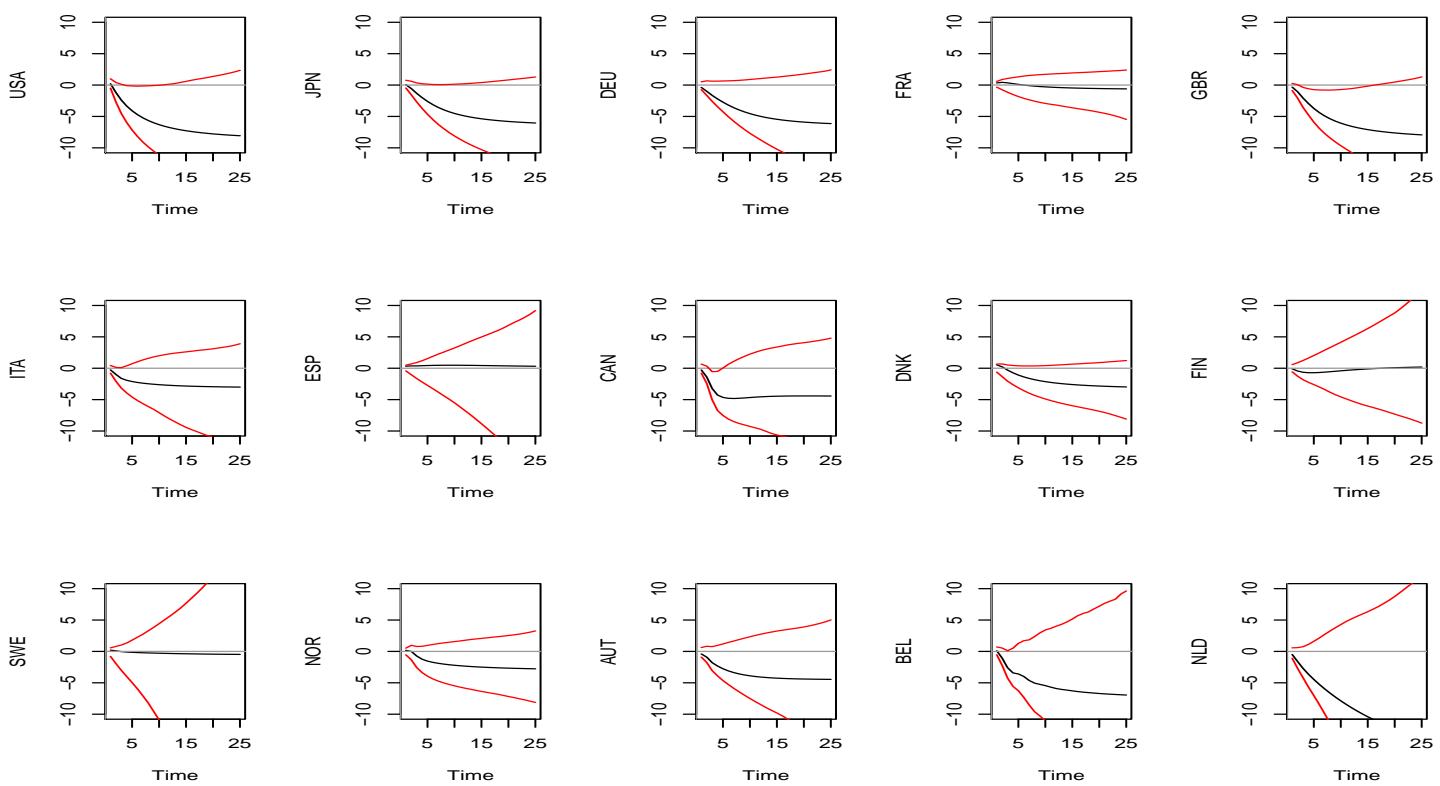

Figure 14: Responses of financial stress to a USA GIP shock in the high stress regime
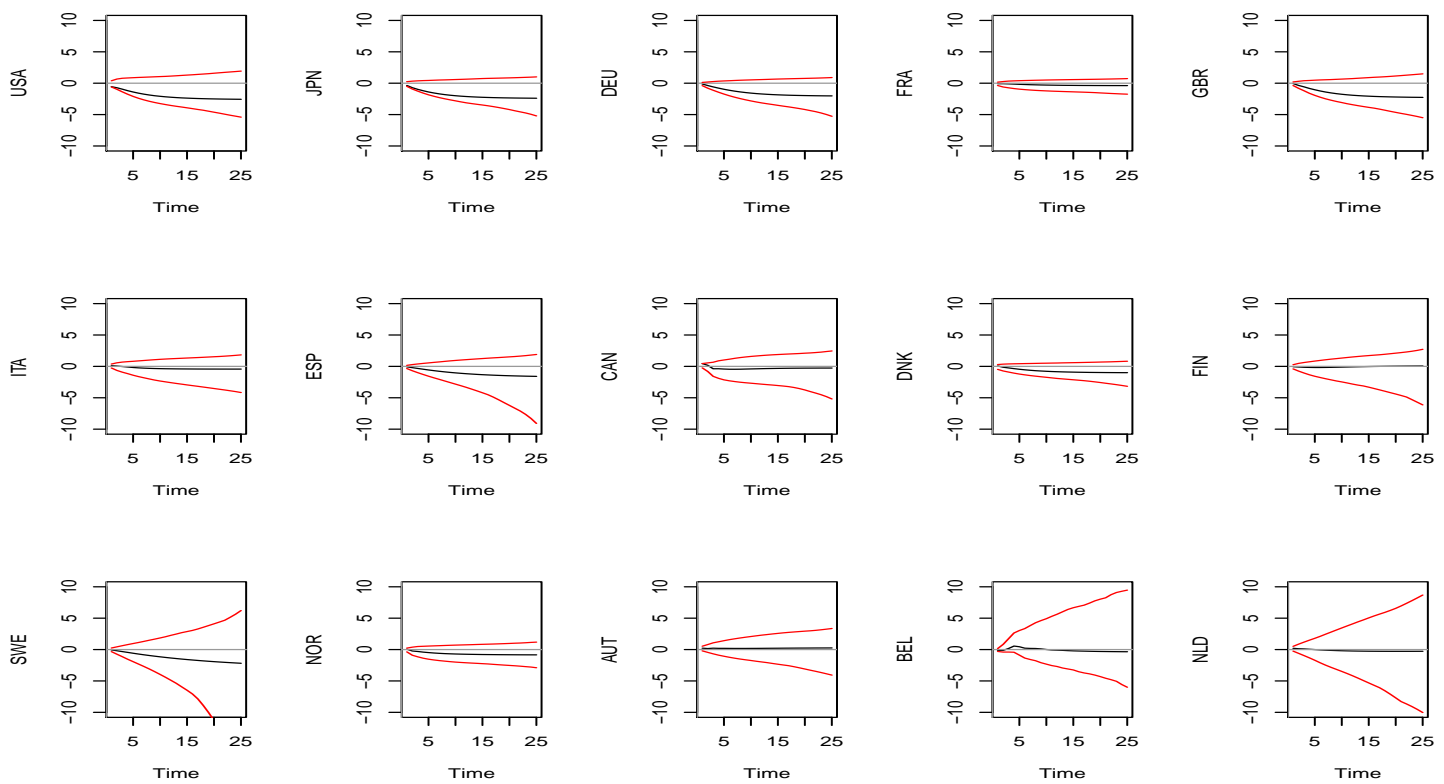

Figure 15: Responses of financial stress to a BEL GIP shock in the high stress regime

In a high stress regime, foreign output shocks have generally the tendency to reduce the domestic financial stress, reflected in the negative trending of the cumulative responses of financial stress to the output shocks in Figure 14 and Figure 15. The responses of financial stress to the USA output shocks are significantly larger than the responses to the BEL output shocks.

While the responses to the BEL output shocks are statistically insignificant, the responses to the USA output shocks are more significant in countries such as USA, 
JPN, DEU, GRB, and DNK at least in the short run. The responses of GIP to GIP shocks are generally positive, reflected in the upwards trending of the impulse response functions in Figure 16 and Figure 17. Again, it is the case that the responses to the USA output shocks are larger than the responses to the BEL output shocks.
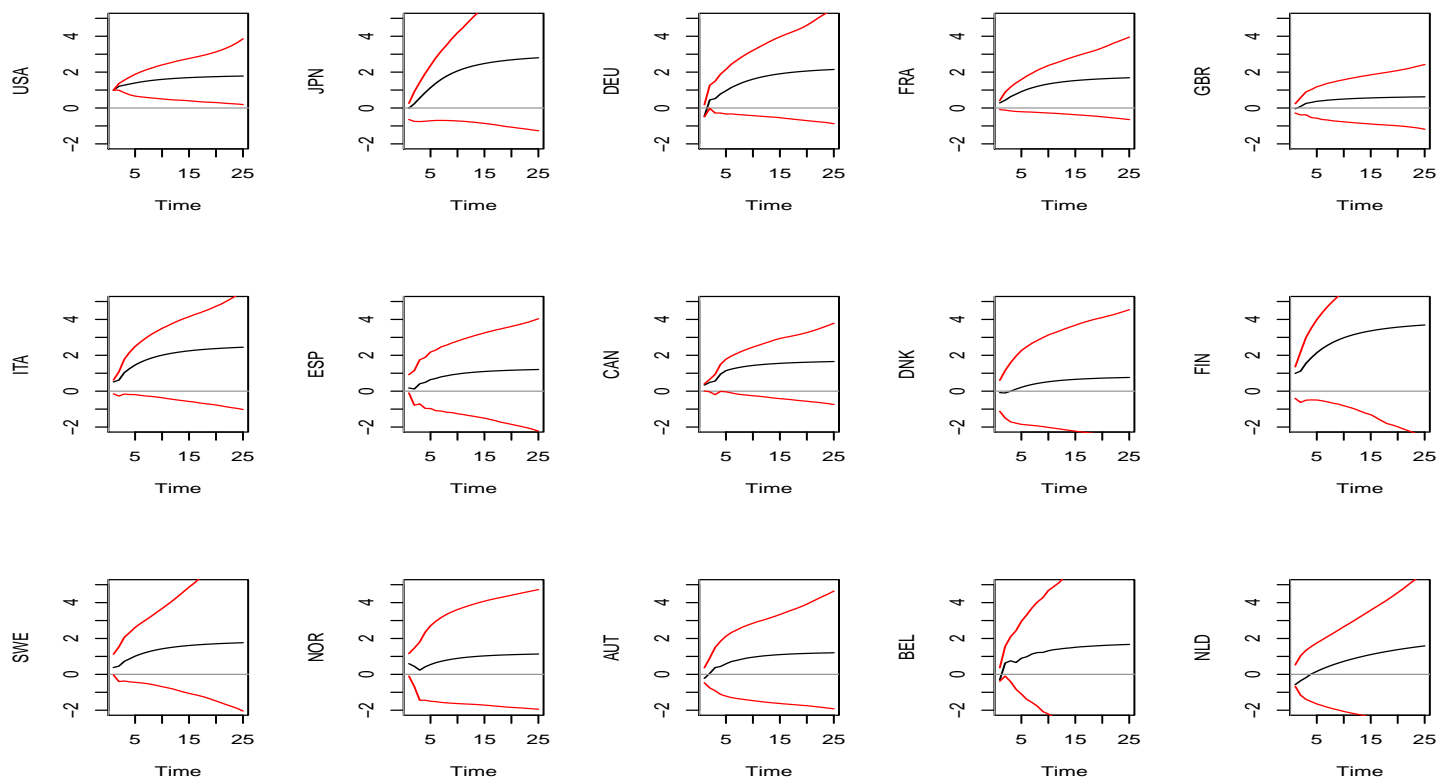

Figure 16: Responses of GIP to a USA GIP shock in the high stress regime
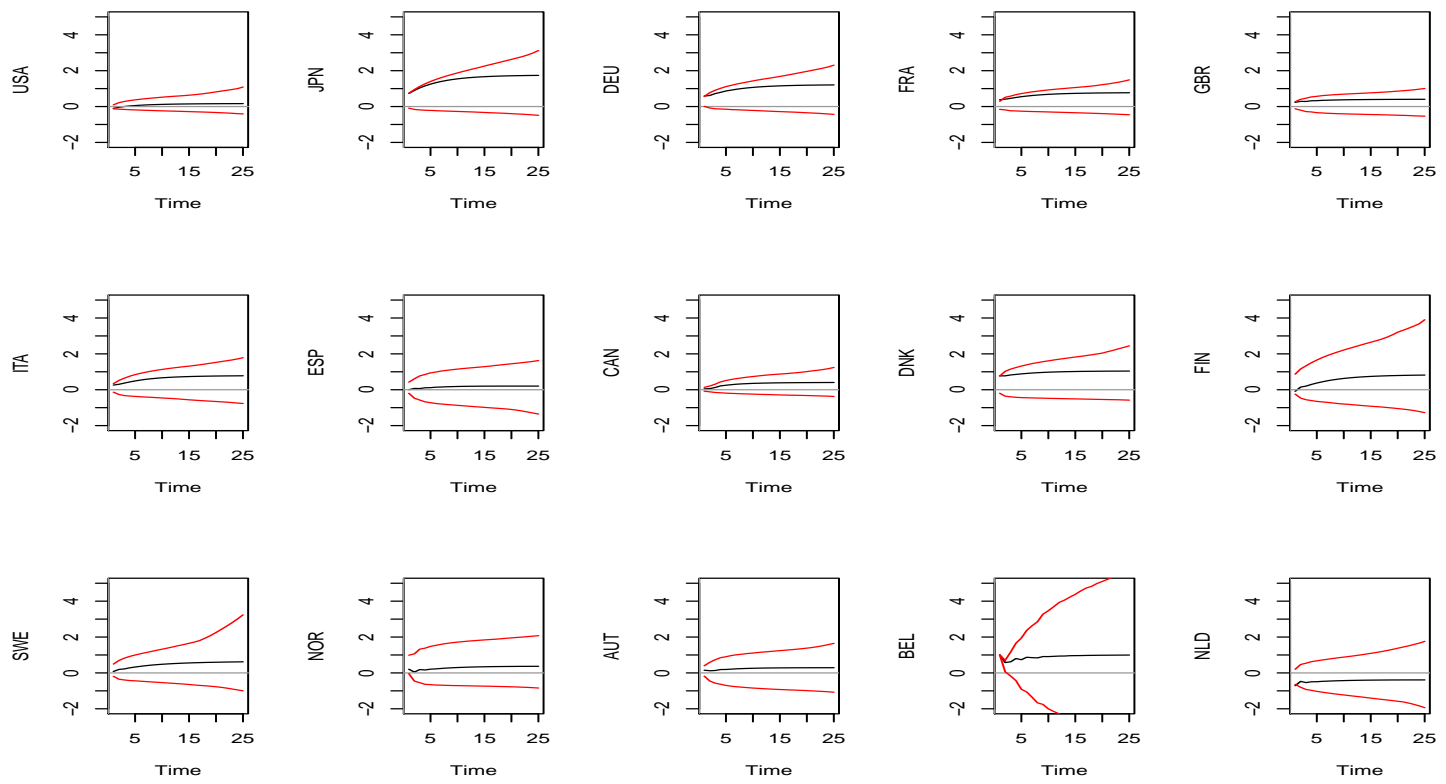

Figure 17: Responses of GIP to a BEL GIP shock in the high stress regime

In the low stress regime, the impulse response functions show largely a similar patters as in the high stress regime. However the responses are generally much weaker than those in the high stress regime and almost all responses are statistically 
insignificant. The responses of financial stress to the financial shocks from USA and BEL are the only significant responses. Here again the responses to the USA shocks are larger than the responses to the BEL shocks. The impulse response functions are given in Figure 18 to Figure 25
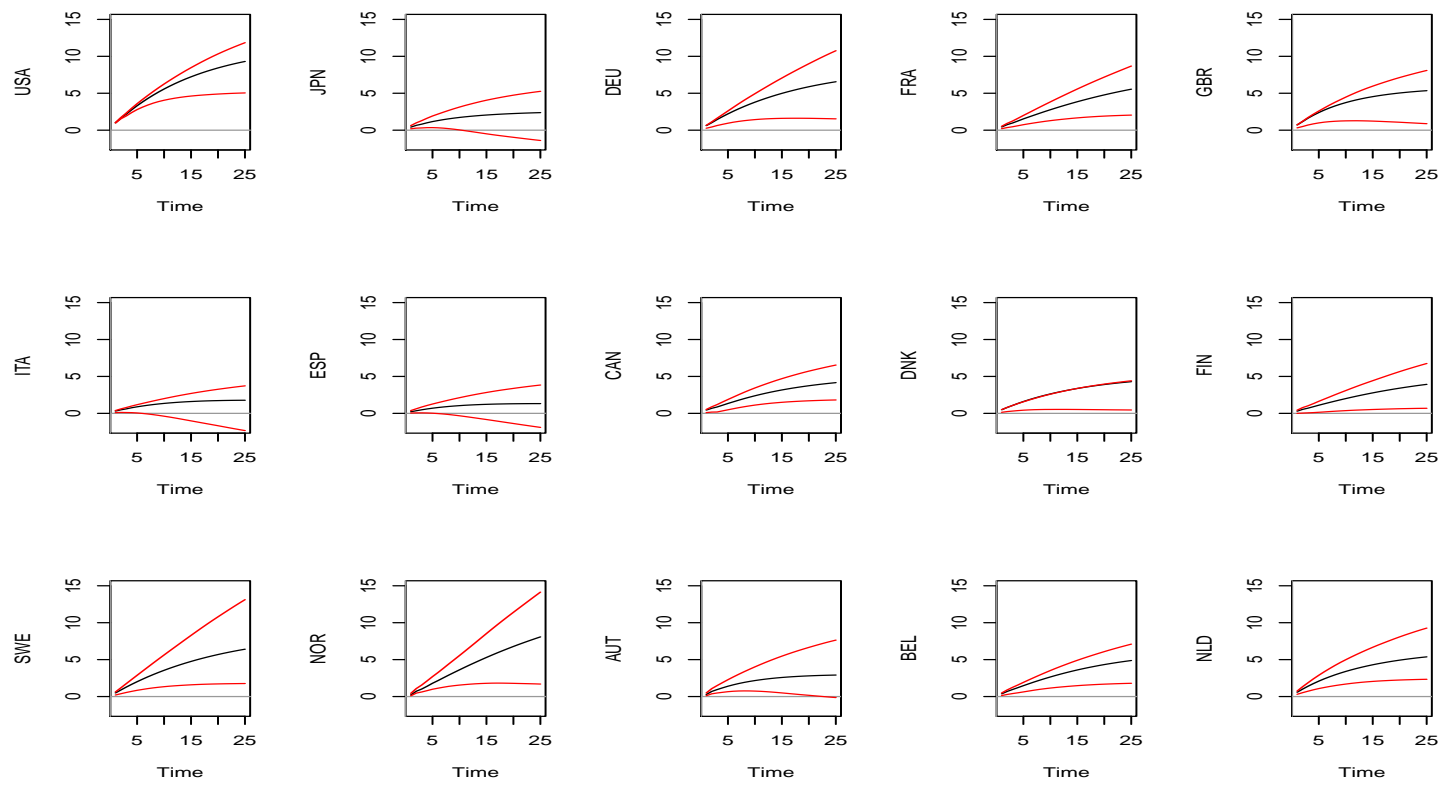

Figure 18: Responses of financial stress to a USA financial shock in the low stress regime
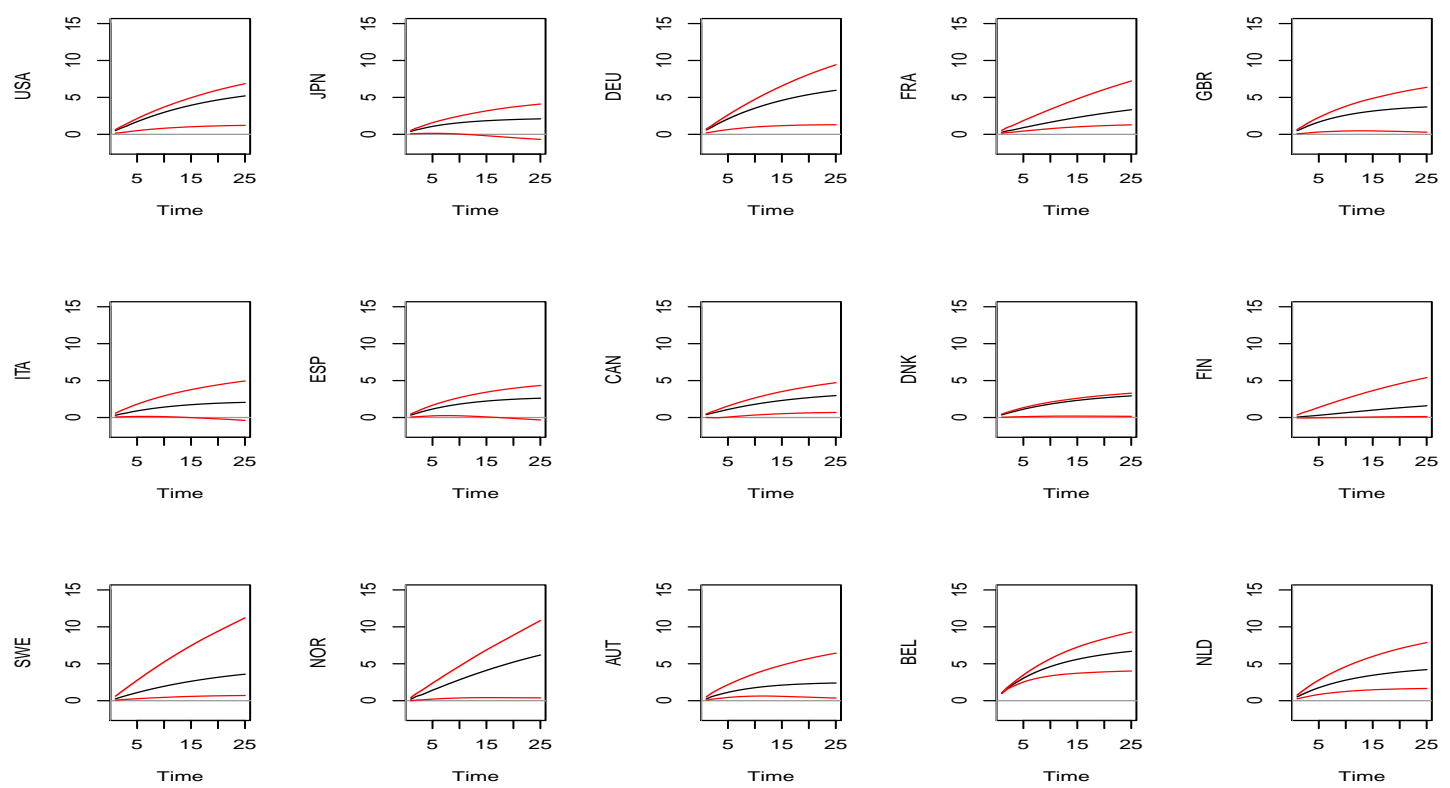

Figure 19: Responses of financial stress to a BEL financial shock in the low stress regime 

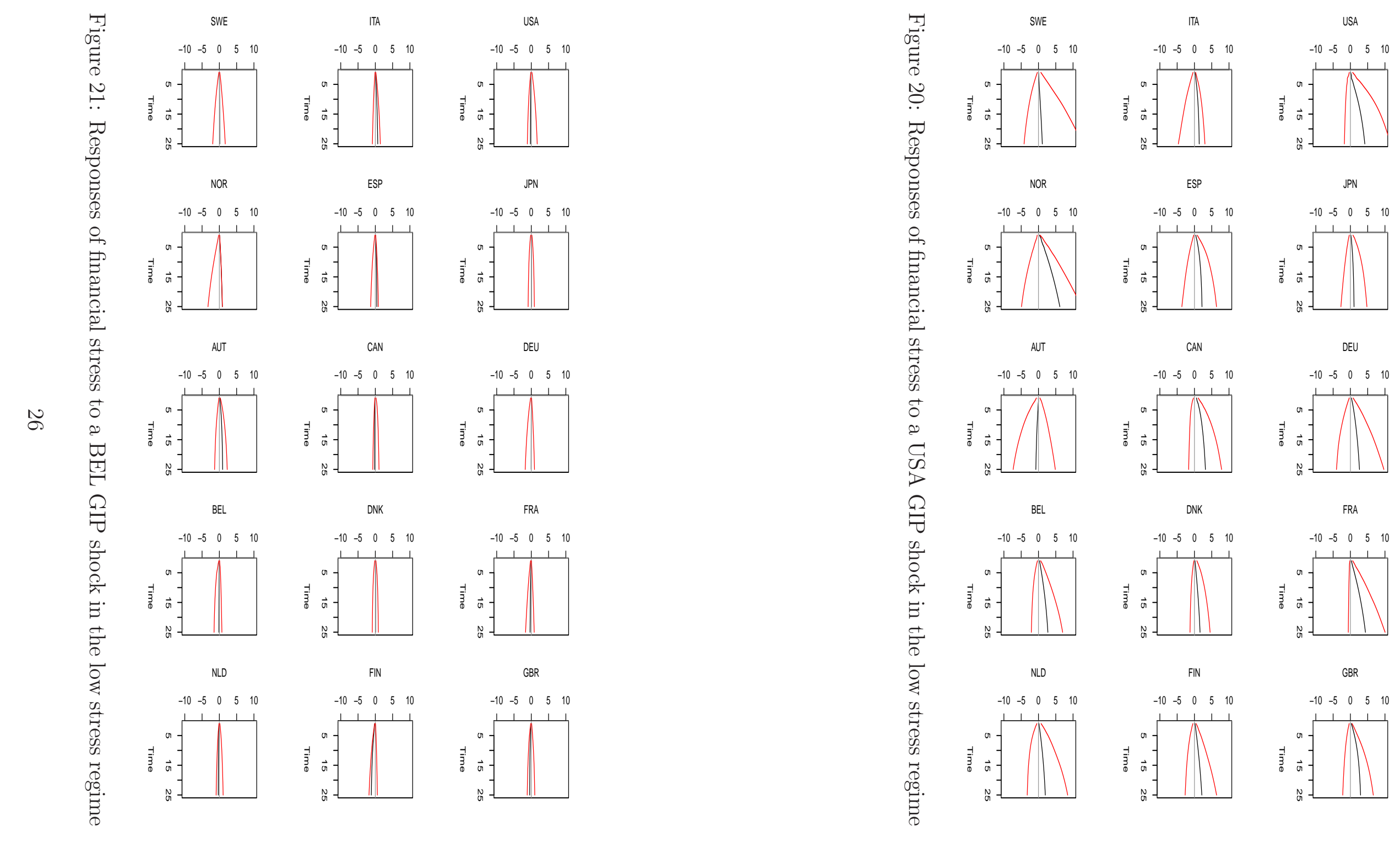

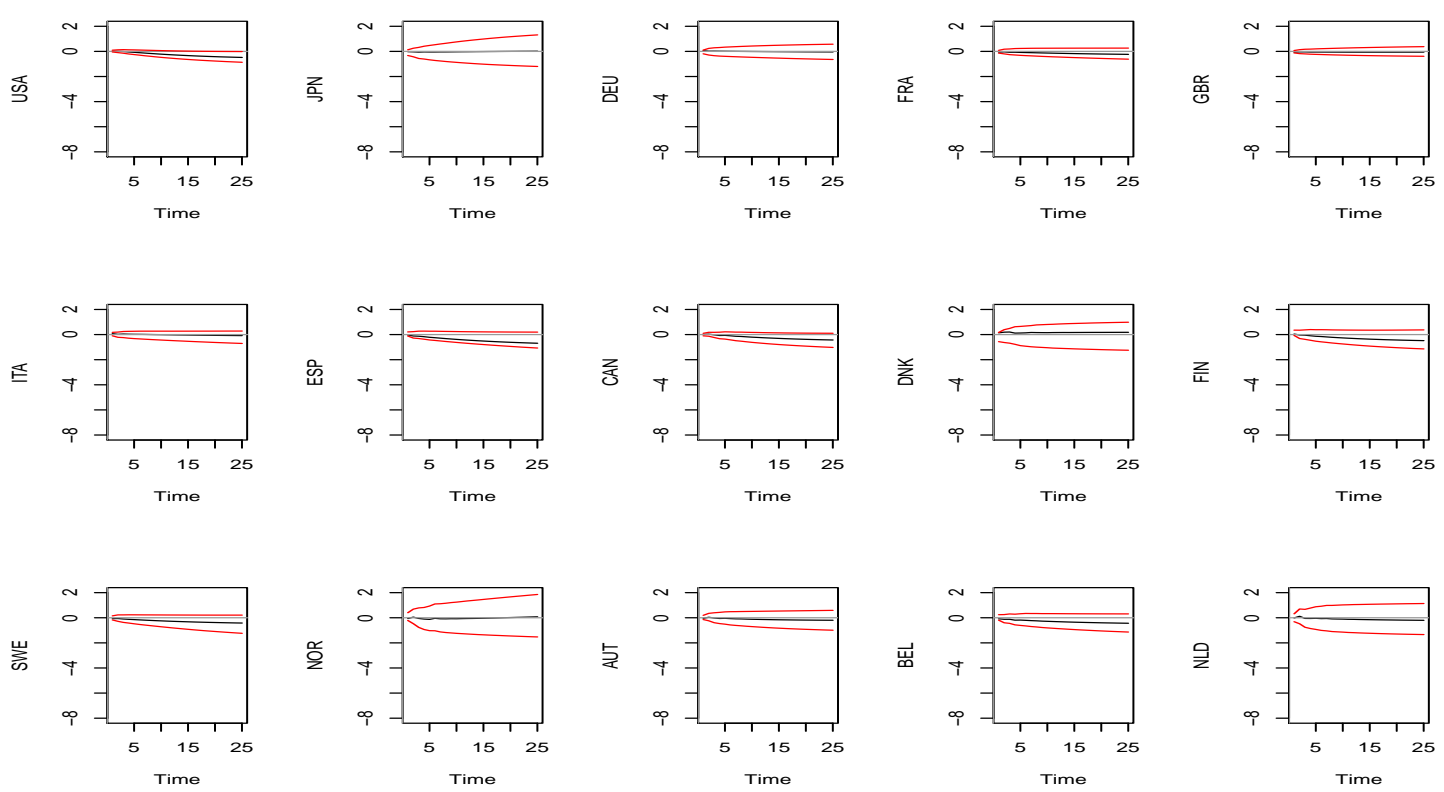

Figure 22: Responses of GIP to a USA financial shock in the low stress regime
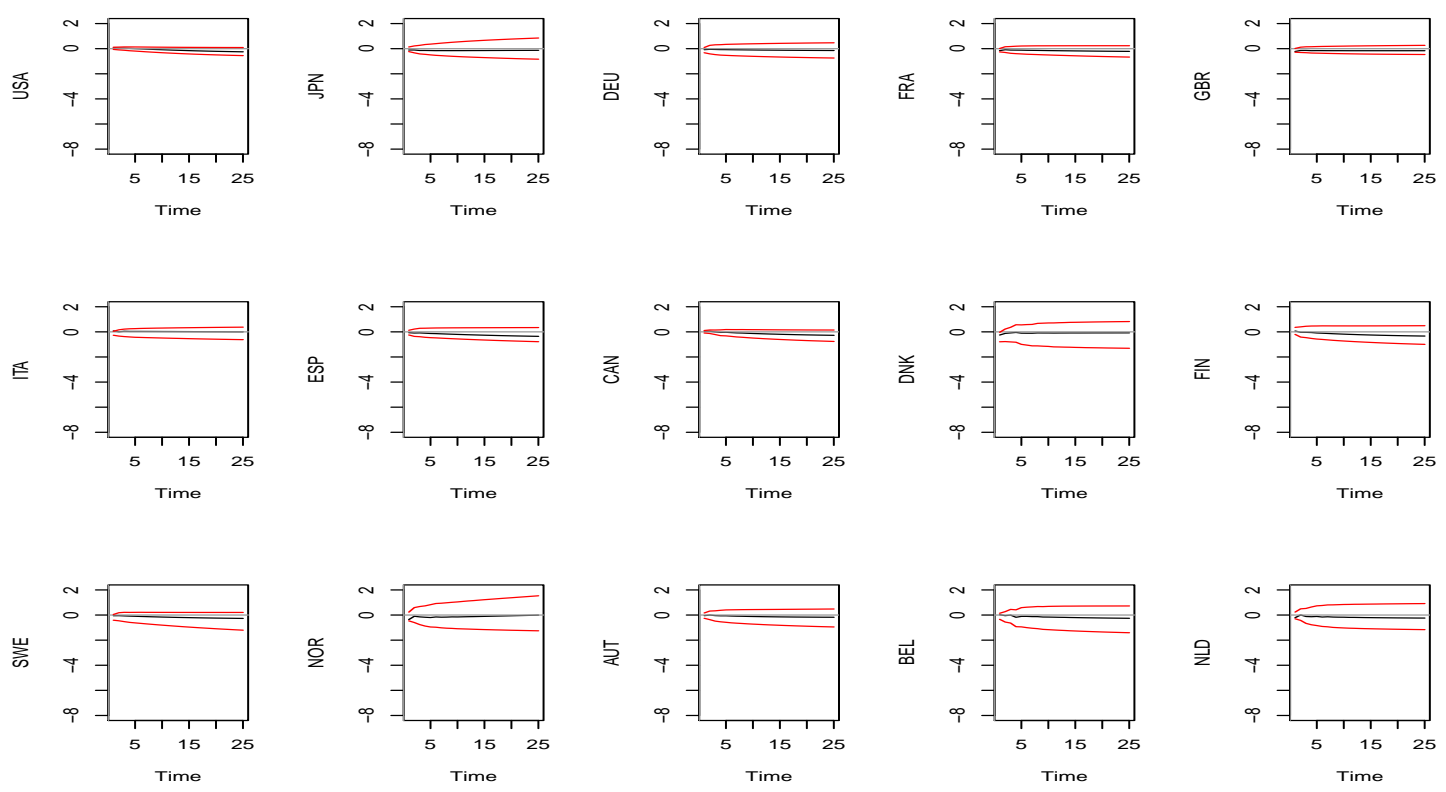

Figure 23: Responses of GIP to a BEL financial shock in the low stress regime 

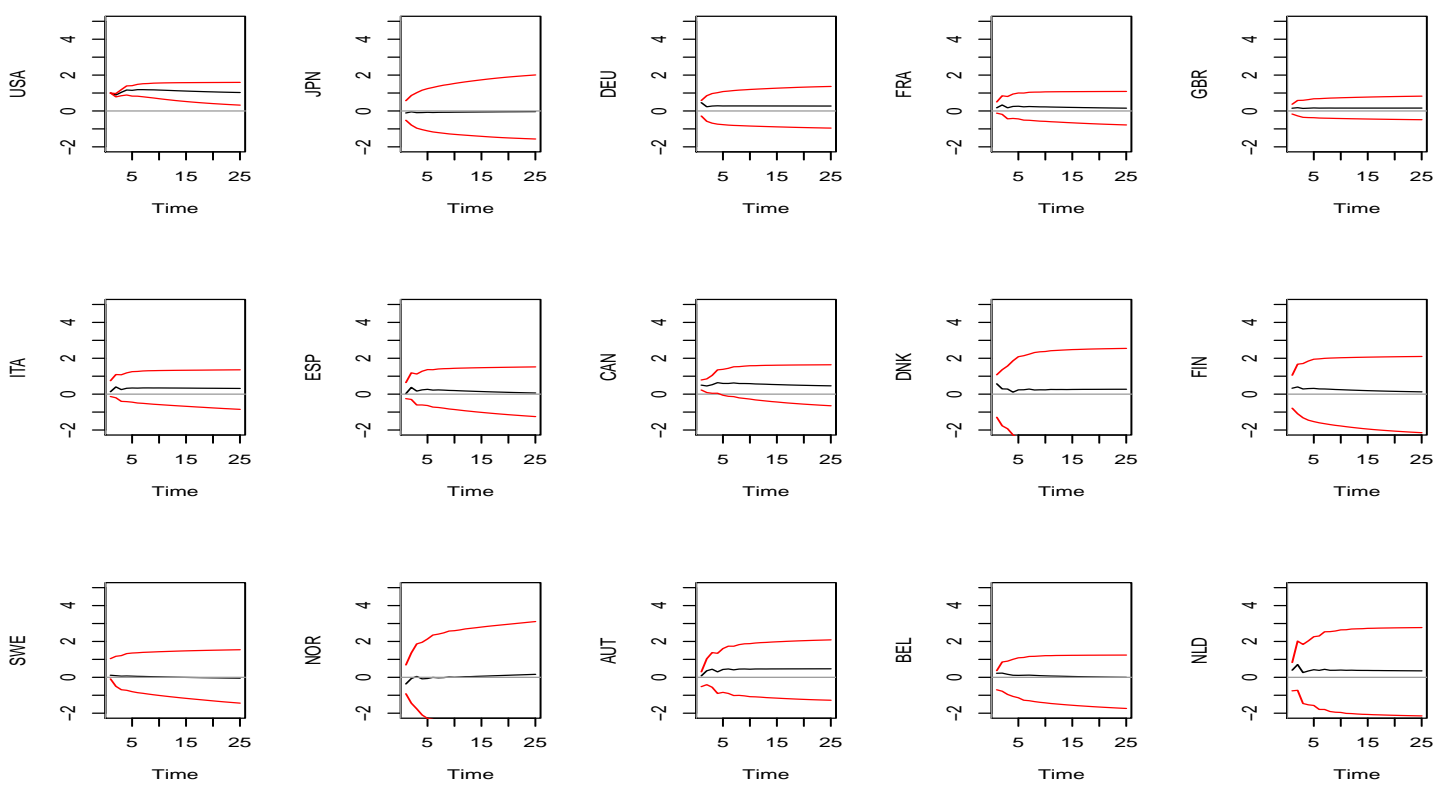

Figure 24: Responses of GIP to a USA GIP shock in the low stress regime
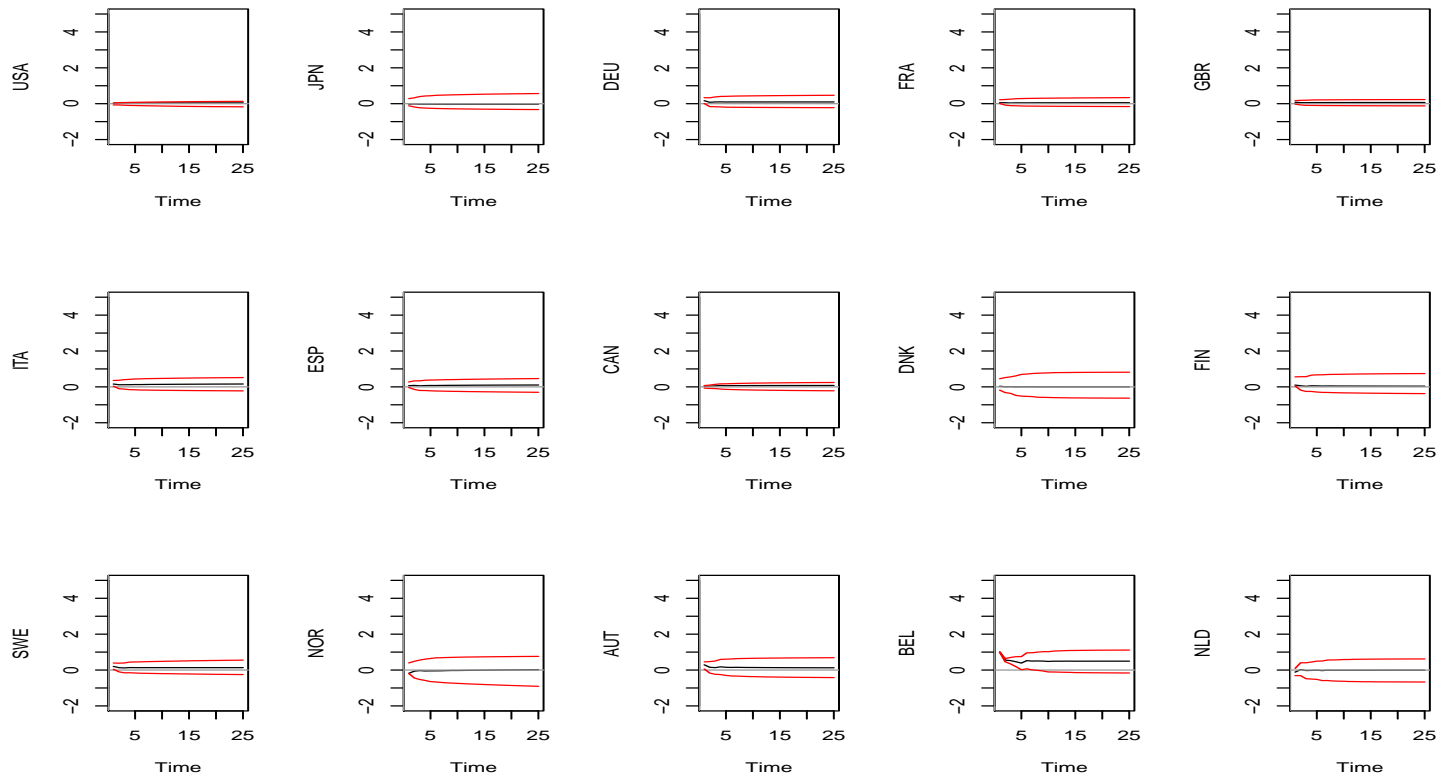

Figure 25: Responses of GIP to a BEL GIP shock in the low stress regime

\subsection{Impact of Global and Regional Shocks}

For a given configuration of state, i.e. the state vector $S$, under the assumption that the MRGVAR remains in the state, we can treat the MRGVAR in (2.3) as conventional VAR and calculate the state-specific impulse response functions for all the variables in the system. In particular, we can derive responses to global or regional shocks for any given configurations of the state. For example we can consider the responses to a euro-zone financial shock when all countries are under 
high financial stress, or when only the euro-zone countries are under high financial stress while the other countries are in the low financial stress regime.

A global shock is defined as weighted average of the shocks of all countries in the same variable. Using the weightings which are used in the construction of the foreign variables in each countries, we can defined a global financial stress shock in state $S: v_{t, S}^{g f}=\left(w_{1}, 0, w_{2}, 0, \ldots, w_{N}, 0\right) \epsilon_{t, S}$ with $\sum_{i=1}^{N} w_{i}=1$. Denoting $w^{\prime}=$ $\left(w_{1}, 0, w_{2}, 0, \ldots, w_{N}, 0\right)$, we have $u_{t, S}^{g f}=w^{\prime} \epsilon_{t, S}$ and the standard error of the global financial shock is $\sqrt{w^{\prime} \Sigma_{S} w}$. Following Chudik and Pesaran (2014), the generalized impulse response function to a one standard error global financial shock is given by:

$$
\begin{aligned}
\operatorname{irf}\left(h, y \mid v_{t, S}^{g f}\right) & =E\left(y_{t+h} \mid v_{t, S}^{f g}=\sqrt{w^{\prime} \Sigma_{S} w}, \Omega_{t-1}\right)-E\left(y_{t+h} \mid \Omega_{t-1}\right) \\
& =\frac{R_{h} \Sigma_{S} w}{\sqrt{w^{\prime} \Sigma_{S} w}}
\end{aligned}
$$

where $R_{h}$ are obtained recursively as

$$
R_{h}=\sum_{l=1}^{p} G_{l, S} R_{h-1} \text { with } R_{0}=I \text { and } R_{l}=0 \text { for } j<0
$$

$\Omega_{t}$ denotes all information available up to time $t$. For the time period $t$ the simultaneous response is

$$
\operatorname{irf}\left(0, y, v_{t, S}^{g f}\right)=\frac{\Sigma_{S} w}{\sqrt{w^{\prime} \Sigma_{S} w}}
$$

In a similar way we can construct regional shocks through an appropriate choice of the weightings. For euro-zone financial stress shocks, all the weightings that correspond to non-euro-zone countries are set to be zero, only the weightings that corresponds to the financial stress variables of the euro-zone countries are positive. These positive weightings have to be renormalized so that they sum up to unit. In this context a country specific shock is a particular case of a regional shock, where the region consists of only that country. In the following we want to investigate the effect of global shocks and euro zone shocks. 


\subsubsection{Responses to Global Shocks}
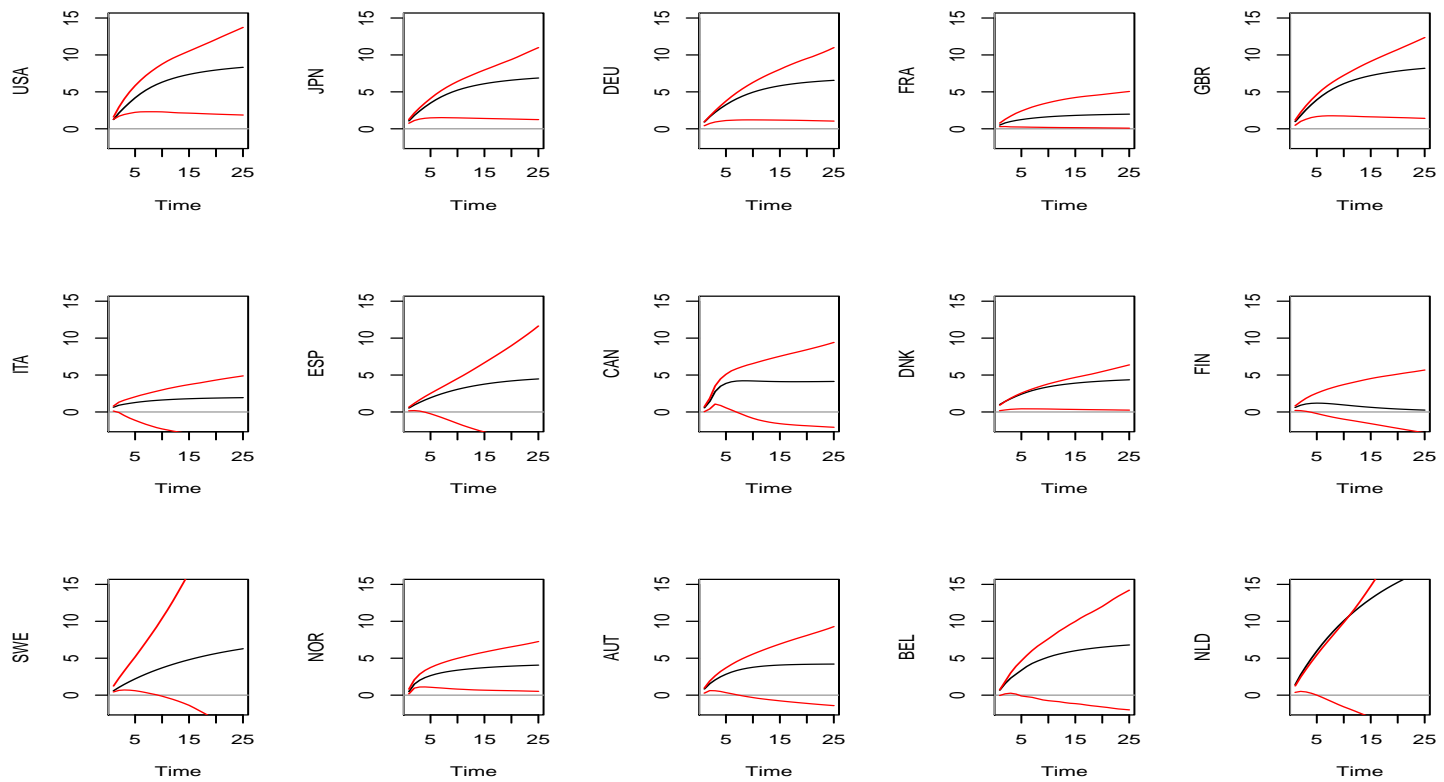

Figure 26: Responses of financial stress to a global financial shock in the high stress regime

Figure 26 contains the cumulative responses of the financial stress index of each country to a one unit global financial shock in the high stress regime. In the high stress regime, a global financial shock will significantly increase the financial stress across all countries. Comparing Figure 26 with Figure 10 we see that the responses to a one unit global financial shock are larger than the responses to a one unit financial shocks of USA.

The responses are statistically significant in USA, JPN, DEU, FRA, GBR, DNK and NOR throughout the response periods. For the other countries, the responses are statistically significant, at least in the short run up to 4 period). Global financial shocks have a negative impact on the growth of industrial output across all countries though the responses are statistically insignificant in most countries (see Figure 27). 

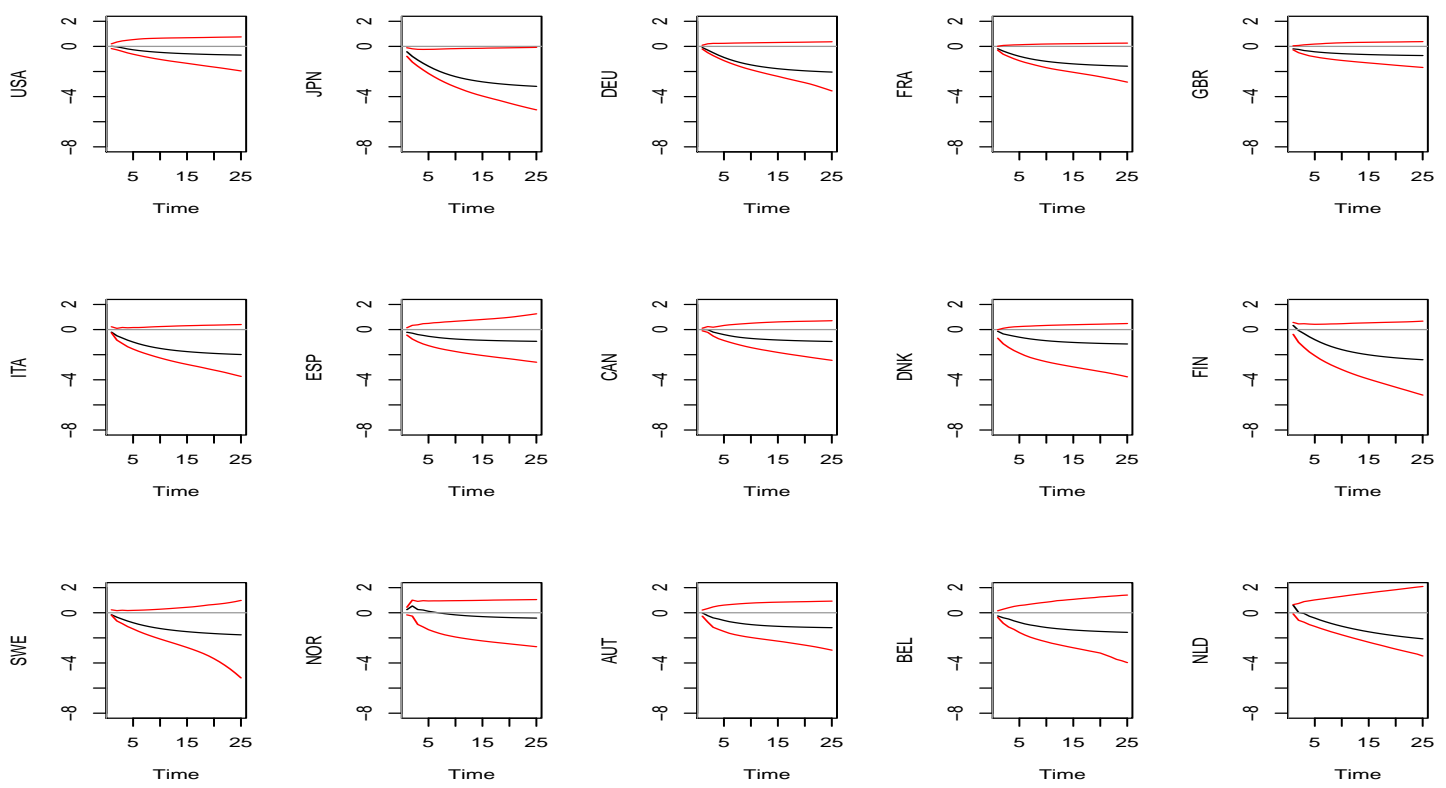

Figure 27: Responses of GIP to a global financial shock in the high stress regime

Figure 28 contains cumulative responses of the financial stress index of each countries to a one unit global output shock. A positive global output shock will decrease the financial stress across all countries. In the big economies such as USA, JPN, DEU and GBR the decreases in financial stress are statistically significant, while in other smaller economies the decreases are not statistically significant.

Comparing Figure 28 with Figure 12 we observe that the global output shocks have much larger effects on financial stress than the USA output shocks. The global positive output shocks lead generally to positive responses of the growth of industrial output across all countries. The responses are statistically significant in JPN, DEU, FRA, USA and ITA, while in other countries the responses are not statistically significant (see Figure 29). 

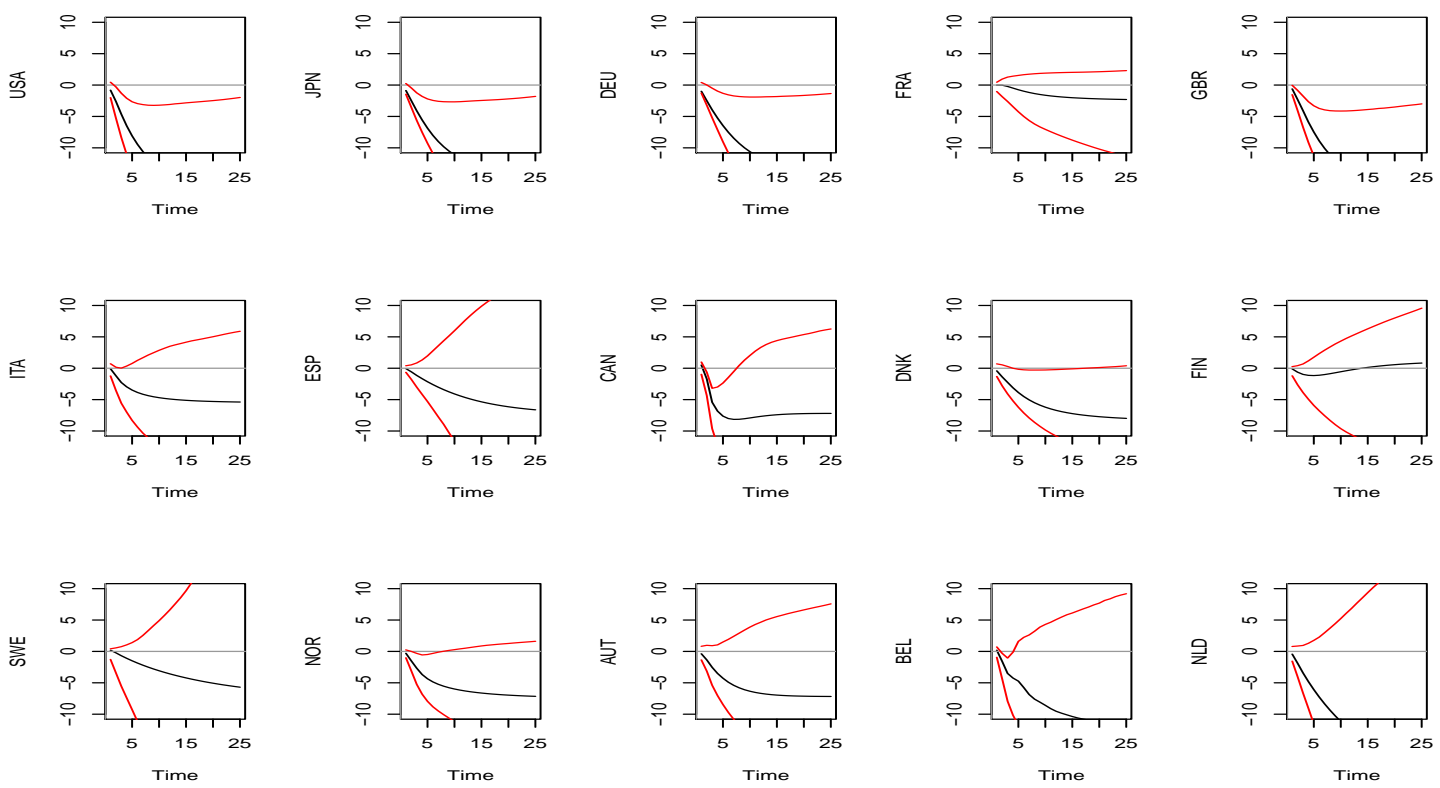

Figure 28: Responses of financial stress to a global GIP shock the high stress regime
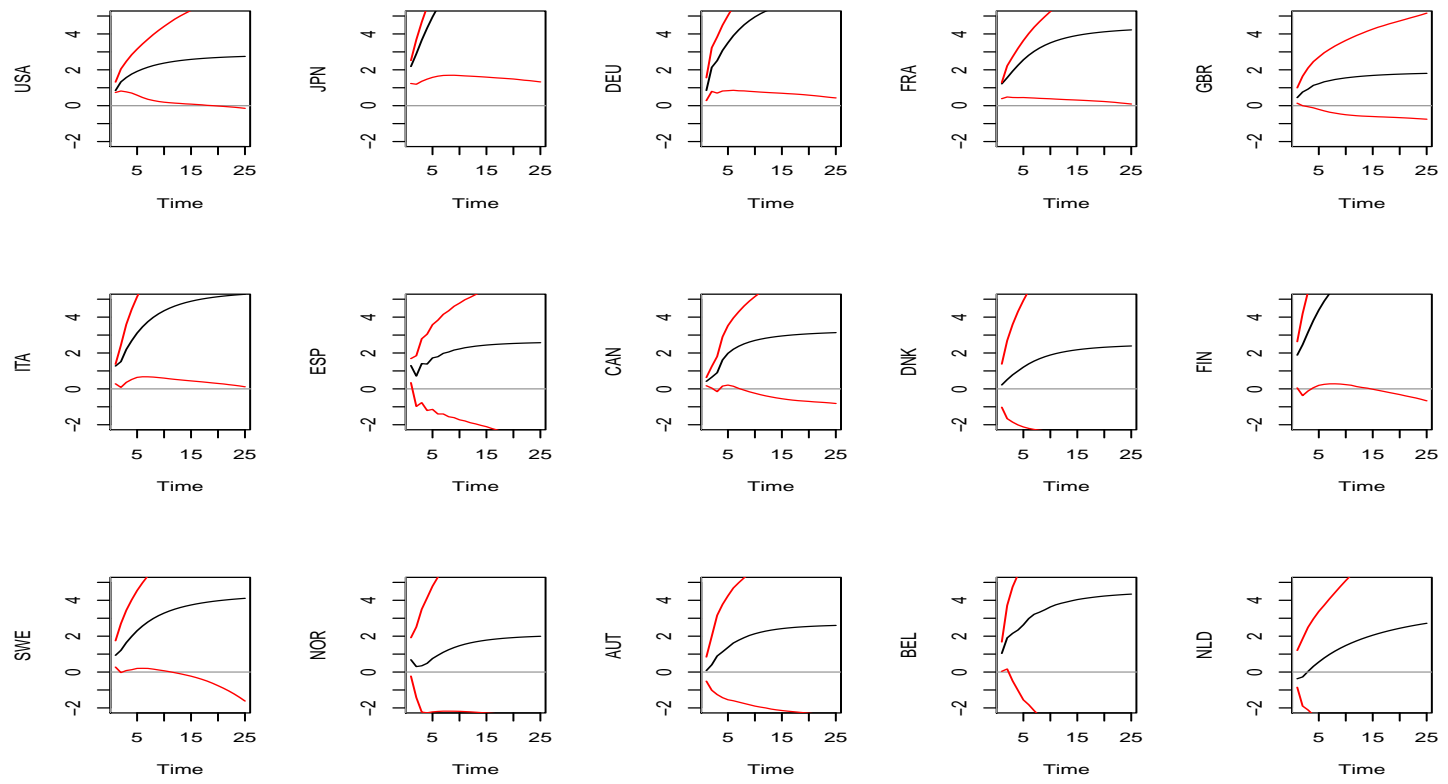

Figure 29: Responses of GIP to a global GIP shock the high stress regime

In the low stress regime, global financial shocks will still significantly increase the financial stress across all countries. Comparing Figure 30 with Figure 26, we see that the effects are very similar. In all countries the responses in the low stress regime are even larger than the responses in the high stress regime except in NOR and NLD the responses of which are bigger in the high stress regime. All other responses in the low stress regime are much weaker than their counterparts in the high stress regime and they are all statistically insignificant. The cumulative responses of financial stress to a one unit global output shock (see Figure 31 lie in the middle of the 
almost symmetric $95 \%$ confidence bands across all countries. In some countries the responses are slightly positive in other countries the responses are slightly negative.

The cumulative responses of the growth of industrial output to the one unit global financial shock in the low stress regime (see Figure 32) lie also in the middle of the almost symmetric $95 \%$ confidence bands in all countries, indicating that there are no effects of a global financial shock on the growth of industrial output in the low stress regime. In a low stress regime a positive global output shock has the tendency to increase the growth of industrial output across all countries though the most responses are not statistically significant at the level of 95\% (see Figure 33). It is worth noting that JPN benefits most from a positive global output shock. Its growth of industrial output will stabilize at $2 \%$, which is much higher than its $1 \%$ fair contribution of the global output shock.
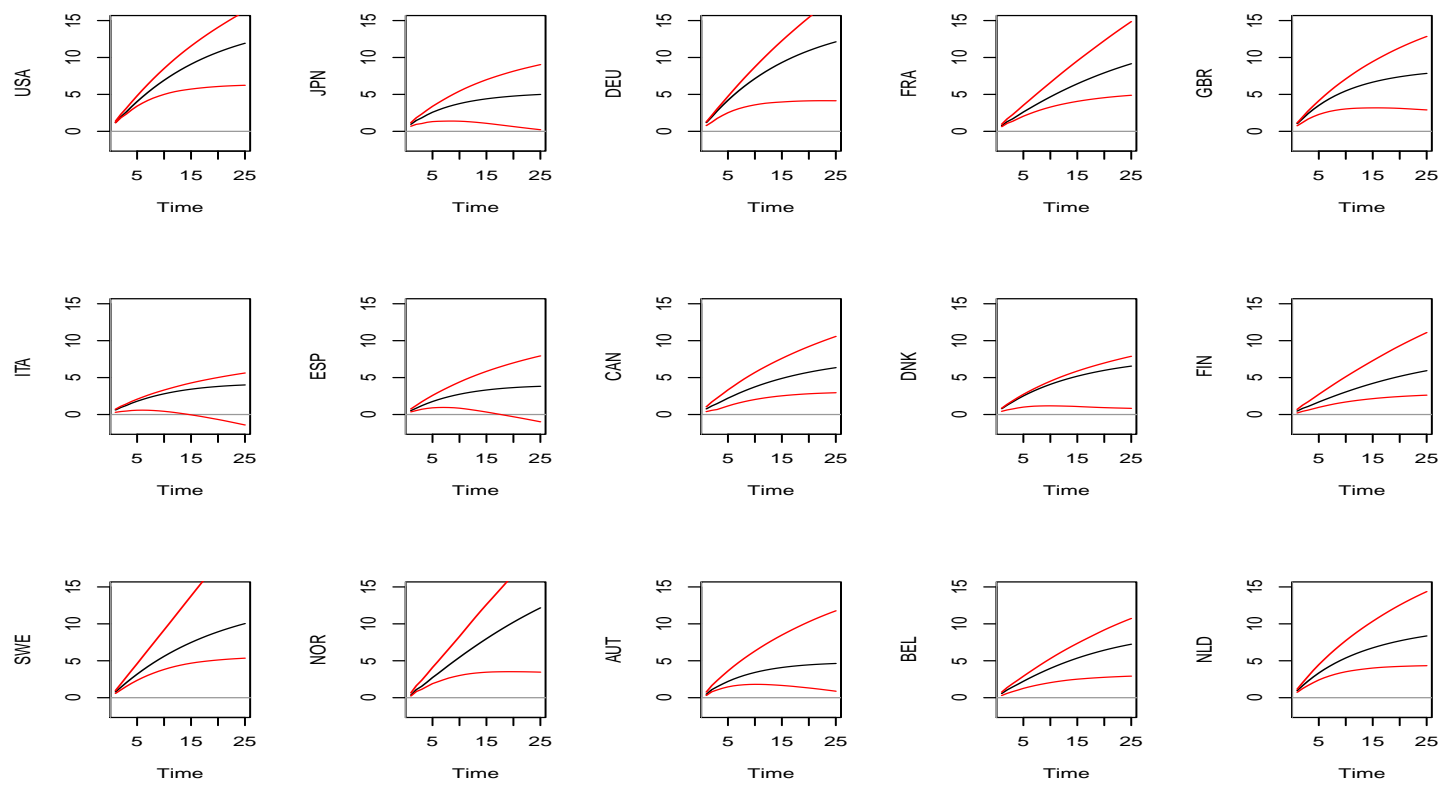

Figure 30: Responses of financial stress to a global financial shock in low stress regime 

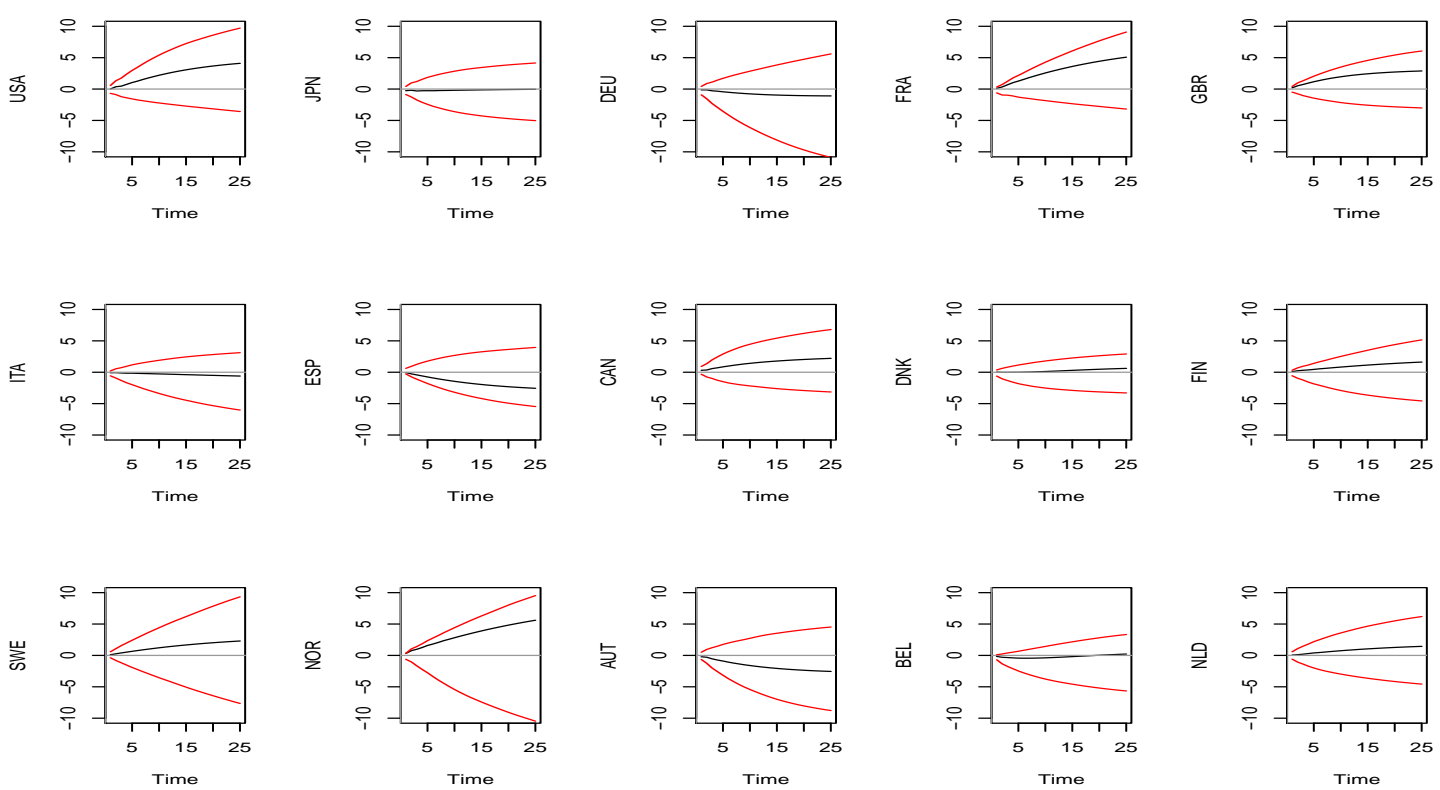

Figure 31: Responses of financial stress to a global output shock in the low stress regime
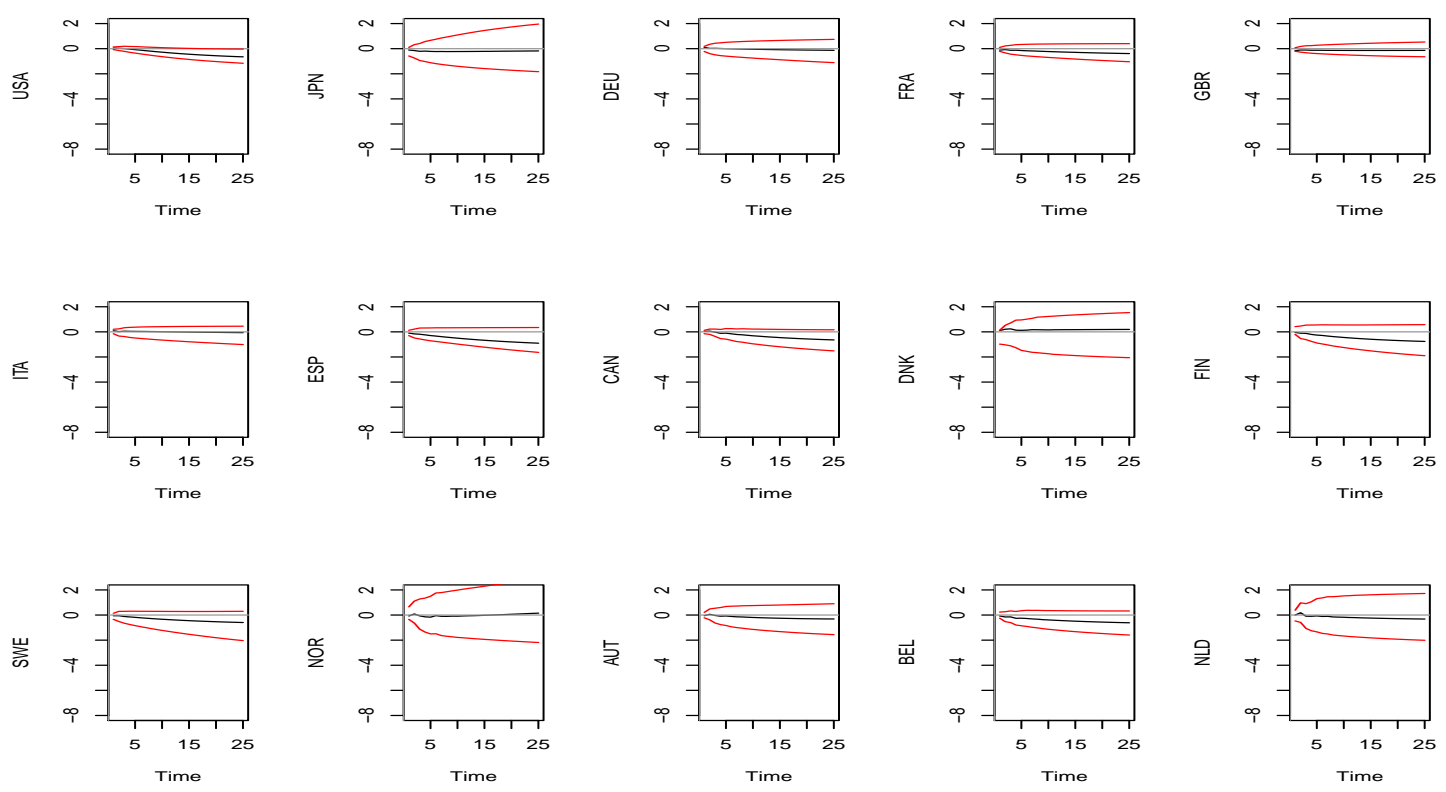

Figure 32: Responses of GIP to a global financial shock in the low stress regime 

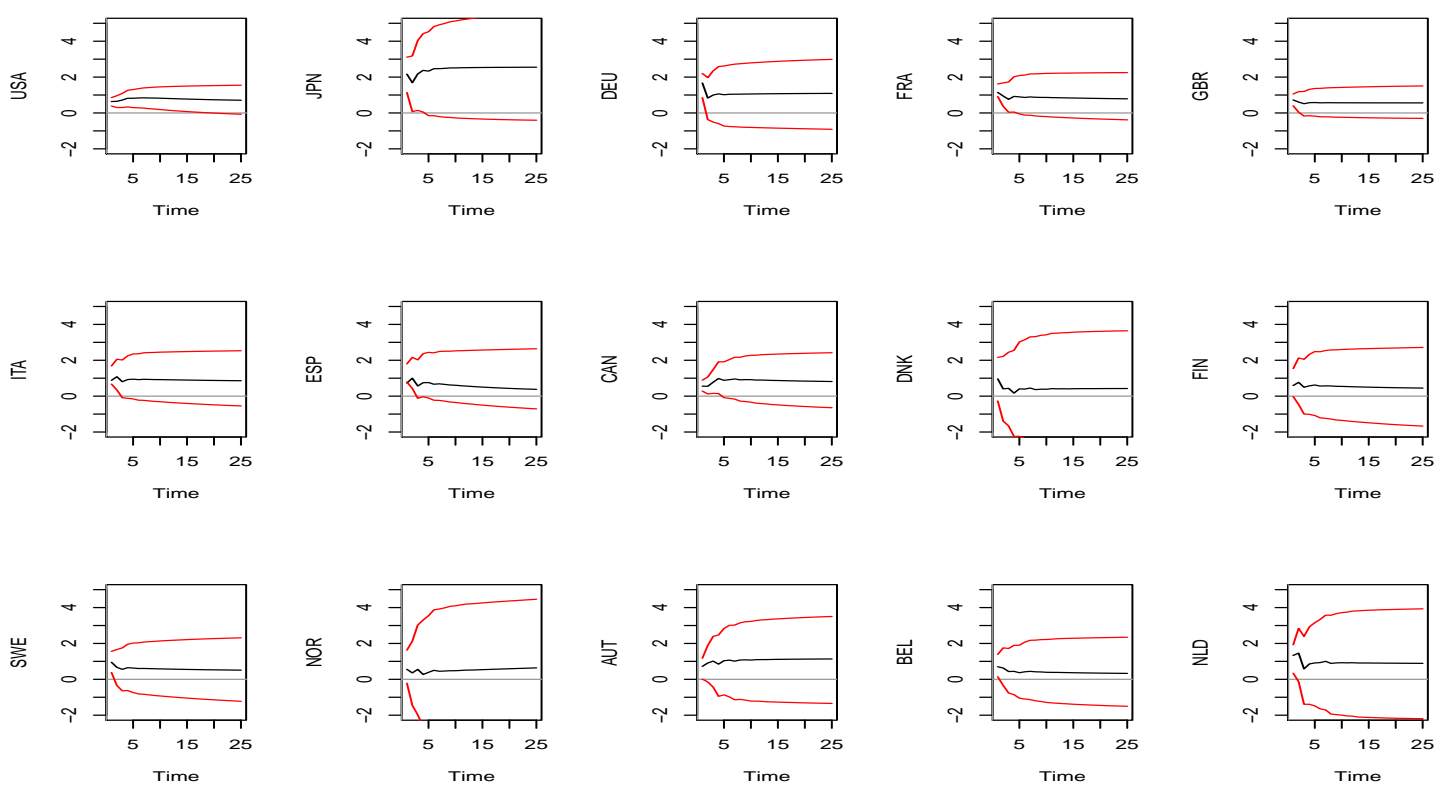

Figure 33: Responses of GIP to a global GIP shock in the low stress regime

\subsubsection{Responses to Euro Zone Shocks}

In this section we would like to investigate the effects of euro zone shocks. For this purpose we use the weightings of DEU, FRA, ITA, ESP, FIN, AUT, BEL and NLD to construct the regional shock weighting vectors as described in Section 5.2. Figure 34 to Figure 37 are the impulse response functions to the euro zone financial shocks and euro zone output shocks in the high stress regime and Figure 38 to Figure 41 are the impulse response functions to the euro zone shocks in the low stress regimes.
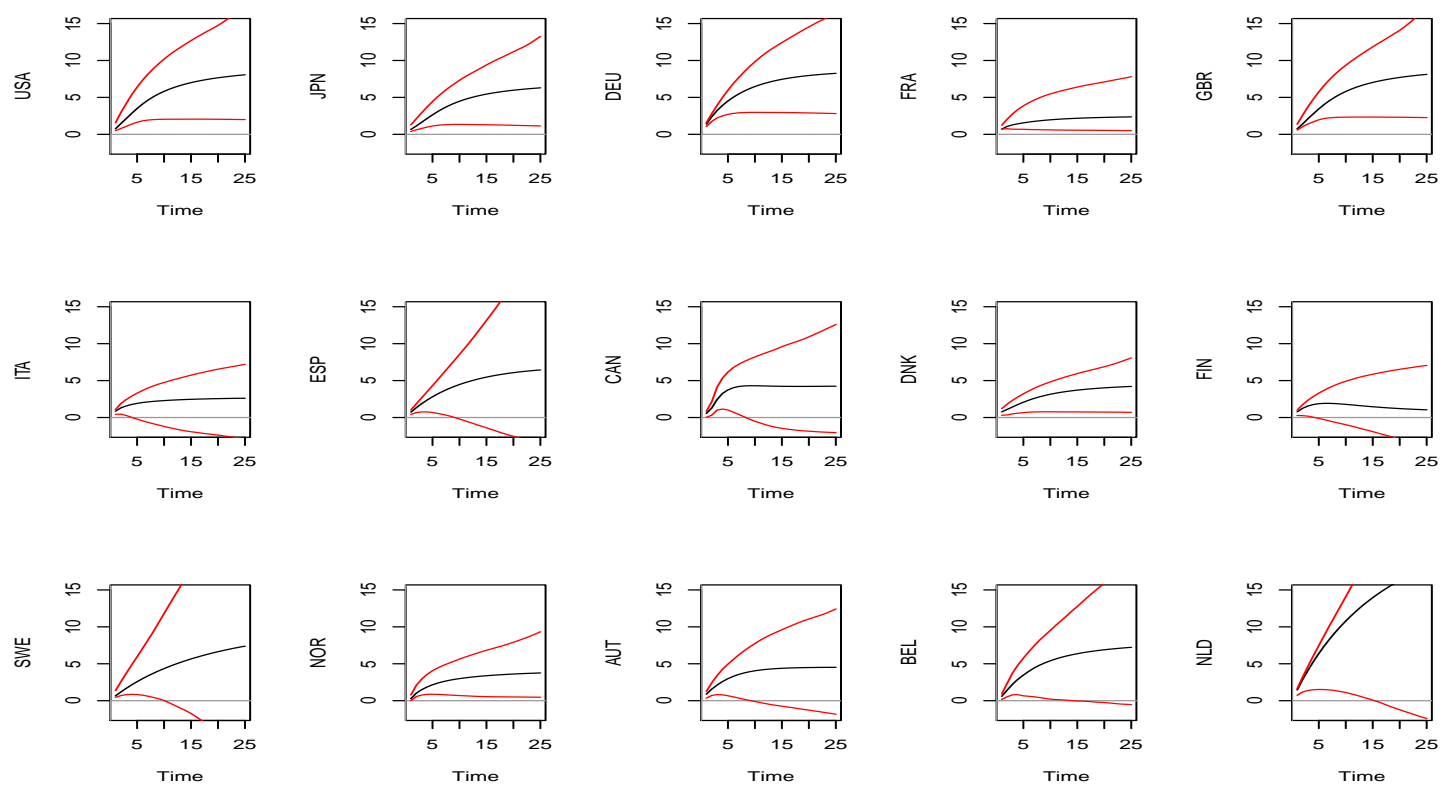

Figure 34: Responses of financial stress to a euro zone financial shock in the high stress regime 
In the high stress regime, a euro zone financial shock will significantly increase the financial stress across all countries. Comparing Figure 34 with Figure 26, the effects of a euro zone financial shock are very similar to the effects of a global financial shock. However, to a one unit euro zone financial shock the increases in financial stress in the euro zone countries: DEU, FRA, ITA, ESP, FIN, AUT, BEL and NLD are slightly higher than the increases in financial stress induced by a one unit global financial shock.

The euro zone financial shock has negative effects on the growth of industrial output across all countries. But the effects are statistically insignificant in all countries except in JPN (see Figure 35). However, the effects in DEU, FRA, GBR and ITA are more significant than for other countries.
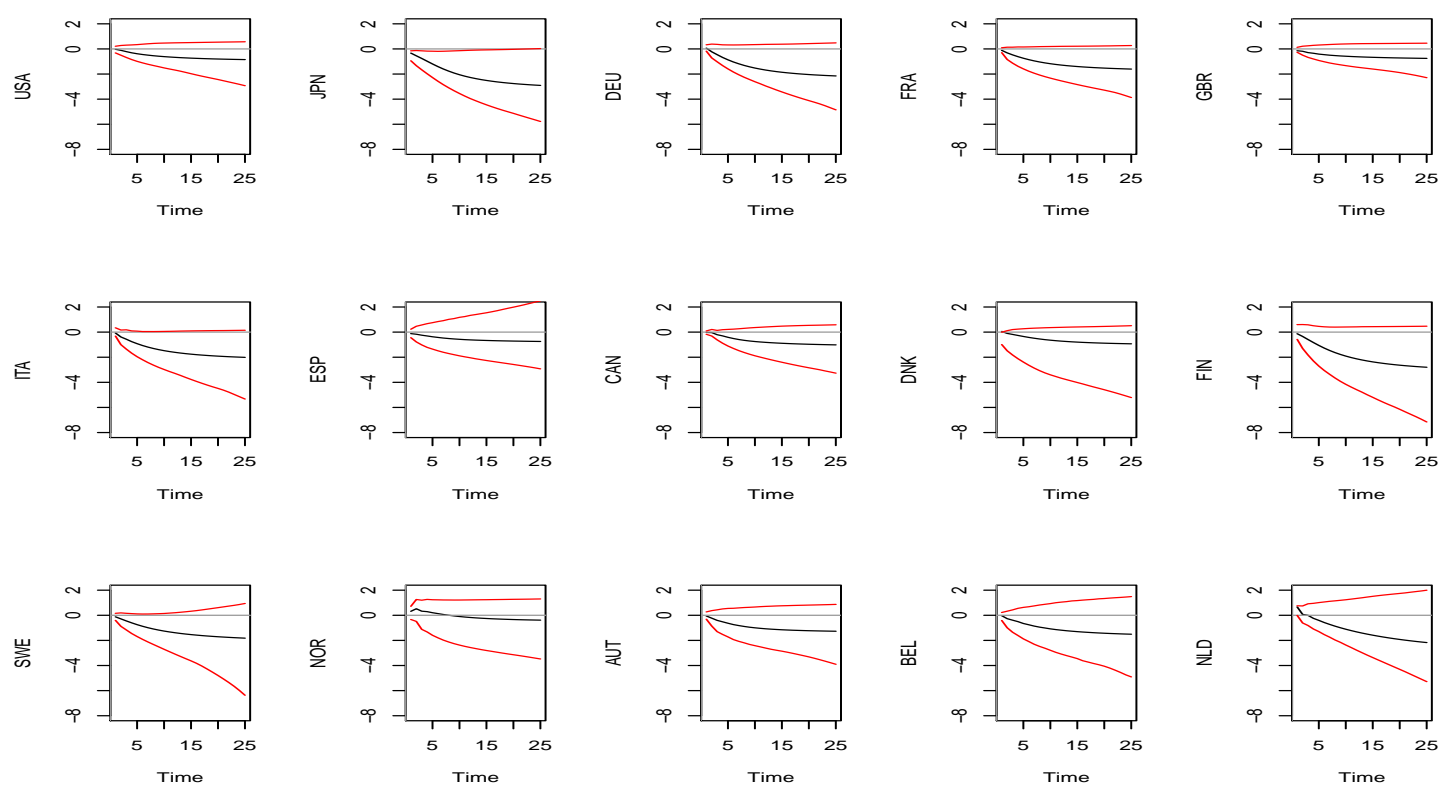

Figure 35: Responses of GIP to a euro zone financial shock in the high stress regime

In a high stress regime a positive euro zone output shock will tend to reduce the financial stress in almost all countries. The effects are significant only in JPN, GBR, USA and DEU, but insignificant in other countries (see Figure 36). The positive euro zone output shock will potentially have a positive effect on the growth of industrial output across all countries. The effects are significant in JPN, DEU, FRA, ITA. In other countries the effects are not significant. 

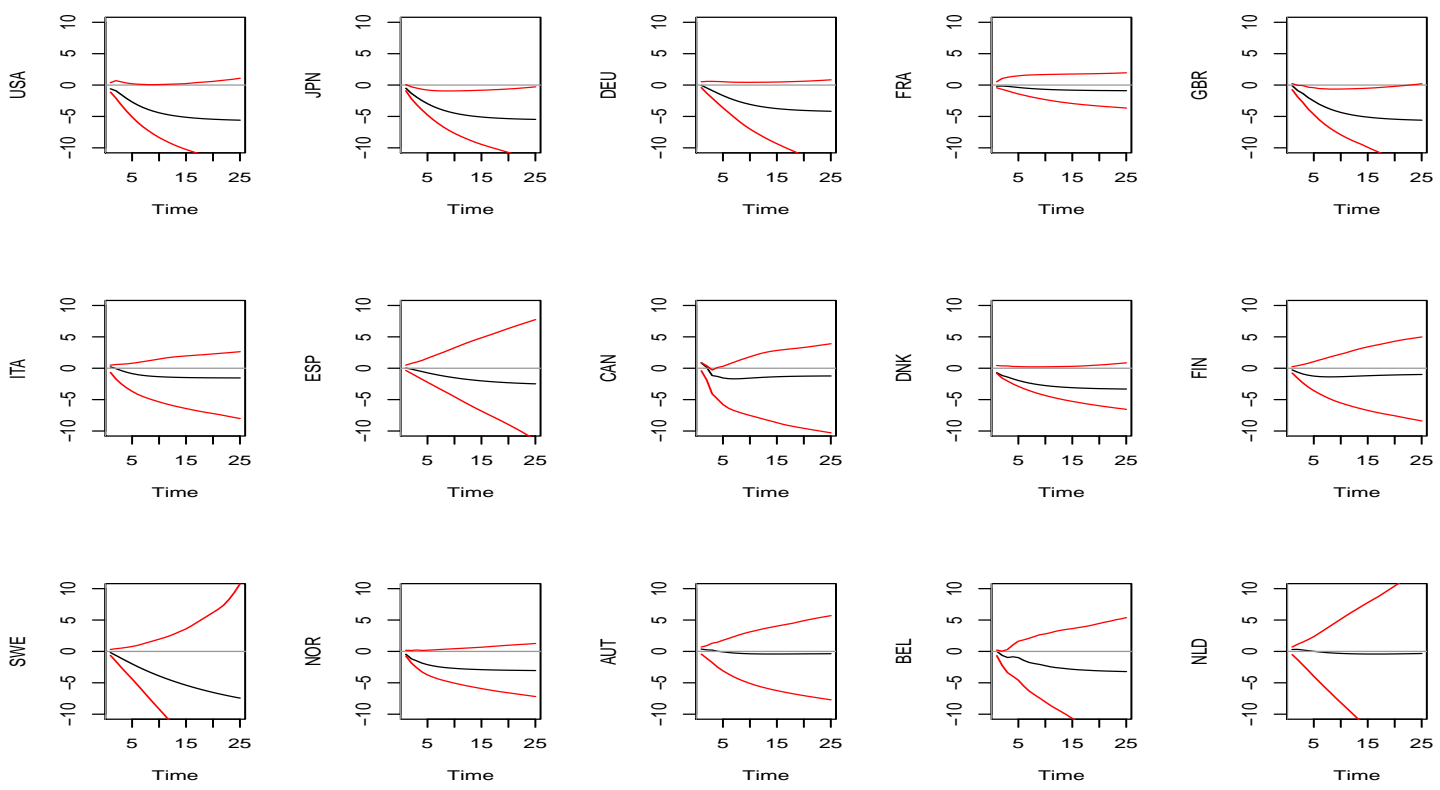

Figure 36: Responses of financial stress to a euro zone GIP shock in the high stress regime
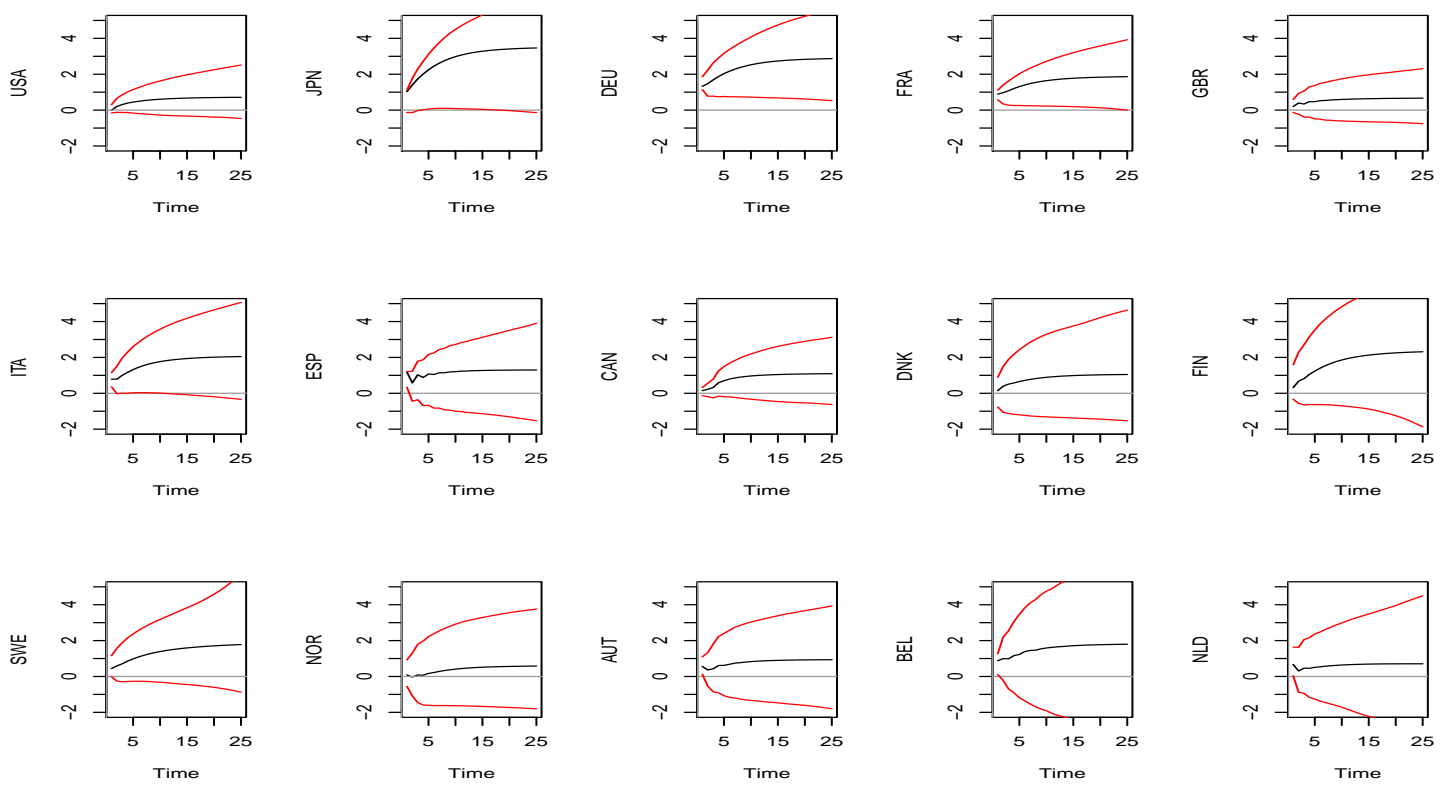

Figure 37: Responses of GIP to a euro zone GIP shock in the high stress regime

In the low stress regime, a one unit euro zone financial shock will significantly in crease the financial stress across all countries. The increases are larger in DEU, ITA, and ESP, and less in USA, JPN and GBR compared to the increases due to a one unit global financial shock. In other countries the responses are the same compared to the responses to a one unit global financial shock (see Figure 38 and Figure 30).

In the low stress regime, other responses to the euro zone financial shocks and to euro zone output shocks are much weaker than the responses in the high stress 
regime. In most cases the responses are not statistically significant (see Figure 39 for Figure 41). However, cumulative responses of the growth of industrial output to a one unit euro zone output shock are almost significant in DEU, FRA, ITA and ESP.
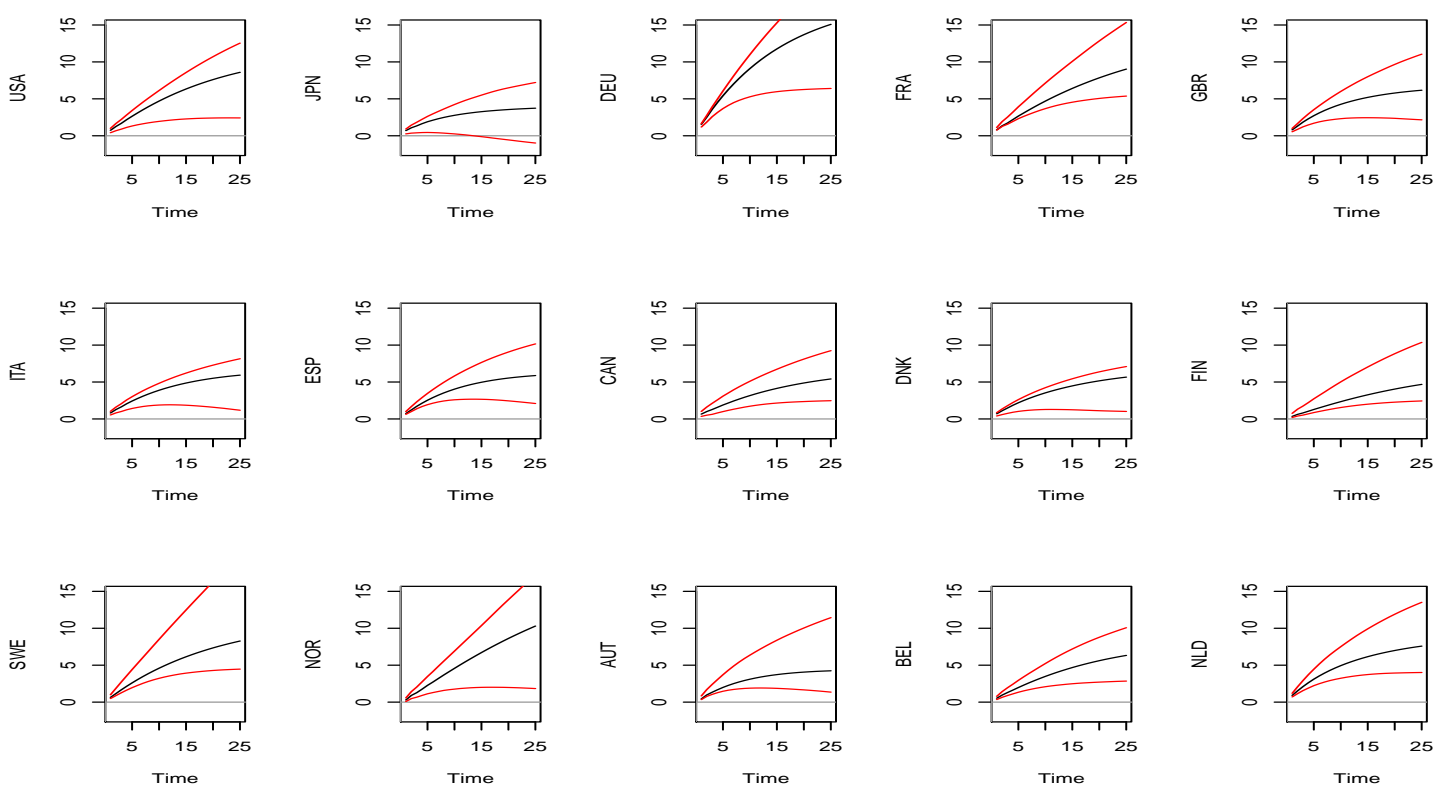

Figure 38: Responses of financial stress to a euro zone financial shock in the low stress regime
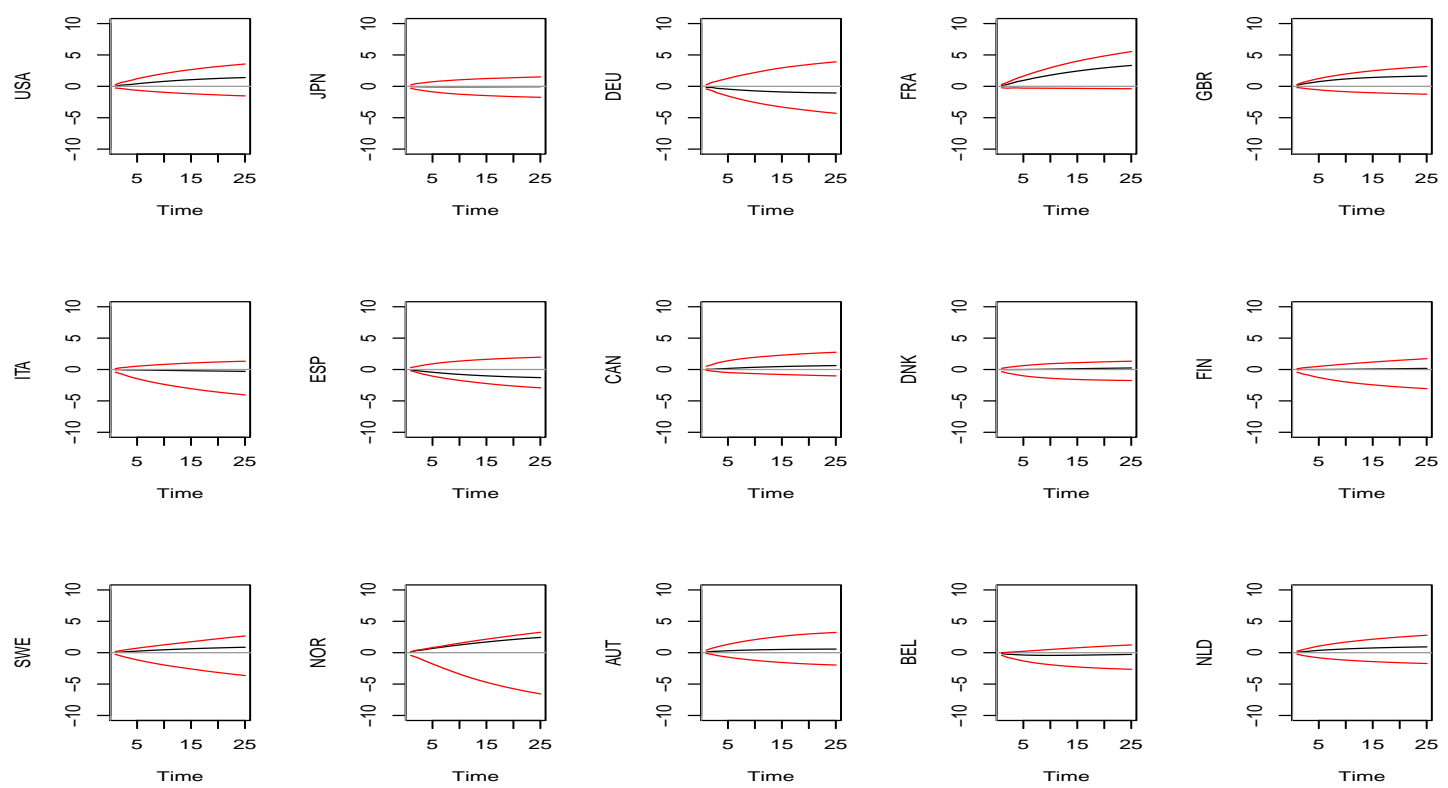

Figure 39: Responses of financial stress to a euro zone GIP shock in the low stress regime 

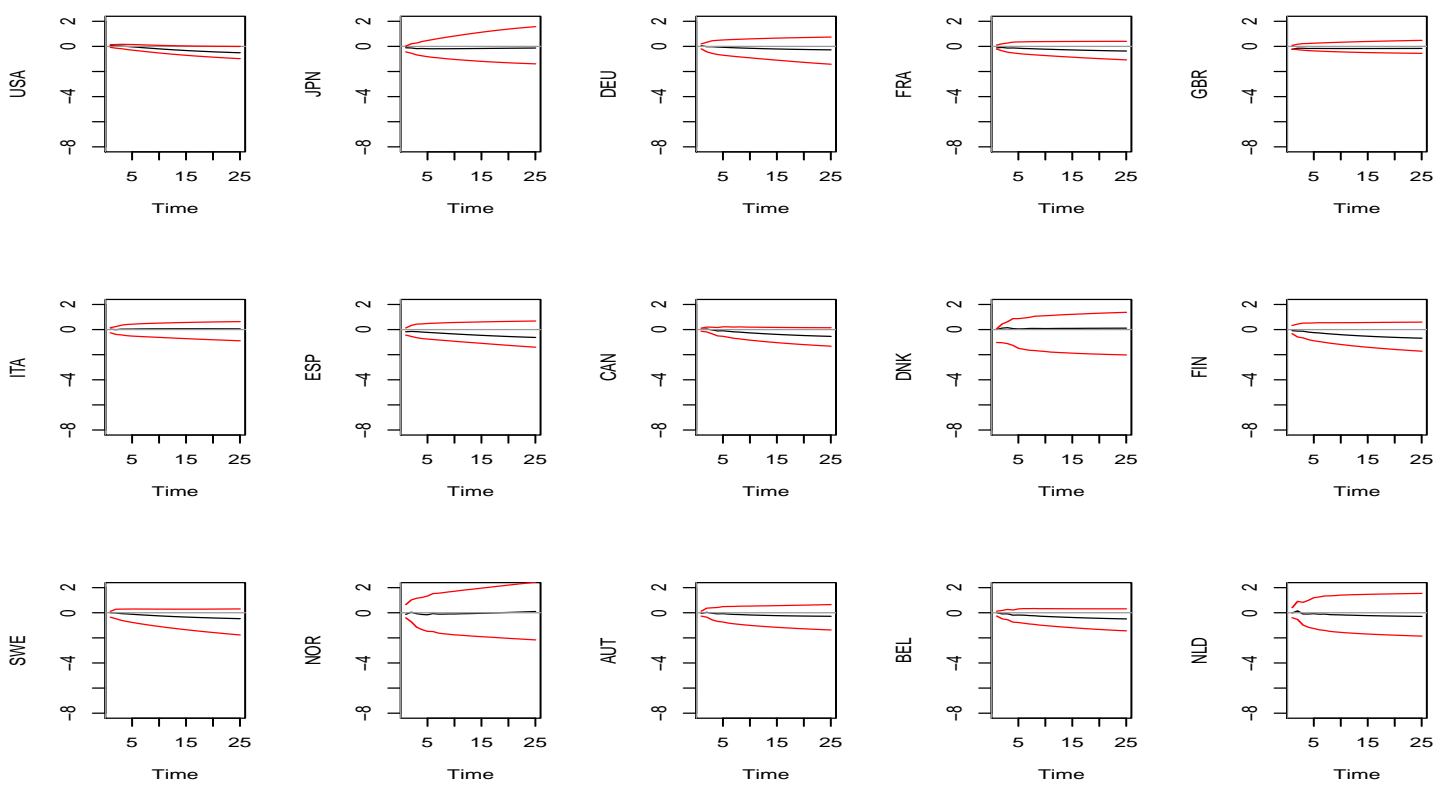

Figure 40: Responses of GIP to a euro zone financial shock in the low stress regime
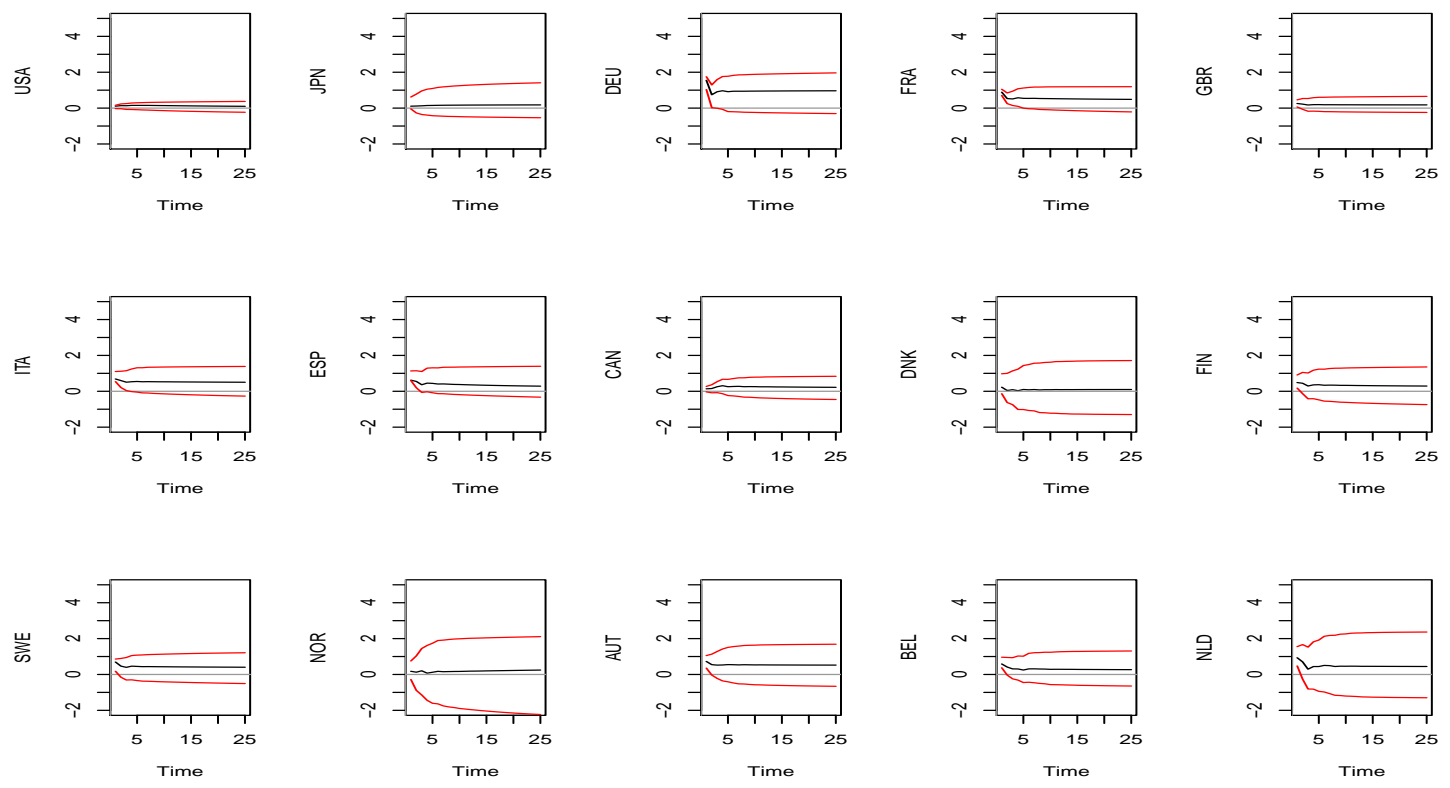

Figure 41: Responses of GIP to a euro zone GIP shock in the low stress regime

\section{Concerted Policy Actions and Global Effects}

As aforementioned the global interconnectedness of the different countries and regions is a significant challenge for monetary policy. We thus want to study next the spill-over effects of national monetary policies and internationally coordinated, meaning concerted policies on the financial and real sectors. 
GVAR models provide a suitable instrument to analyze effects of linear combinations of shocks ${ }^{12}$, hence our MRGVAR model lends itself to study the effect of concerted policy actions. While it is still debated (See IMP Staff Report (2015)) whether monetary policy should be altered to contain financial risks, empirical studies (See Baxa, Horvath, and Vasicek (2013), Adrian and Liang (2014), Dahlhaus (2014) and Zheng (2013)) show a clear evidence that the monetary policy by central banks did respond to financial stresses. We might ask the question of how effective such responses, in particular joint responses could be.

In this section we explore how financial stress and real activities in our model would respond to monetary policy shocks. Since we do not have monetary policy variables explicitly in our MRGVAR model, we cannot directly assess the effects of monetary policy on financial stress indices and growths of industrial output. To go around this problem, we assume an accommodative monetary policy will induce a negative shock to the financial stress index.

This assumption is partly supported by some current empirical studies such as Dahlhaus (2014) and Zheng (2013). In this way we interpret FSI shocks as monetary policy shocks and hence we can use the impulse response functions to gauge the effects of monetary policy. Beside studying the effect of single country monetary policy, we want in particular to assess the effect of concerted policy actions as compared to single country policy shocks.

We define concerted financial stress shocks (interpreted as monetary policy shocks) in state $S$ : $v_{t S}^{c f}=\left(v_{1}, 0, v_{3}, 0, \ldots, v_{2 N-1}, 0\right)$, where $v_{i}$ is the scale of the financial stress shock $\epsilon_{i, t}$. Following the idea of generalized impulse response function, we define the impulse response function for concerted shocks as follows

$$
\begin{aligned}
\operatorname{irf}\left(h, y \mid v_{t, S}^{c f}\right) & =E\left(y_{t+h} \mid \epsilon_{1, t}=v_{1}, \epsilon_{2, t}=v_{2}, \epsilon_{n, t}=v_{n}, \Omega_{t-1}\right)-E\left(y_{t+h} \mid \Omega_{t-1}\right) \\
& =R_{h} \operatorname{irf}\left(0, y \mid v_{t, S}^{c f}\right)
\end{aligned}
$$

where $R_{h}$ are obtained recursively as

$$
R_{h}=\sum_{l=1}^{p} G_{l, S} R_{h-1} \text { with } R_{0}=I \text { and } R_{l}=0 \text { for } j<0
$$

Defining the impulse response function in this way, the simultaneous response of $y_{i, t}$ to the concerted shock $v_{t, S}^{c f}$ is the sum of conditional expected value of $\epsilon_{i, t}$ given concerted shocks of other countries plus the shock of the own countries ${ }^{13}$.

\footnotetext{
${ }^{12}$ See Greenwood-Nimmo, Nguyen, and Shin (2013) for more details.

${ }^{13}$ For more details of the calculation of the impulse response function of concerted shocks see Appendix 8.2.
} 

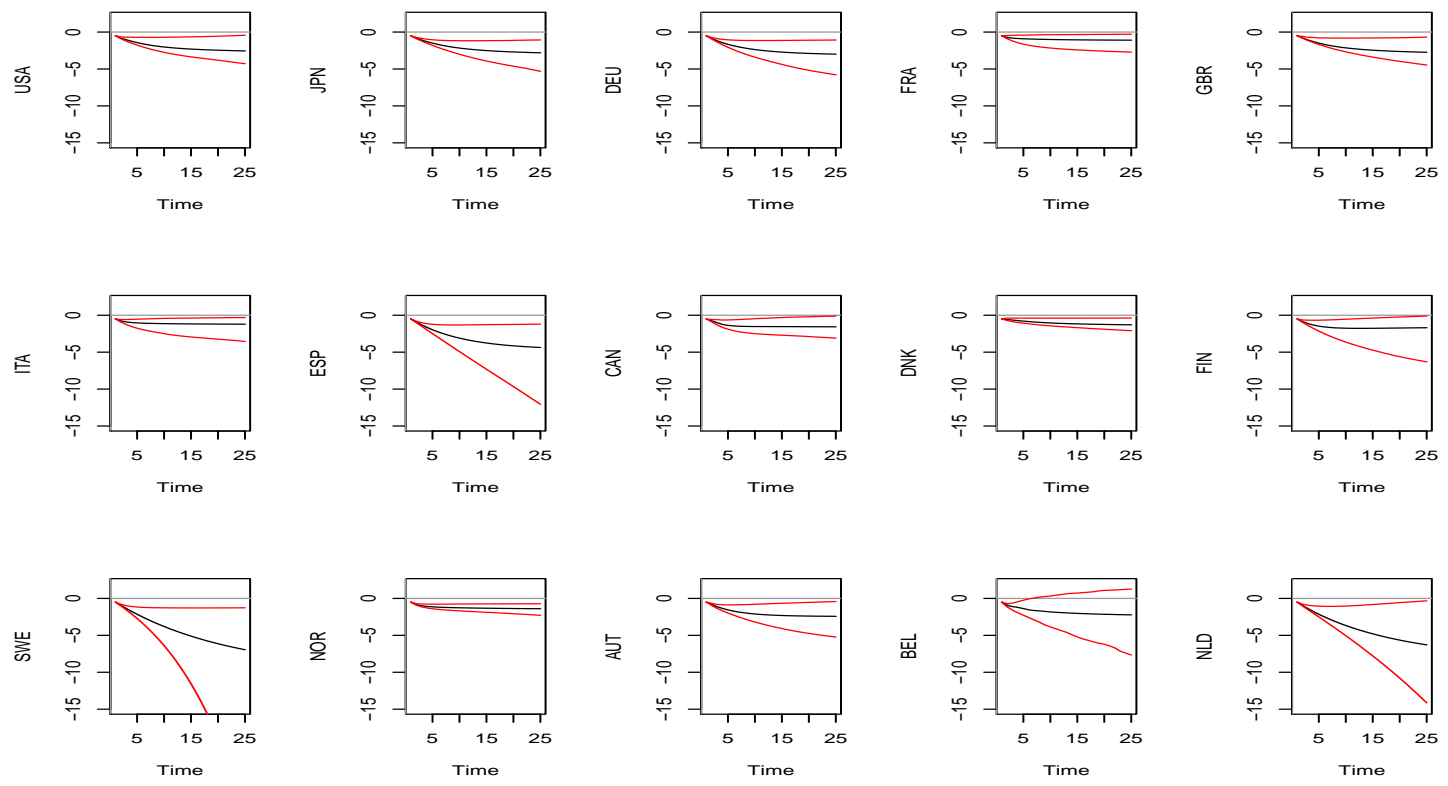

Figure 42: Responses of FSI to respective country's policy shocks in the high stress regime
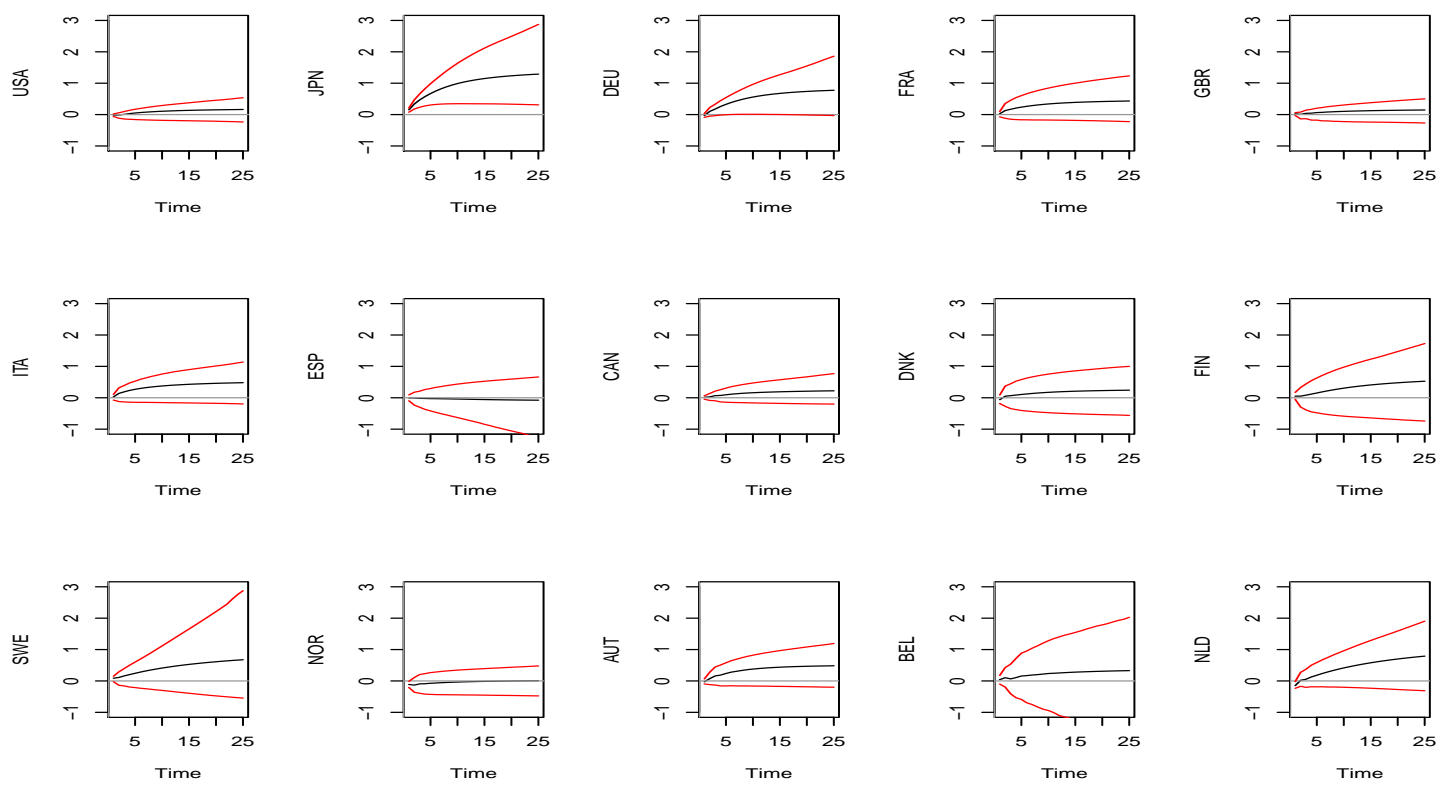

Figure 43: Responses of GPI to respective country's policy shocks in the high stress regime

Graphs 42 and 45 show the accumulative responses of each country's FSI and GIP to the respective country's negative financial stress shock of -0.5 unit over 25 periods. We see that the effects of this kind of policy shocks will ease the financial stress: in most countries FSIs will reduce by about 2 unit over 10 periods. While the effects in SWE and NLD are as large as -6, the effects are as small as only 1.0 in FRA, ITA and DNK. 
Graphs 44 and 45 show the effects of a concerted policy action when each country exerts a -0.5 unit financial shock. We see in Graph 44 that the effects of the concerted policy action in easing the financial stress are much two to three times larger than the single country action. We also observe that effects of a concerted policy action are not uniform across all countries. While in ITA, FIN and BEL, the effects are less significant, the effects in other countries are very significant in all other countries.

Figures 44 and 45 show the output responses to the single country financial policy shocks and to the concerted policy action respectively. Although the output effects of the concerted policy is stronger than the single country policy shocks, they are not statistically significant, implying that the concerted monetary policy action may possibly positively influence the real activity but they will not necessarily increase the output.
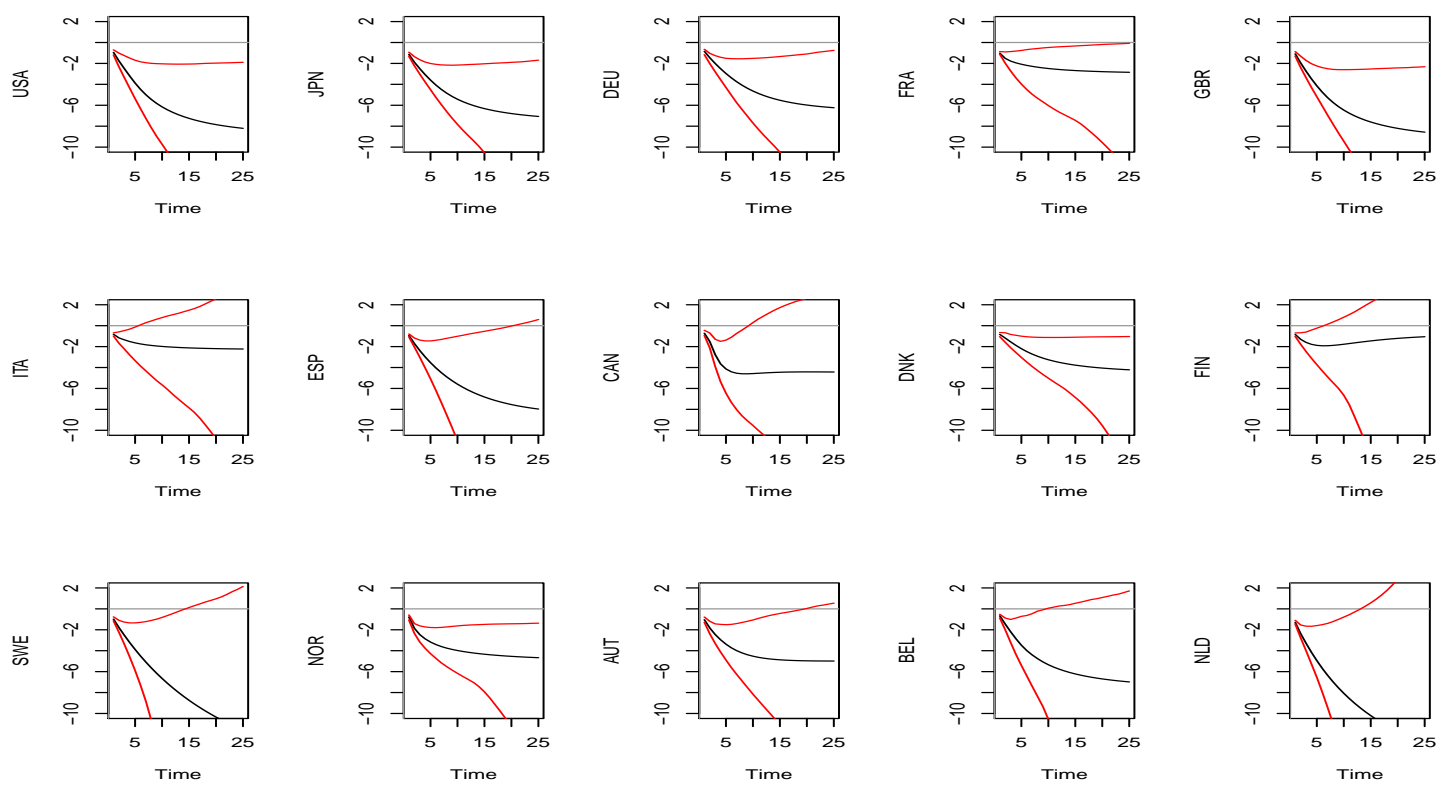

Figure 44: Responses of FSI to concerted policy shocks in the high stress regime 

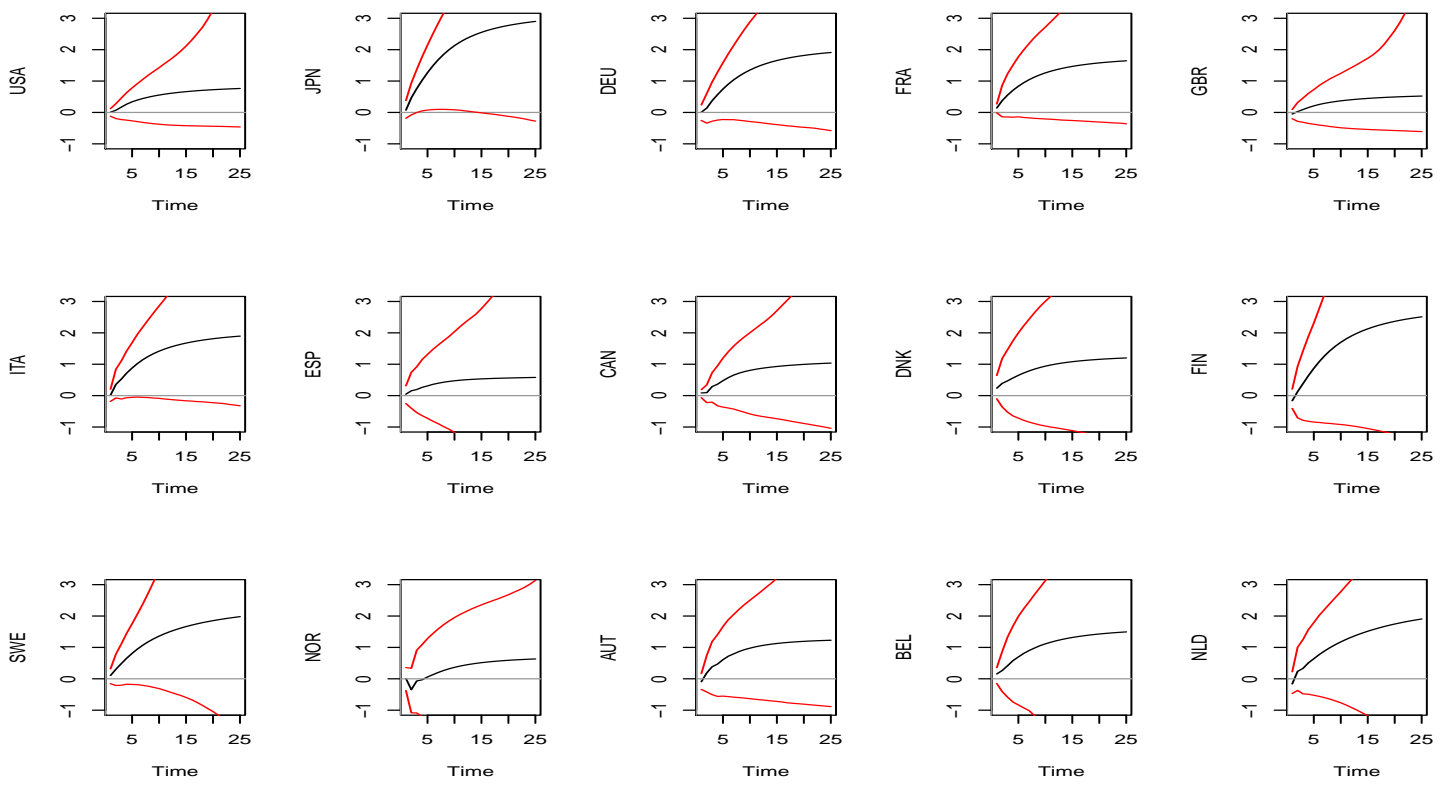

Figure 45: Responses of GPI to concerted policy shocks in the high stress regime

The global effect of a policy shock can be evaluated as a linear combination of each country's response to the shock, see Greenwood-Nimmo et al. (2013) for this type of application. Using the same weights which we use to construct the global shocks, we can calculate the global effects of the concerted policy shocks Figure 46 shows the global responses to the concerted financial shocks.

We can observe that a concerted policy shock has significant global effects in reducing the global financial stress and in the short run it has also significant positive effects on the global real activities. The cumulative effects of the concerted policy shocks of -0.5 unit in each country will reduce the global FSI by 7 after 25 periods and the growth of industrial output will be increased by about 1.4 percent.
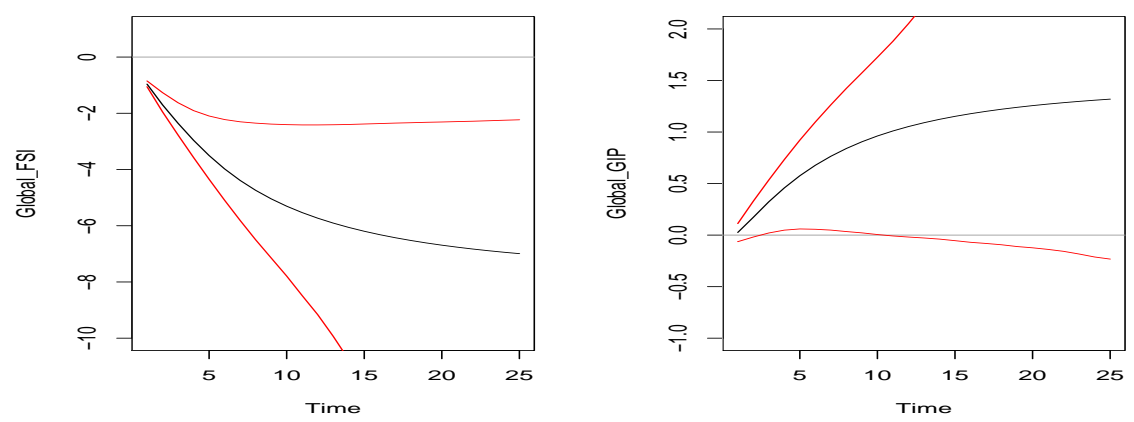

Figure 46: Global Responses to concerted financial stress shocks in the high stress regime 


\section{Concluding Remarks}

Using the IMF (2011) financial stress index and OECD industrial production data, our MRGVAR model enables us to study the spill-over effects across countries in financial markets, in goods markets and between the financial markets and the good markets for various configurations of regimes.

Using a MRGVAR we could show that financial shocks of a country, big or small one, can have large and persistent impacts on financial markets of other countries in both high and low financial stress regimes and only in the high stress regime financial shocks of a country can have some negative output effects on other countries. This implies that the financial market are tightly integrated and consequently deterioration of the financial conditions of a country, even it is a small country, could lead to deterioration of global financial conditions and thus might trigger a global economic downturn.

We show that large positive financial stress shocks in a high stress regime tend to have more contractionary effects than in a low stress regime, which is consistent with the results of our single country study in Semmler and Chen (2014). In high financial stress regime output shocks of a big country can have larger a effect to ease financial stress than those of a small country, while in low financial stress regime output shocks of a country, big or small, have little impact on financial conditions. Thus empirically, we find that financial stress shocks and output shocks have asymmetric effects, depending on the regime configurations.

Further, MRGVAR allows us to investigate the short-run spill-over effects in some fictitious but relevant configurations of regimes across countries, such as the spill-over effects when a part of Euro-zone countries are under high financial stress and the rest of the world not.

The monetary policy simulations show that although individual country's policy actions are able to ease the financial stress in the respective country in high financial stress regime, the policy has in most cases little expansionary output effect. The concerted monetary policy actions will have larger and persistent effects in improving the financial conditions and they have also larger and persistent expansionary output effects. The latter seems to be in particular important when coping with a global financial crisis or a joint business cycle downturn. It is also an important result concerning monetary policy if there are external risk drivers that policy cannot impact. Concerted policy actions seem to be advisable also in this case. 


\section{Appendix}

\subsection{Key of Country Abbreviations}

Table 4: Abbreviation of Country Names

\begin{tabular}{l|r}
\hline Abbreviation & Country \\
USA & The United States \\
JPN & Japan \\
DEU & Germany \\
FRA & France \\
GBR & Italy \\
ITA & Spain \\
ESP & Denmark \\
DNK & Sweden \\
SWE & Finland \\
FIN & Austria \\
AUS & Belgium \\
BEL & Netherlands \\
NLD & \\
\hline
\end{tabular}




\subsection{Response to Concerted Shocks}

We define the impulse response function for concerted shocks as follows

$$
\begin{aligned}
\operatorname{irf}\left(h, y \mid v_{t, S}^{c f}\right) & =E\left(y_{t+h} \mid \epsilon_{1, t}=v_{1}, \epsilon_{2, t}=v_{2}, \ldots \epsilon_{n, t}=v_{n}, \Omega_{t-1}\right)-E\left(y_{t+h} \mid \Omega_{t-1}\right) \\
& =R_{h} \operatorname{irf}\left(0, y \mid v_{t, S}^{c f}\right)
\end{aligned}
$$

where $R_{h}$ are obtained recursively as

$$
R_{h}=\sum_{l=1}^{p} G_{l, S} R_{h-1} \text { with } R_{0}=I \text { and } R_{l}=0 \text { for } j<0 .
$$

Under the assumption of normality of the residuals in a given state, for the $i$ th component of $\operatorname{irf}\left(0, y \mid v_{t, S}^{c f}\right)$

$$
\begin{aligned}
\operatorname{irf}\left(0, y_{i} \mid v_{t, S}^{c f}\right):= & E\left(y_{i, t} \mid \epsilon_{1, t}=v_{1}, \ldots \epsilon_{i-1, t}=v_{i-1}, \ldots \epsilon_{i+1, t}=v_{i+1}, \ldots \epsilon_{n, t}=v_{n}, \Omega_{t-1}\right) \\
& +E\left(y_{i, t} \mid \epsilon_{i, t}=v_{i}, \Omega_{t-1}\right)-E\left(y_{t} \mid \Omega_{t-1}\right) \\
= & \operatorname{Cov}\left(\epsilon_{i}, \epsilon_{-i}^{\prime}\right) \operatorname{Var}\left(\epsilon_{-i}\right)^{-1}\left(\begin{array}{c}
v_{1} \\
\vdots \\
v_{i-1} \\
v_{i+1} \\
\vdots \\
v_{n}
\end{array}\right)+v_{i}
\end{aligned}
$$

where $\epsilon_{-i}^{\prime}$ is the $n-1$ vector of $\left(\epsilon_{1}, \ldots \epsilon_{i-1}, \epsilon_{i+1}, \ldots \epsilon_{n}\right)$. 


\section{References}

T. Adrian and N. Liang. Monetary policy, financial conditions, and financial stanility. Federal Reseerve Bank of New York Stuff Report, No. 690, 2014.

P. Backé, E. Gnan, and P. Hartmann. CONTAGION AND SPILLOVERS:NEW INSIGHTS FROM THE CRISIS. Larcier, 1st edition, 2010.

J. Baxa, R. Horvath, and B. Vasicek. Time-varying-monetary-policy rules and financial crisis:does financial instability matter for monetary policy? Journal of Financial Stability, 9:117-138, 2013.

M. Binder and M. Gross. Regime-switching global vector autoregressive models. ECB Working Paper Series, No.1569, 2013.

A. Chudik and M. H. Pesaran. Theory and practice of gvar modeling. Federal Reserve Bank of Dallas Working Paper, 2014/0180, 2014.

T. Dahlhaus. Monetary policy transmission during financial crisis: An empirical analysis. Bank of Canada Working Paper, 2014-21, 2014.

F. X. Diebold and K. Yilmaz. Measuring the dynamics of global business cycle connectedness. in S.J. Koopman and N. Shephard(eds.) Unobserved Components and Time Series Econometrics, Oxford University Press, pages 45-70, 2015.

M. Ehrmann, M. Ellison, and N. Valla. Regime-dependent impulse response functions in a markov-switching vector autoregressive model. Economic Letter, 78: 295-299, 2003.

M. Greenwood-Nimmo, V. H. Nguyen, and Y. Shin. Chapter \%. Using Global VAR Models for Scenario-Based Forecating and Policy Analysis, The GVAR Handbook. Oxfort University Press, 1st edition, 2013.

C.S. Hakkio and W.R. Keeton. Financial stress: What is it, how can it be measured, and why does it matter? Economic Review, Q II:5-50, 2009.

IMP Staff Report. Monetary Policy and Financial Stability. International Monetary Fund, 1st edition, 2015.

G. Koop, M. Pesaran, and S. Potter. Impulse responses in nonlinear multivariate models. Journal of Econometrics, 74:119-147, 1996.

S. Mittnik and W. Semmler. Estimating a banking-macro model for europe using a multi-regime var. http://ssrn.com/abstract=2012106, 2012.

S. Mittnik and W. Semmler. Regime dependence of the fiscal multiplier. Journal of Economic Behavior and Organization, 83,Issue 3:502-522, 2013.

M. H. Pesaran, T. Schuermann, and S. M. Weiner. Modeling regional interdependencies using a global error-correcting macroeconometric model. Journal of Business Ef Economic Statistics, 22. Issue 2:129-162, 2004. 
W. Semmler and P. Chen. Financial stress, regime switching and macrodynamics: Theory and empirics for the us, the eu and non-eu countries. Economics: The Open-Access, Open-Assessment E-Journal, 2014-20, 2014.

J. Zheng. Effects of us monetary policy shocks during financial crisis - a threshhold vector autoregression approach. ANU CAMA Working paper, 64/2013, 2013. 